\title{
Integration of Raman Spectroscopy and Cone Penetration Technology Characterize Chlorinated Hydrocarbon Contaminant Plumes
}

by

J. Rossabi

Westinghouse Savannah River Company

Savannah River Site.

Aiken, South Carolina 29808

W. L. Bratton

J. D. Shinn II

J. Haas

M. Carrabba

This paper was prepared in connection with work done under the above contract number with the U.S.

Department of Energy. By acceptance of this paper, the publisher and/or recipient acknowledges the U.S. Government's right to retain a nonexclusive, royalty-free license in and to any copyright covering this paper, along with the right to reproduce and to authorize others to reproduce all or part of the copyrighted paper. 


\title{
WSRC-OS-59-00010:
}

\section{INTEGRATION OF RAMAN SPECTROSCOPY AND CONE PENETRATION TECHNOLOGY CHARACTERIZE CHLORINATED HYDROCARBON CONTAMINANT PLUMES}

\author{
Work performed for
}

Westinghouse Savannah River Company
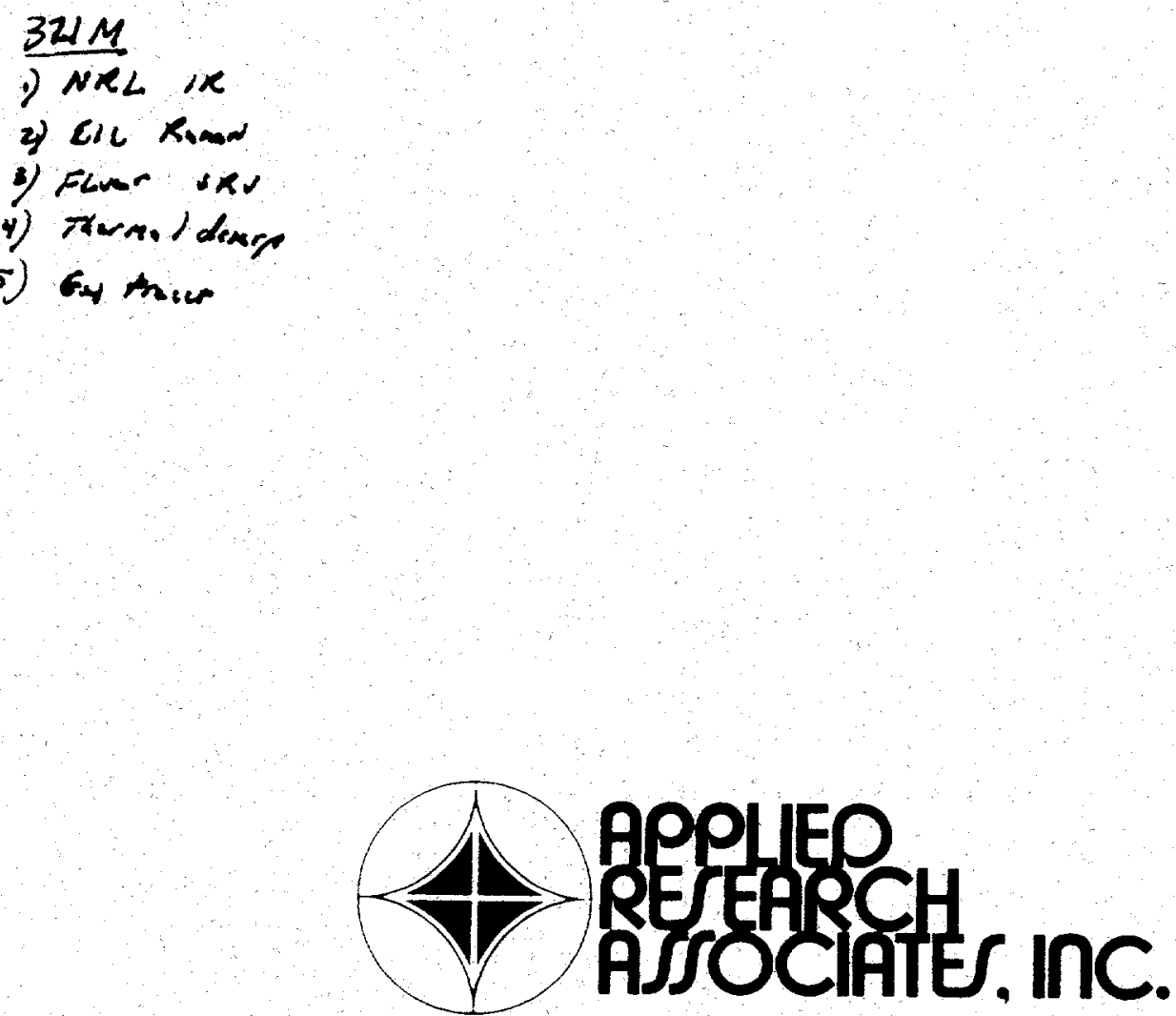

Engineering and Applied Science 


\section{DISCLAIMER}

This report was prepared as an account of work sponsored by an agency of the United States Government. Neither the United States Government nor any agency thereof, nor any of their employees, makes any warranty, express or implied, or assumes any legal liability or responsibility for the accuracy, completeness, or usefulness of any information, apparatus, product, or process disclosed, or represents that its use would not infringe privately owned rights. Reference herein to any specific commercial product, process, or service by trade name, trademark, manufacturer, or otherwise does not necessarily constitute or imply its endorsement, recommendation, or favoring by the United States Government or any agency thereof. The views and opinions of authors expressed herein do not necessarily state or reflect those of the United States Government or any agency thereof.

This report has been reproduced directly from the best available copy.

Available to DOE and DOE contractors from the Office of Scientific and Technical Information, P.O. Box 62, Oak Ridge, TN 37831; prices available from (615) 576-8401.

Available to the public from the National Technical Information Service, U.S. Department of Commerce; 5285 Port Royal Road, Springfield, VA 22161. 


\section{DISCLAIMER}

Portions of this document may be illegible in electronic image products. Images are produced from the best available original document. 


\title{
INTEGRATION OF RAMAN SPECTROSCOPY AND CONE PENETRATION TECHNOLOGY TO CHARACTERIZE CHLORINATED HYDROCARBON CONTAMINANT PLUMES
}

\author{
Work performed for \\ Westinghouse Savannah River Company
}

under

Argonne National Laboratories

Contract No. ANL 23562402

ARA Contract No. 5783

October 28, 1994

by

Wesley L. Bratton, Ph. D.

James D. Shinn II, PE

Applied Research Associates, Inc.

120-A Waterman Road

South Royalton, Vermont 05068

and

John Haas Ph. D.

Michael Carrabba Ph. D.

EIC Laboratories, Inc.

111 Downey Street

Norwood, MA 02062 
TABLE OF CONTENTS

SECTION

$\underline{\text { PAGE }}$

1 INTRODUCTION

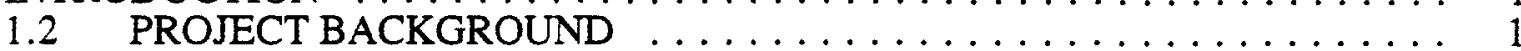

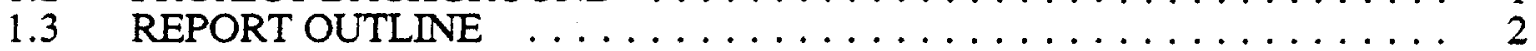

2 RAMAN SPECTROSCOPY/CONE PENETROMETER DEVELOPMENT $\ldots \ldots \ldots 3$

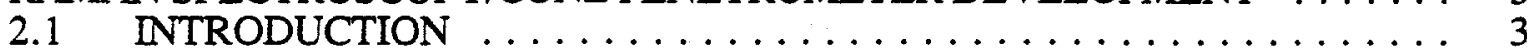

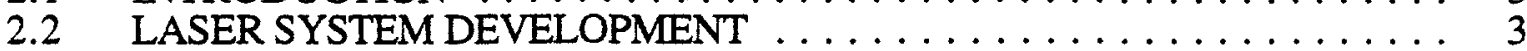

2.3 SIDE-VIEWING RAMAN SPECTROSCOPY CPT PROBE

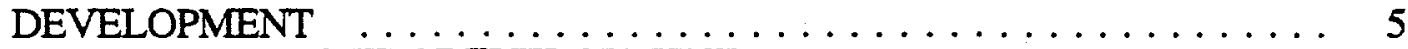

2.4 RECORDING SYSTEM DEVELOPMENT $\ldots \ldots \ldots \ldots \ldots \ldots \ldots \ldots$

2.5 DATA INTEGRATION $\ldots \ldots \ldots \ldots \ldots \ldots \ldots \ldots \ldots \ldots \ldots$

2.6 LABORATORY TESTING $\ldots \ldots \ldots \ldots \ldots \ldots \ldots \ldots \ldots \ldots \ldots \ldots$

3 FIELD DEMONSTRATION OF THE RAMAN/CPT SENSOR PACKAGE $\ldots \ldots, 26$

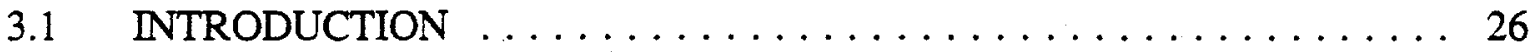

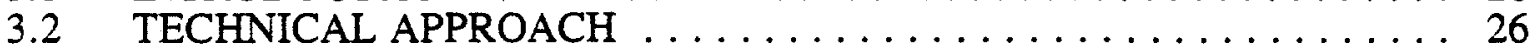

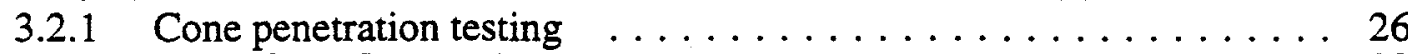

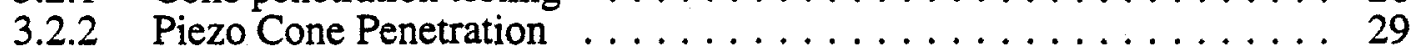

3.2.3 Saturation of the Piezo-Cone $\ldots \ldots \ldots \ldots \ldots \ldots \ldots \ldots \ldots 30$

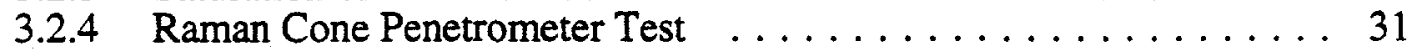

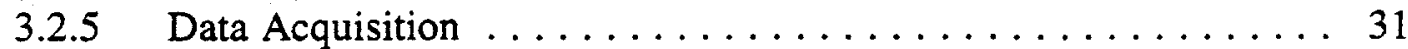

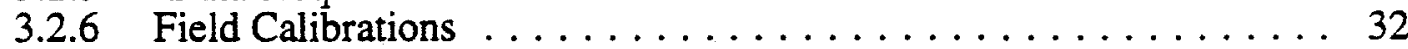

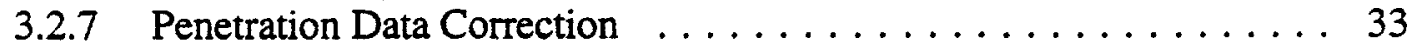

3.2.8 Pore Pressure Correction of Tip Stress . . . . . . . . . . . 33

3.2.9 Depth Correction of the Penetration Data $\ldots \ldots \ldots \ldots \ldots \ldots . . \ldots$

3.3 SOIL CLASSIFICATION FROM THE CPT $\ldots \ldots \ldots \ldots \ldots \ldots \ldots 37$

4 DATA ANALYSIS AND SENSOR EVALUATION $\ldots \ldots \ldots \ldots \ldots \ldots \ldots .43$

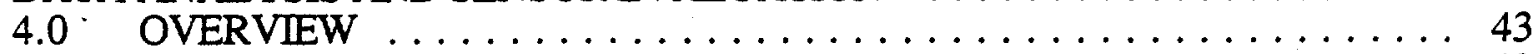

4.1 SUMMARY OF DEMONSTRATION PROGRAM ............ 43

4.2 SOIL STRATIGRAPHY ANAL YSIS OF A TYPICAL PENETRATION

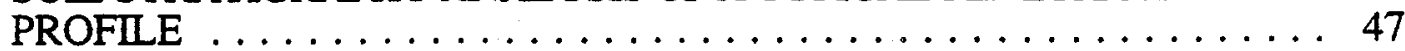

4.3 ANALYSIS OF RAMAN SYSTEM PERFORMANCE $\ldots \ldots \ldots \ldots \ldots 51$

4.4 CENTRAL SHOPS HEATING FUEL DEMONSTRATION .........66 66

4.5 POST DEMONSTRATION EVALUATION OF AN NIR LASER

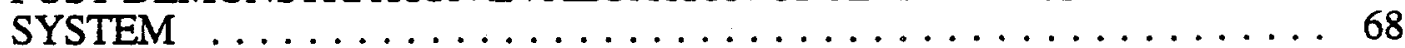

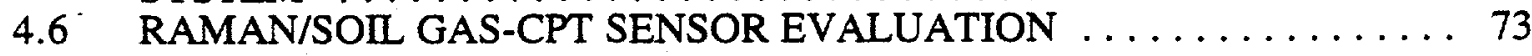

5 SUMMARY, CONCLUSIONS AND RECOMMENDATIONS $\ldots \ldots \ldots \ldots \ldots 80$

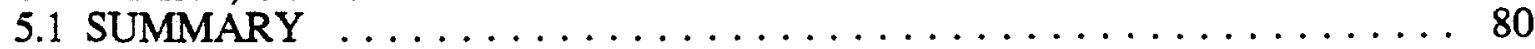

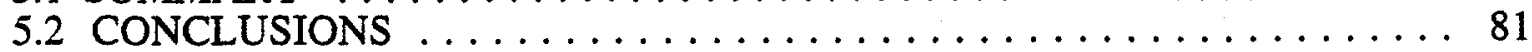

5.3 RECOMMENDATIONS $\ldots \ldots \ldots \ldots \ldots \ldots \ldots \ldots \ldots \ldots$

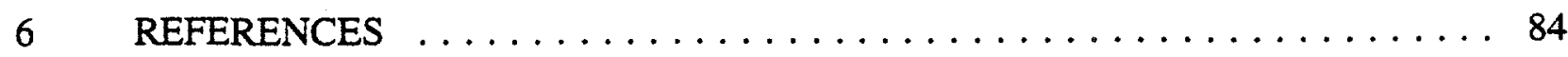




\section{LIST OF FIGURES}

2.1 Schematic of EIC's fieldable Raman Spectrometer. $\ldots \ldots \ldots \ldots \ldots \ldots \ldots$

$2.2 \quad$ Schematic of the side-viewing Raman probe. $\ldots \ldots \ldots \ldots \ldots \ldots \ldots \ldots$

$2.3 \quad$ Schematic of CPT probe showing both Raman module and insert. . . . . . . . 8

2.4 Background spectra from a Raman probe focussing excitation through high purity sapphire and quartz windows as compared with no window (no air). . . . . . . 13

2.5 Raman spectras for four chlorinated solvents typically used at DOE Facilities. . . . . 14

2.6 Fluorescence spectra for gasoline and diesel fuels. . . . . . . . . . . . . 15

2.7 Fluorescence background spectra from three SRS sites. $\ldots \ldots \ldots \ldots \ldots \ldots \ldots 16$

$2.8 \quad$ Raman detection of the SRS red soil saturated with TCE. $\ldots \ldots \ldots \ldots \ldots \ldots 18$

2.9 Raman spectra from a sand saturated with PCE. . . . . . . . . . . . . 19

2.10 Raman spectra from a saturated soil when the probe is focussed on a fissure or void space

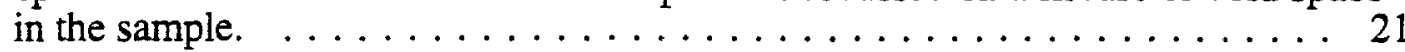

2.11 Fluorescence of Vermont clay soil both with and without TCE, showing increased

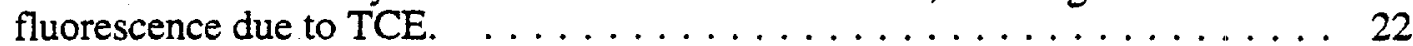

2.12 Fluorescence of a Vermont soil both in situ and after removal. . . . . . . . . 23

2.13 Raman spectra of a sample brought into the CPT for analysis. . . . . . . . 25

3.1 Schematic of CPT probe showing the detail of the optics inside the Raman module. . . 27

3.2 Typical Raman-CPT profile from the ARA A/M site. . . . . . . . . . . . . . 34

3.3 Site specific soil classification based on CPT data. . . . . . . . . . . . . . . 39

3.4 Typical CPT and Raman data from the SRS A/M site. . . . . . . . . . . 40

4.1 Typical CPT and Raman data from the SRS AM area. . . . . . . . . . . . 48

4.2 Typical CPT and Raman data from the SRS A/M area (cont.) . . . . . . . . . . 49

4.3 Raman spectral data from CPT-RAM-8 and three depths. $\ldots \ldots \ldots \ldots \ldots \ldots .53$

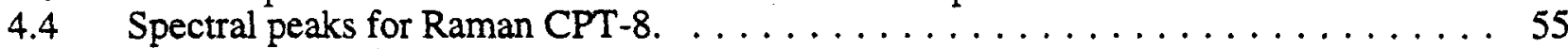

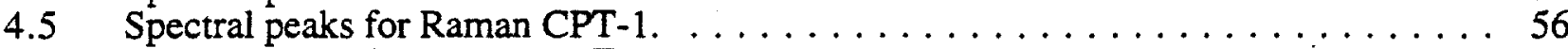

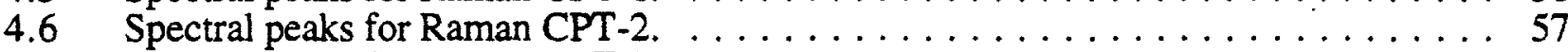

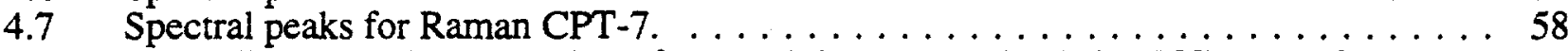

4.8 Three dimensional presentation of spectral data versus depth for CPT-RAM-8. . . . . 59

4.9 Three dimensional presentation of spectral data versus depth for CPT-RAM-1 . . . . . 61

4.10 Three dimensional presentation of spectral data versus depth

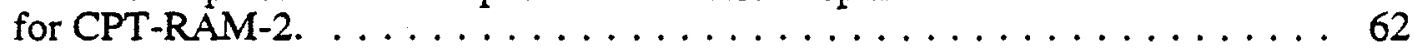

4.11 Three dimensional presentation of spectral data versus depth $\ldots \ldots \ldots \ldots \ldots \ldots \ldots$

4.12 Fluorescence and IR-PAS responses from CPT-RAM-7 with peaks near $80 \mathrm{ft} \ldots \ldots 64$

4.13 Fluorescence and IR-PAS responses from CPT-RAM-6 with peak at $150 \mathrm{ft}$. . . . 65

4.14 Fluorescence depth profile from Central Shops area showing fuel contamination at 15 and $35 \mathrm{ft} . \ldots \ldots \ldots \ldots \ldots 67$

4.15 Fluorescence of SRS bag samples from 16 and 25 feet at the Central Shops Area. . . 69

4.16 Raman spectra of spiked soil samples using a $752 \mathrm{~nm}$ excitation wavelength. . . . . . 7

4.17 Raman spectra of spiked soil samples using a $514 \mathrm{~nm}$ excitation wavelength. . . . . 71

4.18 Raman spectra of an aqueous sample using both 514 and $752 \mathrm{~nm}$ excitation wavelengths.72

4.19 Fluorescence of aqueous samples using $514 \mathrm{~nm}$ excitation wavelength. . . . . . . 74

4.20 Fluorescence of aqueous samples using a $752 \mathrm{~nm}$ excitation wavelength. . . . . . 75

4.21 Raman spectra for gasoline samples using a $752 \mathrm{~nm}$ excitation wavelength. . . . . . 76

4.22 Soil gas concentrations using the $B \& K$ instrument at location CPT-RAM-3 $\ldots \ldots .77$ 


\section{LIST OF TABLES}

TABLE

PAGE

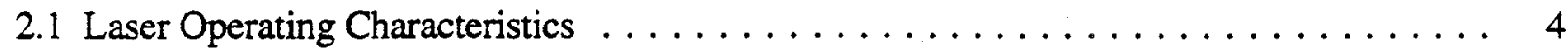

4.1 Summary of Findings during the Raman-CPT Demonstration $\ldots \ldots \ldots \ldots \ldots$

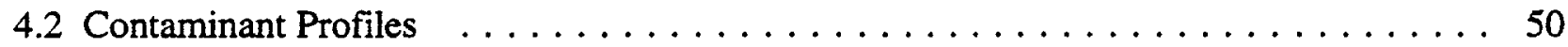




\section{SECTION 1 \\ INTRODUCTION}

Under Argonne National Laboratories' (ANL) Contract No. 23562402, Applied Research Associates, Inc. (ARA) and their subcontractor, EIC Laboratories, developed a new hazardous waste site characterization tool that combined Raman Scattering Spectroscopy and Cone Penetration Technologies (CPT). The primary objective of the project was to develop a minimally intrusive, rapid and cost effective method for locating and identifying nonaqueous phase liquids (NAPL's) in the subsurface. ARA, as prime contractor, was responsible for integrating the Raman system into the cone penetrometer test system and performing a field demonstration of the completed Raman-CPT system. EIC was tasked to develop a field portable system suitable for integration with the CPT, perform a laboratory evaluation of the system, assist in system integration and participate in a two-week demonstration of the Raman-CPT system at the U.S. Department of Energy's (DOE) Savannah River Site (SRS). Contaminants targeted specifically included dense NAPLs (DNAPL's), such as trichloroethylene (TCE) and tetrachloroethylene (perchloroethylene, PCE); along with light NAPLs (LNAPL's), such as gasoline and diesel fuels. These hazards were expected to be present at the selected demonstration site of the DOE Savannah River Site SRS. The completed system was demonstrated at SRS during August,1993. This report documents the system development through all stages including the demonstration and subsequent data analysis.

\subsection{PROJECT BACKGROUND}

In previous projects funded by DOE's Office of Technology Development, ARA and EIC had separately developed CPT and Raman spectroscopic technologies for hazardous waste site characterization. The CPT provides valuable information concerning the soil stratigraphy and material properties in a non-invasive, cost effective and intrinsically safe manner. The CPT method is more rapid than traditional drilling methods and the data is available in real-time, allowing on-site personnel to make timely decisions regarding the investigation program. The CPT method generates no waste during the testing process. Material properties that are measured as part of a CPT sounding include soil classification, strength, electrical conductivity, and hydraulic conductivity parameters, all of which are important parameters for determining the potential extent of any contamination. In addition to providing this information to a high degree of resolution (one data point every $2 \mathrm{~cm}$ ), the CPT provides data in a minimally invasive manner. Besides the Raman Spectroscopy-CPT developed under this effort, CPT probes have been developed that deploy $\mathrm{pH}$, 
temperature, resistivity, laser induced fluorescence, and gamma radiation detectors (Ref. 1,2 and 3).

EIC has developed a novel Raman spectroscopic probe that can be fiber coupled using fiber optics to a variety of fieldable spectrometers. The Raman technique is well suited for the detection and identification of NAPL's because it produces spectra that are rich in detail, each chemical compound producing a unique "fingerprint." Spectra can often be obtained in a few seconds, presenting an opportunity for real-time location of contaminants.

The methodology of integrating Raman spectroscopy with the CPT technology represents a novel approach that uses the strength of the Raman technique for compound identification coupled with the CPT, which is becoming the tool of choice for determining detailed site geologic profiles and hydrologic material properties. Ultimately, the integrated system should provide fast, costeffective, on-site determination of location, concentration, and areal distribution of contaminants. Such a technology is greatly needed at numerous DOE sites such as SRS, where in the Metallurgical Fabrication Area (M Area) Basin mixtures of TCE and PCE DNAPL's have been found in two monitoring wells.

\subsection{REPORT OUTLINE}

This report consists of six sections. Background information concerning the need for development of a Raman spectroscopy CPT system was presented in this section. Section 2 describes the development and laboratory tasks undertaken, and Section 3 describes CPT operating methods and the work performed during the two-week field demonstration at the SRS. Presented in Section 4 is a detailed analysis of the data obtained during field demonstration along with postfield effort laboratory testing. Section 5 contains conclusions and recommendations. Section 6 contains the references. All data collected during the project is contained in the appendices. Appendix A contains the CPT profile obtained during the field demonstration. Appendix B contains soil gas monitoring profiles that were obtained by Westinghouse Savannah River Site personnel during the field demonstration, for comparison to the Raman-CPT data. 


\section{SECTION 2 \\ RAMAN SPECTROSCOPY/CONE PENETROMETER DEVELOPMENT}

\subsection{INTRODUCTION}

The goal of the project was the development and integration of a Raman spectroscopy unit with a CPT system for use in locating contamination below the ground surface. The developed system consisted of three major components:

- A laser system for launching the light

- The CPT probe and fiber-optics to transmit the light to and from the probe.

- A recording device used to convert the light signal to an electrical signal.

The laser system launches the excitation light into a single fiber-optic line, which transmits the light to the CPT probe assembly. There it is launched through an optical window onto the surrounding soils. The emission spectra caused by the laser light is received back through the optical window and transmitted up a second fiber optic cable to the recording device. The device receives the generated light and converts the optical signal into digital signals that are recorded on a 486 compatible computer. The digital signals are displayed on a high resolution video display for real-time analysis. For ease of use, the laser system and the recording system were located in the CPT truck. The only components of the Raman system located downhole were the Raman probe located in the CPT mandrel, and the fiber optic lines used to transmit light to and from the probe assembly. The development of each part of the system is discussed in the following sections along with data integration methods and laboratory testing of the system.

\subsection{LASER SYSTEM DEVELOPMENT}

As part of the laser system development, a laboratory evaluation program was conducted before the field demonstration. The evaluations were conducted with argon, krypton, and diode near infrared light sources. As a result of these tests, a portable, air cooled argon ion laser was selected as an excitation light source. A comparison of the operating characteristics of each of the laser systems is contained in Table 2.1, with the most important characteristics discussed below. 
Table 2.1 Laser Operating Characteristics

\begin{tabular}{|c|c|c|c|}
\hline \multirow{2}{*}{ Characteristic } & \multicolumn{3}{|c|}{ Laser Source } \\
\cline { 2 - 4 } & $\begin{array}{c}514 \mathrm{~nm} \\
\text { (Argon) }\end{array}$ & $\begin{array}{c}647 \\
\text { (Krypton) }\end{array}$ & $\begin{array}{c}810 \mathrm{~nm} \\
\text { (Diode) }\end{array}$ \\
\hline Power @ Laser & 170 milliwatt & 35 milliwatt & 100 milliwatt \\
\hline Power @ Probe & 75 milliwatt & 15 milliwatt & 40 milliwatt \\
\hline Stability & Stable & Stable & $\begin{array}{c}\text { Temperature Sensitive } \\
\text { \& Alignment sensitive } \\
\text { Fragile }\end{array}$ \\
\hline $\begin{array}{c}\text { Suitability for } \\
\text { Field Work }\end{array}$ & Suitable & Suitable & Poor \\
\hline $\begin{array}{c}\text { Background } \\
\text { Fluorescence }\end{array}$ & Some soil type high & Highest & Lowest \\
\hline \hline
\end{tabular}

The laboratory evaluations of soil samples from SRS were tested and found to produce similar background fluorescence signals with green ( $514 \mathrm{~nm}$ argon laser) and near infrared (NIR) excitation (red, $647 \mathrm{~nm}$ krypton laser). The diode laser $(810 \mathrm{~nm})$ displayed only a slight advantage for the samples tested. Second, the sensitivity of a $514 \mathrm{~nm}$ argon laser Raman system was at least 20 -fold greater than an $810 \mathrm{~nm}$ diode laser system based on available power, detector quantum efficiency at $514 \mathrm{~nm}$, and the wavelength dependence of Raman scattering. Third, and perhaps most important, diode lasers are highly unstable compared to the ion laser sources. In our tests, slight temperature or alignment changes caused the laser wavelength to shift, necessitating frequent recalibration (sometimes every few minutes). This situation was deemed unsuitable for typical CPT operations in which a test may be performed over a period of hours. Based upon this instability, the diode laser was eliminated. The argon laser was selected because of the slightly reduced background signal when compared to the Krypton laser and the ability to deliver significantly more power to the sample. 
The argon laser system was housed in a specially designed instrument box used for both the laser system and the recording system, as shown in Figure 2.1. This system facilitated safe shipment of the equipment, rapid hook-up, and modular design for easy repair if a part failed. A custom interface, including a manual shutter, was developed for efficient (>85\%) coupling of laser light into the excitation fiber. Heat from the laser head was removed through a blower tube to a fan outside the CPT truck. Both the Charge Coupled Detector's (CCD) power supply and the laser's 220 voltage supply were housed in a separate power supply case. The case was designed by EIC and had removable front and back lids to facilitate rapid connection and disconnection of power cables from the laser system.

\subsection{SIDE-VIEWING RAMAN SPECTROSCOPY CPT PROBE DEVELOPMENT}

EIC's patented fiber-optic Raman probe was designed for "end-on" detection. For compatibility with the long, narrow shape of the penetrometer cone, a "side-on" detection geometry was preferred for this project. A new "side-viewing" probe was designed and fabricated according to the schematic shown in Figure 2.2. The performance of the probe was comparable to the original end-viewing version. Important features of the new probe were the incorporation of a $90^{\circ}$ reflecting mirror and an adjustable focusing/collection lens holder. The latter feature allowed the sensing distance from the side of the probe to be optimized.

Integration of the side-viewing Raman probe into the penetrometer was accomplished with an interface module fabricated by ARA. This module held the Raman probe close to the cone's sapphire window. An opening in the side of the module large enough to allow the Raman probe's focusing lens to be adjusted without removing the probe from the CPT probe was incorporated into the design. A schematic of the unit is presented in Figure 2.3. This schematic shows the Raman Probe held in place by the module inside the CPT mandrel. Both the Raman insert piece (module) and the Raman probe are located and held in place opposite the sapphire window installed in the side of the CPT.

In addition to a window viewing setup, a special setup that allows a small liquid sample to be drawn into the CPT and analyzed using the Raman probe was also developed. This setup required a slightly different insert module which held the Raman probe in a different position separated from the sample area by a fused silica window. The sapphire window on the exterior of 


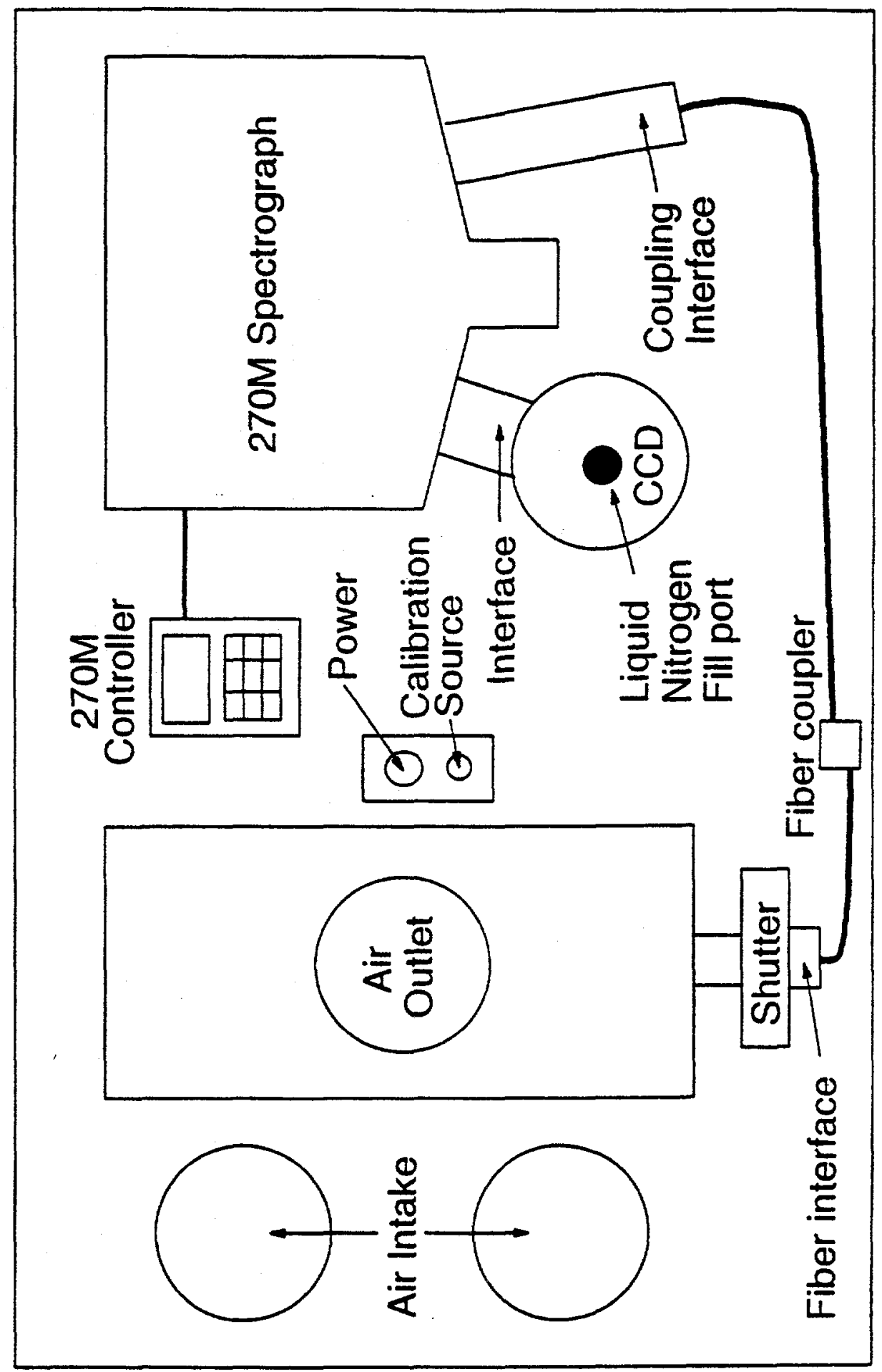

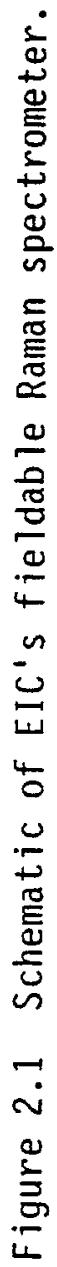




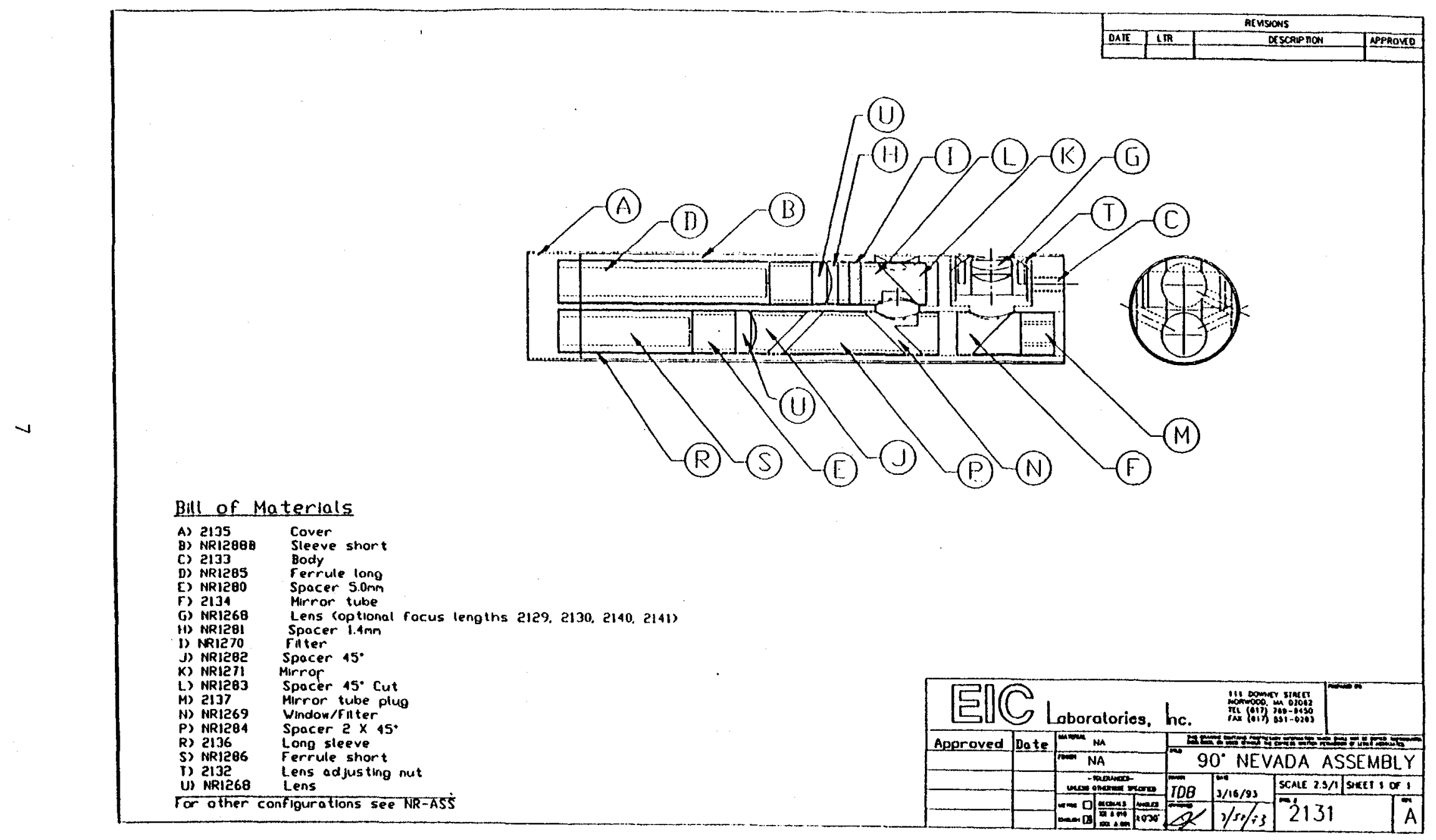

Figure 2.2 Schematic of the side-viewing Raman probe. 


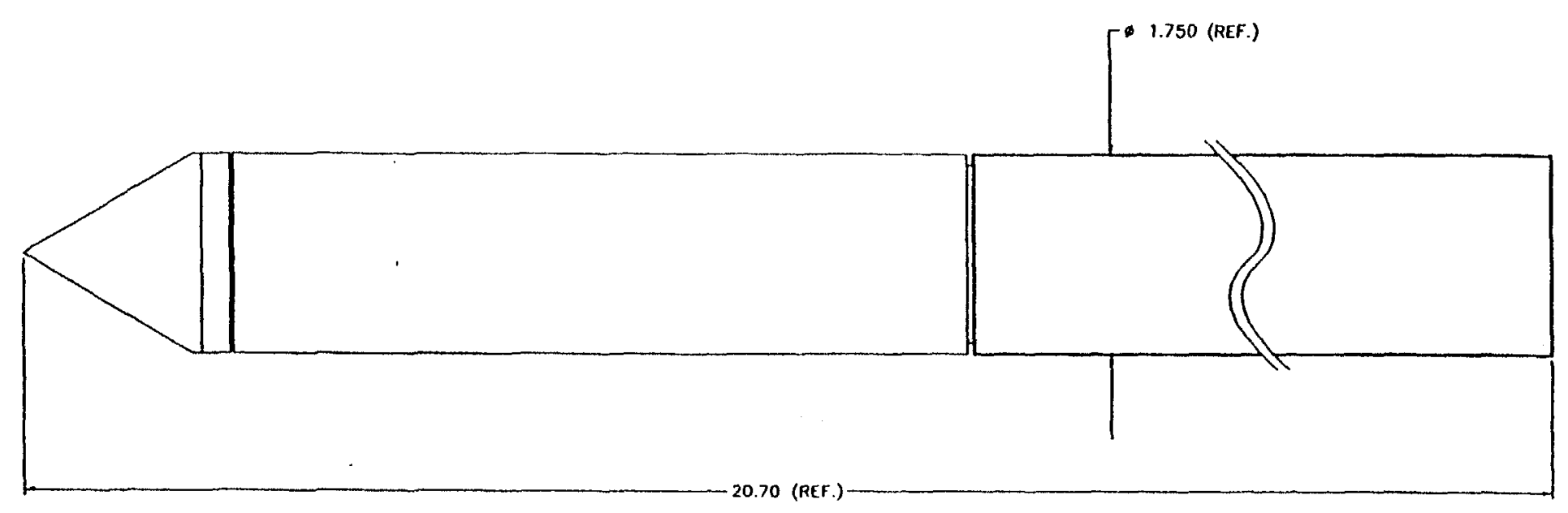

$\infty$

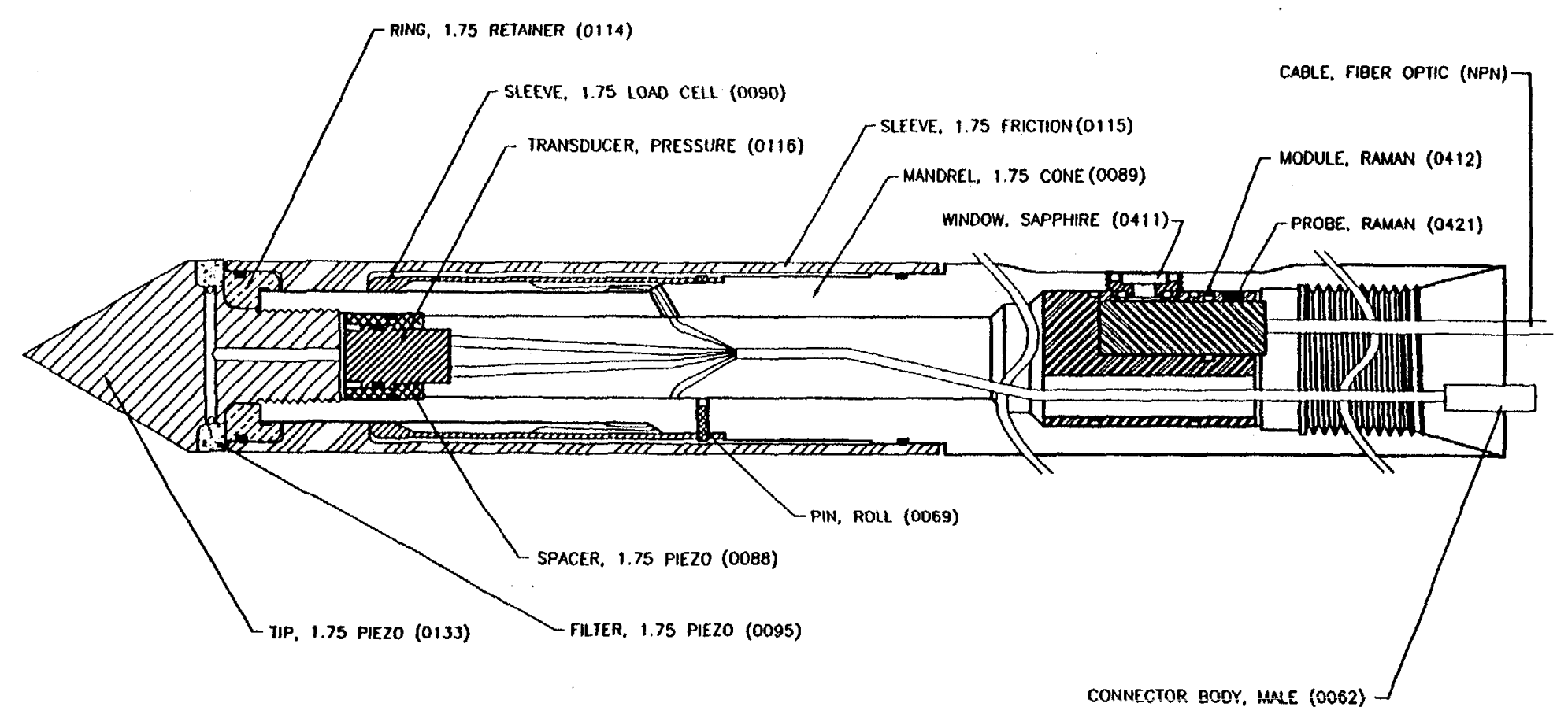

Figure 2.3 Schematic of CPT probe showing Rämän module and insert. 
the CPT was replaced with a porous ceramic frit that allows a water sample to be drawn into the cone, but keeps sand silt and clay sized particles outside the CPT. The system was developed as a backup, in case the background fluorescence of the soils was significant enough to obscure the Raman signal that was being measured. Preliminary testing on bucket samples of both SRS soils and Vermont soils indicated that the background fluorescence may be excessive, although an in situ test in Vermont indicated significant background fluorescence only near the surface (less than 4 feet) which then dropped off significantly to levels at which the Raman signal could be measured at depths greater than $4 \mathrm{ft}$. This is probably due to natural organic matter in the soil near the surface. The modified Raman-CPT probe would eliminate the background fluorescence problem of the native soils at SRS by allowing liquid samples to be analyzed. The drawback of this setup is that tests can only be made at discrete intervals, and not continuously, as with the sapphire window setup.

A total of four Raman probes were fabricated for the field testing and demonstration phases of the project. The probes were constructed of stainless steel and all optical components were secured in place with set screws and epoxy to maintain alignment during the rugged field deployment that this probe must experience. Each probe delivered 50 to $75 \mathrm{~mW}$ of argon light to the sample through a $100 \mathrm{~m}$ connecting fiber-optic cable. The excitation fiber in the cable had a $90 \mu \mathrm{m}$ core and the collection fiber had a $180 \mu \mathrm{m}$ core. The cable was of custom fabrication, combining both the excitation and collection fibers in a fiber reinforced plastic jacket such that the fiber would be able to withstand the harsh handling environment of the CPT.

\subsection{RECORDING SYSTEM DEVELOPMENT}

As mentioned previously, the laser system and the recording system were housed in the same instrumentation box for ease of operation. A schematic of the instrument box is shown in Figure 2.1 and shows the recording system consisting of a $270 \mathrm{M}$ Spectrograph and CCD. For maximum sensitivity, a small, high-throughput spectrograph and liquid nitrogen cooled CCD detector were used. The spectrograph was controlled from an external keypad that the operator could position at a convenient location. Customized interfaces were developed to couple the $C C D$ to the spectrograph and to image Raman scattered light from an optical fiber into the spectrograph. Several features of the device were designed to enhance ease of operation in the field, including the following: 
1. A CCD extender was fabricated to allow filling the detector with liquid nitrogen without opening the instrumentation system.

2. An optical fiber coupling port was located on top of the spectrometer to facilitate rapid exchange of probes or connecting fibers, thereby avoiding misalignment of the laser-tofiber or fiber-to-spectrograph couplers inside.

3. A spectral calibration lamp was mounted in the instrument cover.

4. A custom shipping case that provided rapid unpacking and setup in the field was designed.

The final component of the instrument was a 486DX IBM-compatible PC used to collect spectra from the CCD camera and transfer data to ARA's CPT computer system This computer system was shipped separately and consisted of a third instrumentation box. The computer interfacing between the ARA CPT system computer and the EIC Raman Spectroscopy computer is described below, in the section on data integration.

\subsection{DATA INTEGRATION}

Standard CPT testing consists of making measurements of tip stress, sleeve stress, pore pressure, and depth. All of the measurements are made using electronic devices as described in Section III. The electronic signals are converted to digital values and stored on the CPT computer system, once every second, for a depth resolution of $2 \mathrm{~cm}$, at normal CPT penetration rates. These values are displayed in real-time on the CPT computer to inform the operator of the type of materials that are being encountered during the CPT test. Since the major goal of this project was to detect contamination in real-time, adaptations to the CPT data presentation system were made to display some of the Raman data in real-time. This assisted the CPT operator in locating the contamination, and guided the site investigation.

Since the Raman system records an entire spectra $(519$ to $590 \mathrm{~nm})$ of 1064 data points every 10 seconds, the data requires simplification to allow transport and display on the CPT computer system in real-time. The indications of contamination from the Raman system are peaks above baseline values at specified Raman peak wavelengths. To simplify this data, five windows 
of predetermined wavelength intervals were selected and the area under the signal curve in each of the windows was determined. The five areas were then communicated from the Raman computer to the CPT computer where they were stored and displayed. At the same time, the depth value from the CPT computer was communicated to the Raman computer for storage with the entire Raman spectrum. The two computers were connected using digital L/O boards. Using this setup, six 16-bit values could be passed between the two computers.

Data transfer was automatically controlled by computer programs developed by both EIC and ARA for operation on their computer systems. The EIC code collected the spectra at selected intervals and converted the spectra to an ASCII code for storage. ARA developed software to read the stored ASCII spectra data and integrate the signal in each of the five windows. These values were then transferred to the CPT computer for display.

\subsection{LABORATORY TESTING}

Throughout the instrument development phase of the project, tests were conducted to assess the performance of individual components of the system. Results from the laboratory tests are plotted as wave numbers which can be converted to wave length as

$$
\begin{aligned}
& \lambda=\frac{1}{v_{\text {laser }}-\Delta v} * 10^{7}(\mathrm{~nm}) \\
& \text { and } v_{\text {laser }}=\frac{1}{\lambda_{l}} * 10^{7}
\end{aligned}
$$

where: $\quad \lambda=$ wavelength $(\mathrm{nm})$

$$
\begin{aligned}
\Delta v & =\text { wavenumber of interest }\left(\mathrm{cm}^{-1}\right) \\
\lambda_{l} & =\text { laser wavelength }(\mathrm{nm}) \\
v_{\text {laser }} & =\text { Wavenumber of laser line }\left(\mathrm{cm}^{-1}\right)
\end{aligned}
$$

The following is a summary of the most significant tests performed: 
1. Sapphire window testing. A sapphire window used by ARA in previous CPT fluorescence tests was found to produce a high background fluorescence. New high purity sapphire windows were obtained and found to produce almost 10-fold less background fluorescence. As shown in Figure 2.4, quartz (fused silica) gave an even lower spectral background and was used in the liquid sampling cone module where window strength and resistance to scratching was not an issue.

2. Spectra from standard compounds: Spectra of neat (undiluted) chlorinated solvents, gasoline, and diesel fuel were obtained using the field Raman system for reference and are presented in Figures 2.5 and 2.6. TCE, PCE, and diesel fuel were anticipated to be present at SRS. The additional materials tested are commonly found at other DOE sites. It is clear from the spectra that the chlorinated solvents can be easily differentiated. In addition, Figure 2.6 clearly shows that gasoline and diesel are strongly fluorescent when excited at $514 \mathrm{~nm}$. The fluorescence is attributable to large, polycyclic aromatic hydrocarbons present in the fuels. Diesel, a heavier fuel, shows a red-shifted fluorescence compared to the lighter unleaded gasoline, allowing the two fuels to be distinguished.

\section{Background spectra from soils: Three soils from SRS and several local} soils were tested by directing the "side-viewing" Raman probe through a sapphire window onto the sample. The focal position of the laser beam on the sample was adjusted so that the focal volume (visible in a liquid sample) began just at the sapphire/sample interface. The results for the three SRS soils are shown in Figure 2.7 and demonstrate the wide variability in fluorescence background that can be expected at a single site. The gray-green soil from $105 \mathrm{ft}$ produced the largest background by far. In subsequent tests it was not possible to obtain Raman spectra of chlorinated solvents saturating this soil. Spectra could, however, be obtained from solvents in the other two soils. Table 2.2 summarizes the background intensities at $1600 \mathrm{~cm}^{-1}$ (all the contaminants of interest have a Raman band there), for each of the soils tested, using a 1-second integration time. A silica sand sample produced the lowest background, whereas the two surface soils collected outside the EIC Laboratories gave large backgrounds. The surface soil backgrounds might be expected due to the significant presence of organic materials in these soils. 


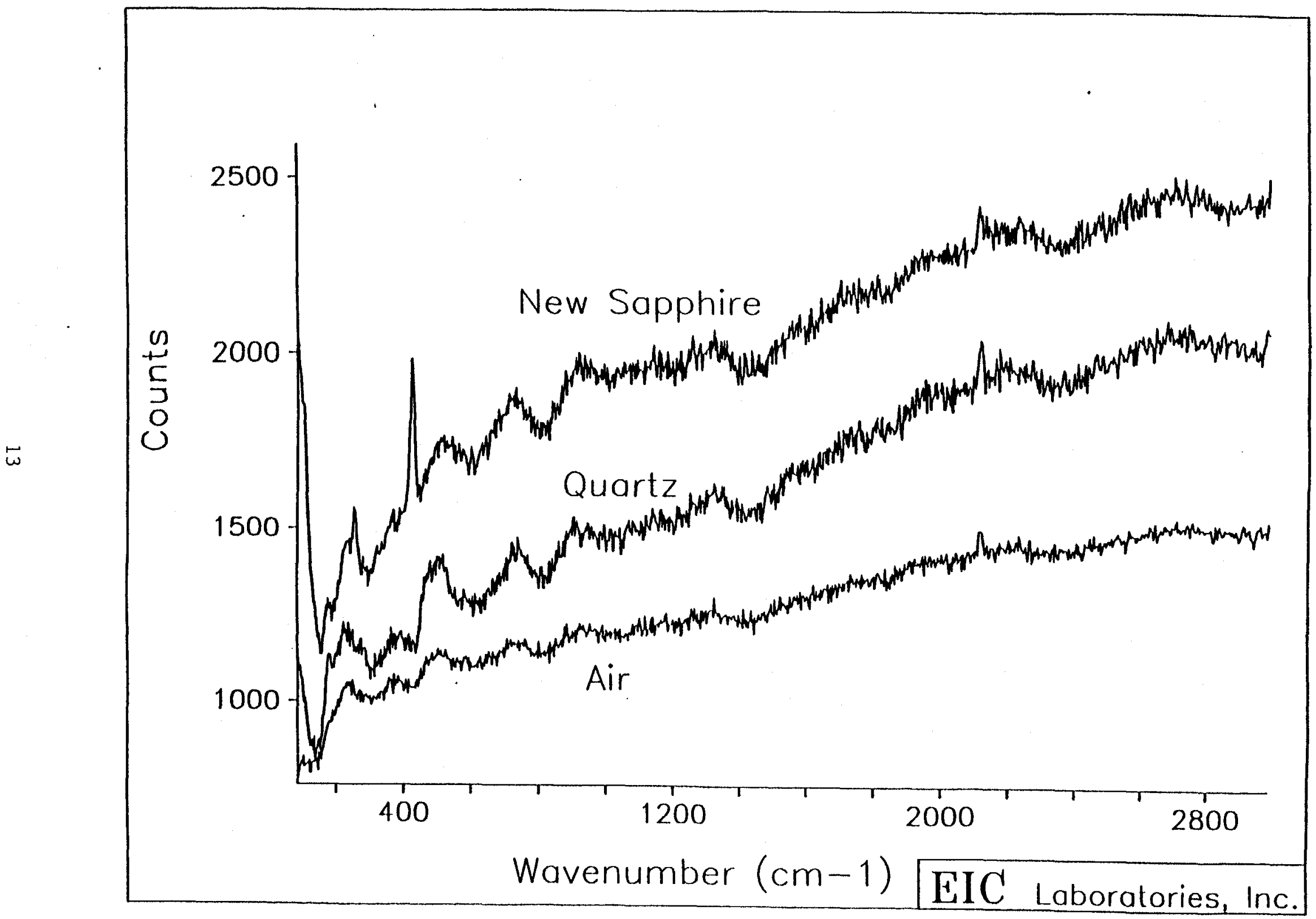

Figure 2.4 Background spectra from a Raman probe focusing exitation light through high purity sapphire and guartz windows as compared with no window (Air). 


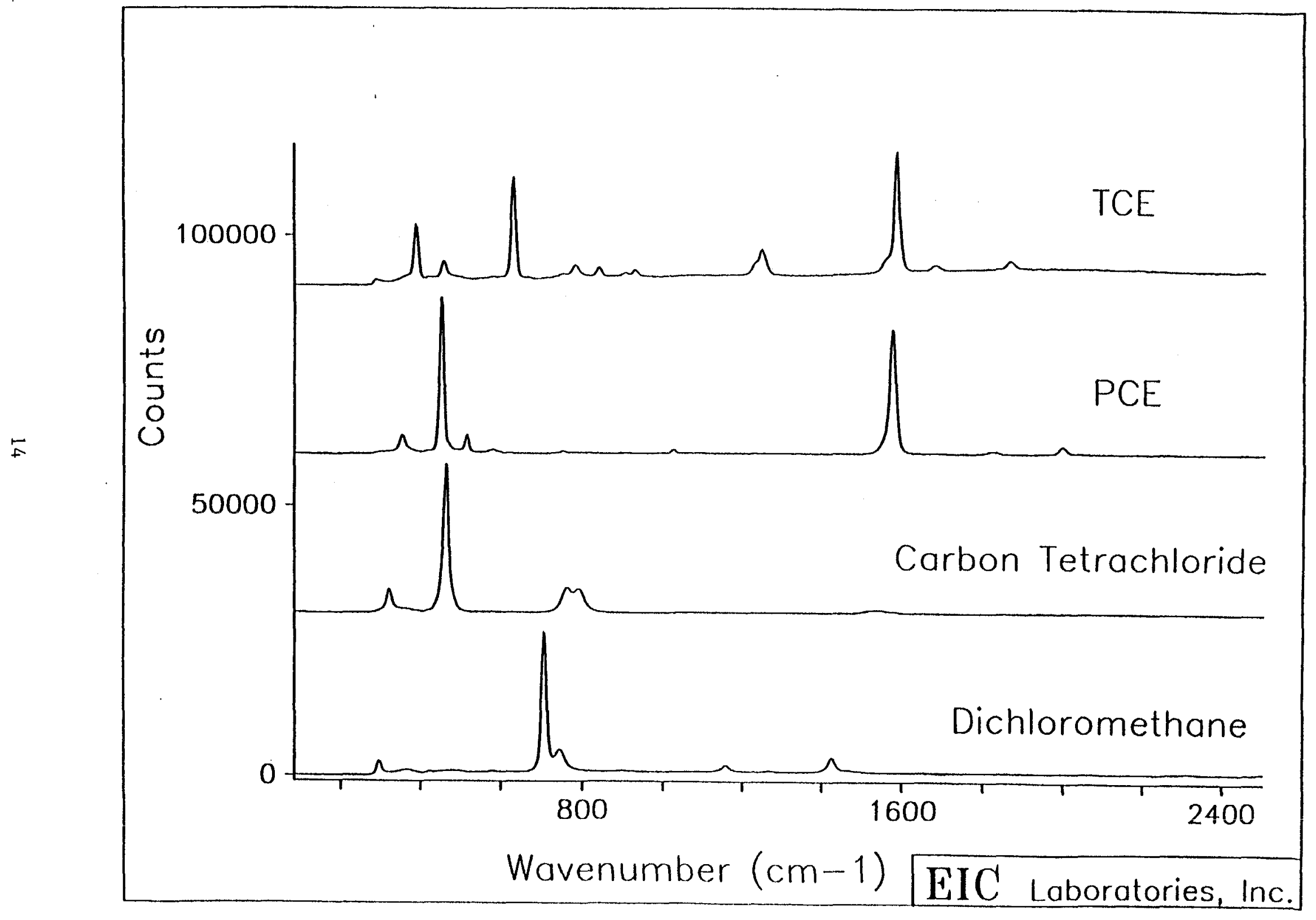

Figure 2.5 Raman spectra for four chlorinated solvents typically used at D0E facilities. 


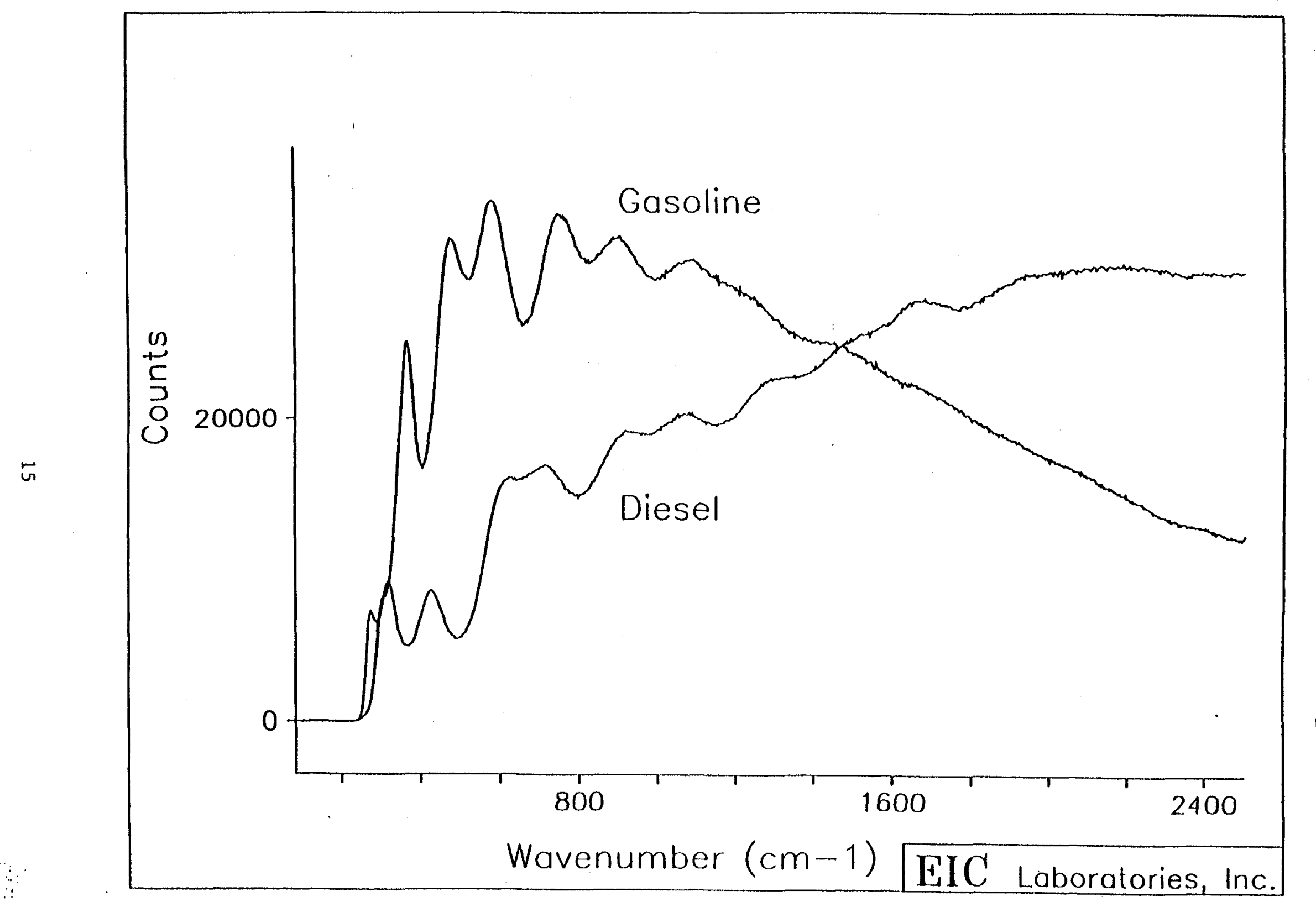

Figure 2.6 Fluorescence spectra for gasoline and diesel fuels. 


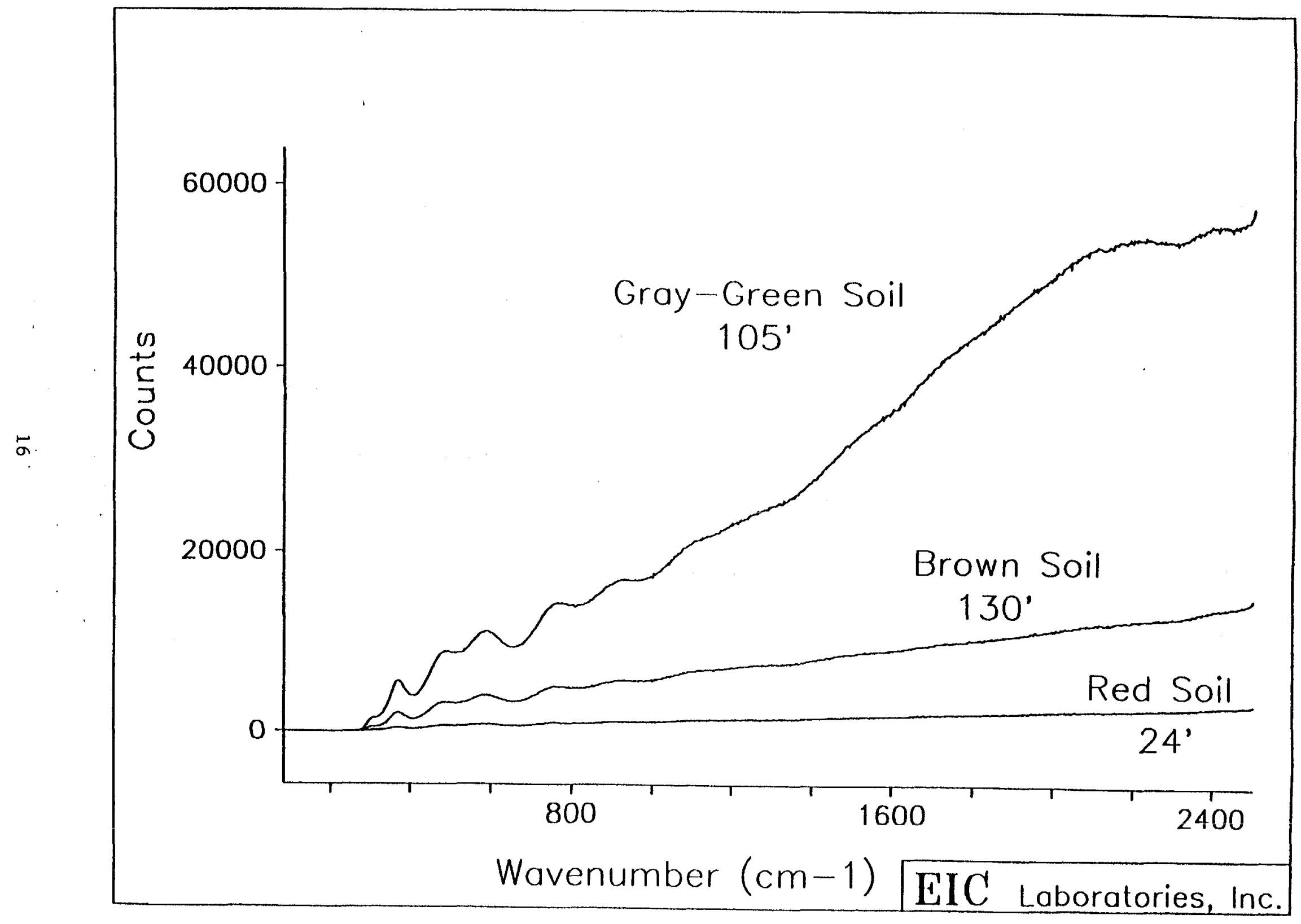

Figure 2.7 Fluorescence background spectra from three SRS soils. 
Table 2.2. Fluorescence background intensities for soils (with $514 \mathrm{~nm}$ excitation)

\begin{tabular}{|c|c|c|}
\hline Soil & Depth (ft) & Intensity @ 1600 cm-1 \\
\hline \hline SRS Red & 24 & 1850 \\
\hline SRS Gray -Green & 105 & 355,000 \\
\hline SRS Brown & 130 & 9300 \\
\hline EIC Garden & 0.5 & 63,000 \\
\hline EIC Parking lot & 1 & 48,000 \\
\hline Silica Sand & N/A & 750 \\
\hline VT Soils Clayey & & 10,000 \\
\hline VT Soils In Situ Sand & & $2,000-4,000$ \\
\hline
\end{tabular}

4. Raman spectra for NAPL spiked soil samples: The soil samples tested above were spiked to saturation with TCE, PCE, gasoline, or diesel fuel. Because the solvents evaporated quickly the probe was directed to the sample through a closed glass vial rather than the sapphire window for this test. When soil was pressed firmly against the side of the vial, Raman spectra could be collected from the spiked SRS Red, SRS Brown, and Playbox Sand samples. The other soils produced fluorescent backgrounds that masked the Raman signals. An example of TCE detected in the SRS Red soil is shown in Figure 2.8, and Figure 2.9 shows PCE detected in sand. Note that the "pure" sand sample has three Raman bands at about 465,575 , and $750 \mathrm{~cm}^{-1}$ not present in the other soils tested. These bands could possibly be used as a marker for sandy soil type, but more importantly, must not be misidentified as contaminant bands. Gasoline and diesel spiked soil samples all showed a marked increased fluorescence over the clean. Integration times of less than a second were required to avoid saturating the $\mathrm{CCD}$ detector.

Much stronger Raman signals were obtained when cracks and fissures more than a few hundred microns in size, and filled with analyte, were present in the soil samples. Figure 


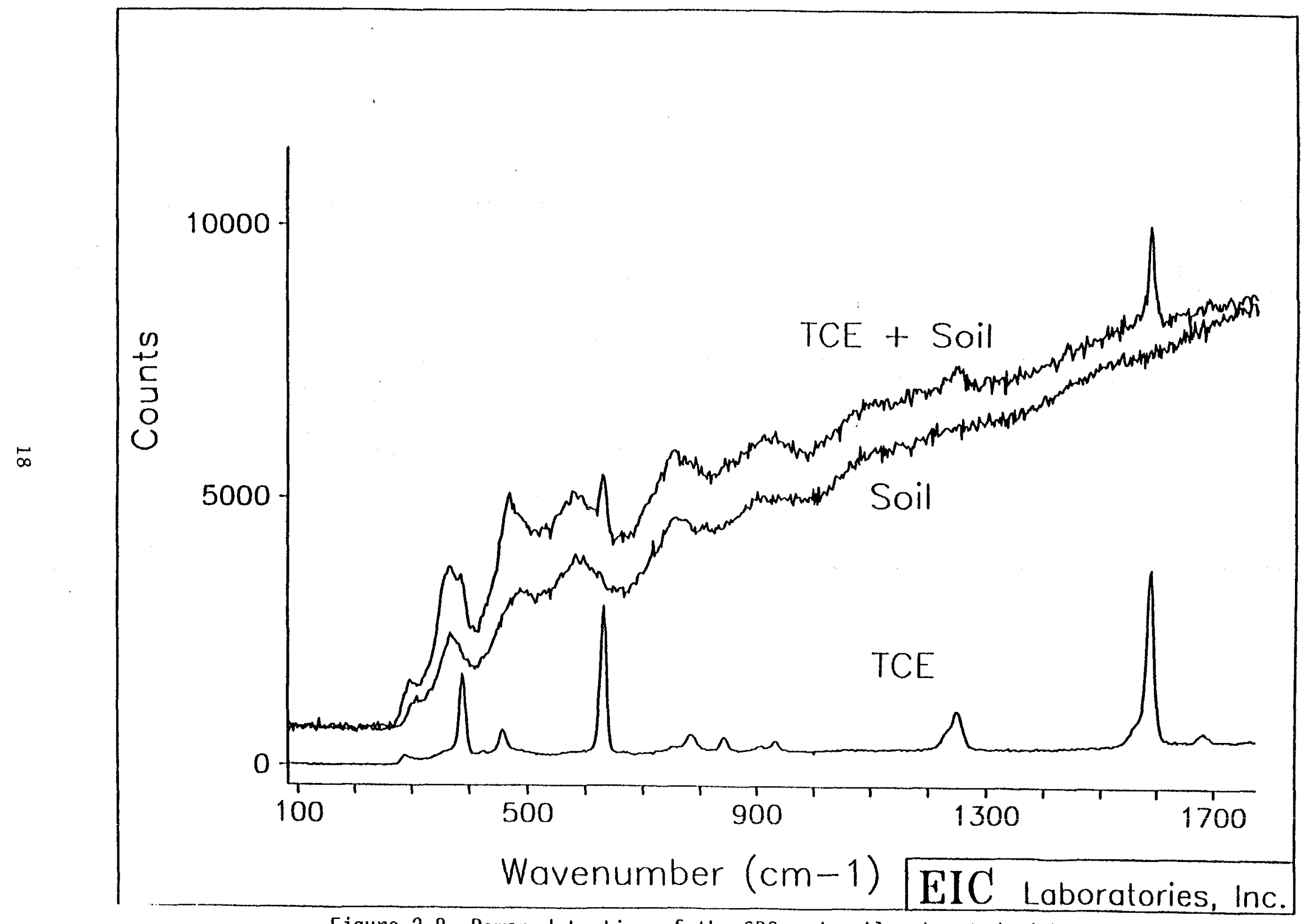

Figure 2.8 Raman detection of the SRS red soil saturated with TCE. 


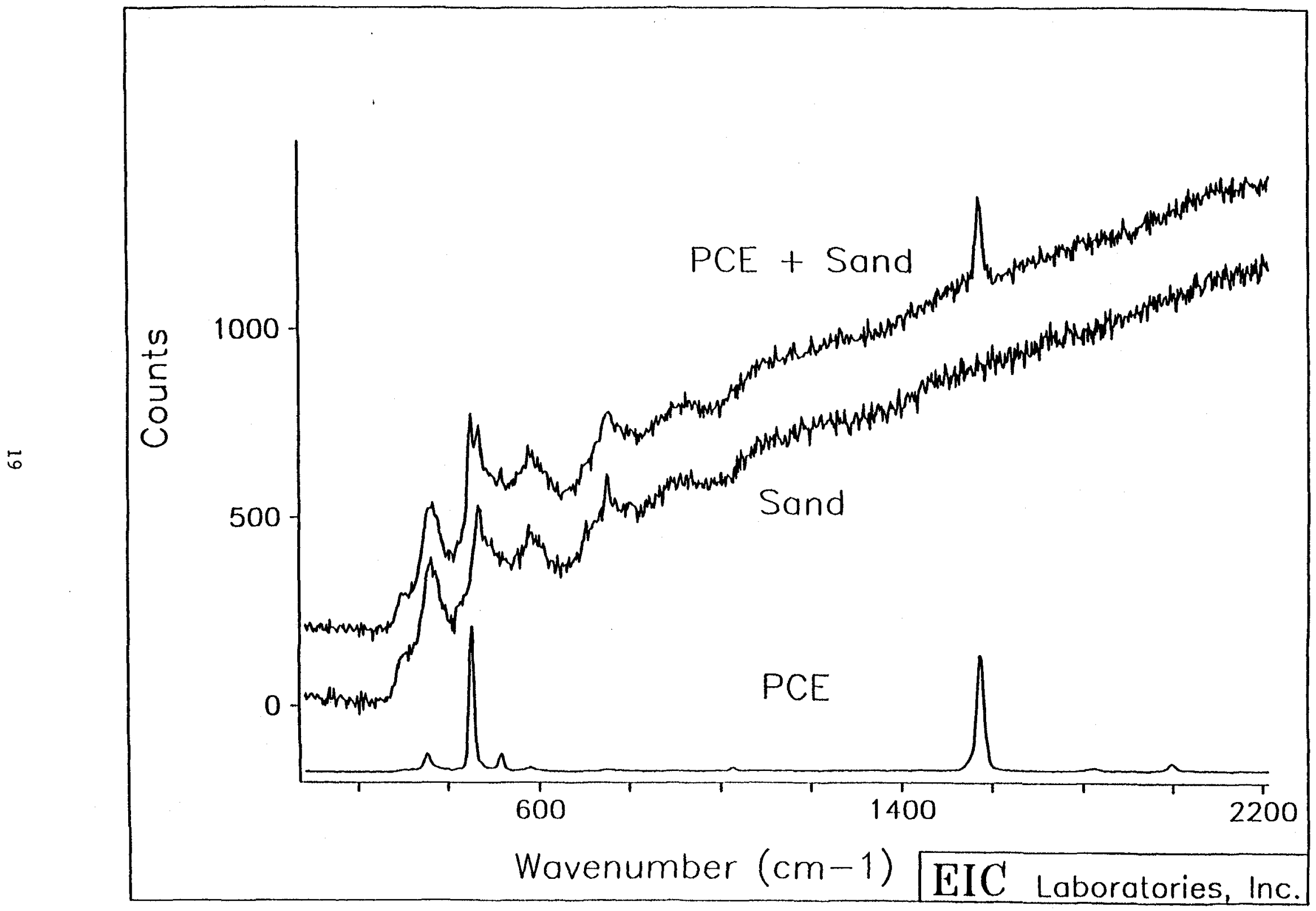

Figure 2.9 Raman spectra from a sand saturated with PCE. 
2.10 shows the enhanced Raman spectrum obtained when the laser beam from the probe was focused into a pocket of TCE about $0.5 \mathrm{~mm}$ in diameter in a soil sample. If similar pockets are present in the subsurface and are not compressed by the CPT probe, the capability for detecting NAPL in fluorescent soils improves dramatically.

\subsection{VERMONT FIELD TESTING}

A week of field testing at ARA's Vermont field test facility and follow-up laboratory work were conducted to prepare the Raman system for the SRS demonstration. The Vermont testing began with an installation of the Raman system into the CPT. This process went very smoothly due to good preliminary planning and communicating on the part of both EIC and ARA.

A series of tests using the Raman/CPT system were conducted. In this testing the Raman/CPT probe was manually inserted into soil columns containing TCE. A local clayey soil was used in these tests. This soil produced a large fluorescence background, precluding TCE detection. In fact, it was observed that soil fluorescence increased $50 \%$ upon addition of TCE (shown in Figure 2.11), a phenomenon observed with most of the soils tested. Extraction of fluorescent materials accounts for only a small part of the enhanced fluorescence, solvation or other effects must also contribute significantly to the enhancement. However, in some cases where highly uniform backgrounds are encountered, fluorescence enhancement might be used to detect the presence of NAPL's. This indirect approach has major drawbacks because the spectral profile is the same as the background and comparable responses could be caused solely by a change in soil type.

Ruggedness of the Raman probe was tested by performing a penetration with the penetrometer truck to a depth of $20 \mathrm{ft}$. through gravelly soil. No problems were encountered during the deployment, and optical power coming out of the CPT's sapphire window remained unchanged afterward. In the course of the penetration, the soil background fluorescence levels at depths of more than a few feet, were considerably lower (see Table 2.2) than those measured for the local clay in the previous tests. Therefore, a core sample was collected at $18 \mathrm{ft}$ and later analyzed at EIC. As shown in Figure 2.12, the background increased substantially for the ex situ sample, perhaps due to oxidation reactions upon removal from the subsurface. This observation suggested that in situ background fluorescence in soils at SRS might be less than the fluorescence of SRS soils measured in the laboratory tests, as presented in Figure 2.7. 


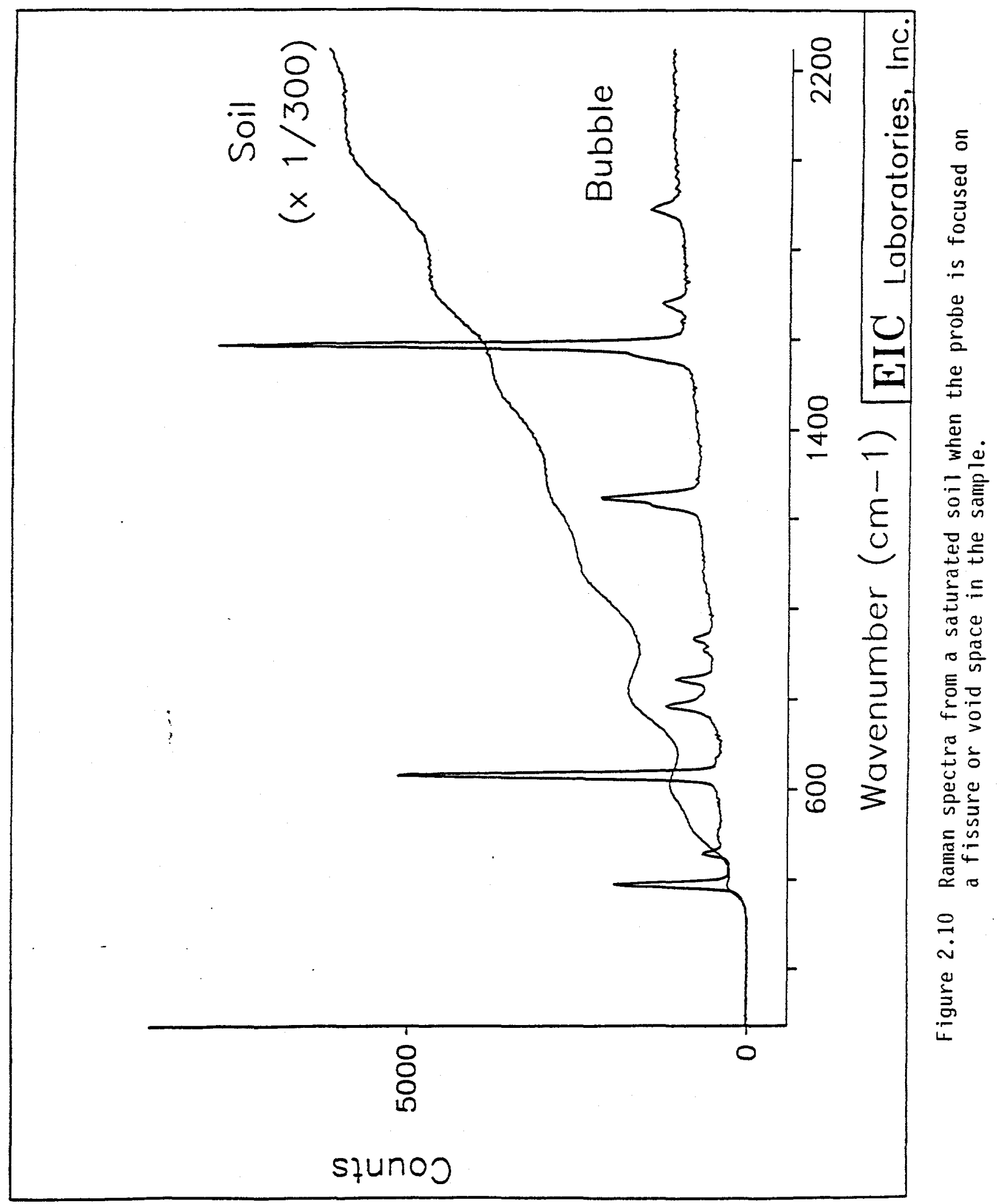




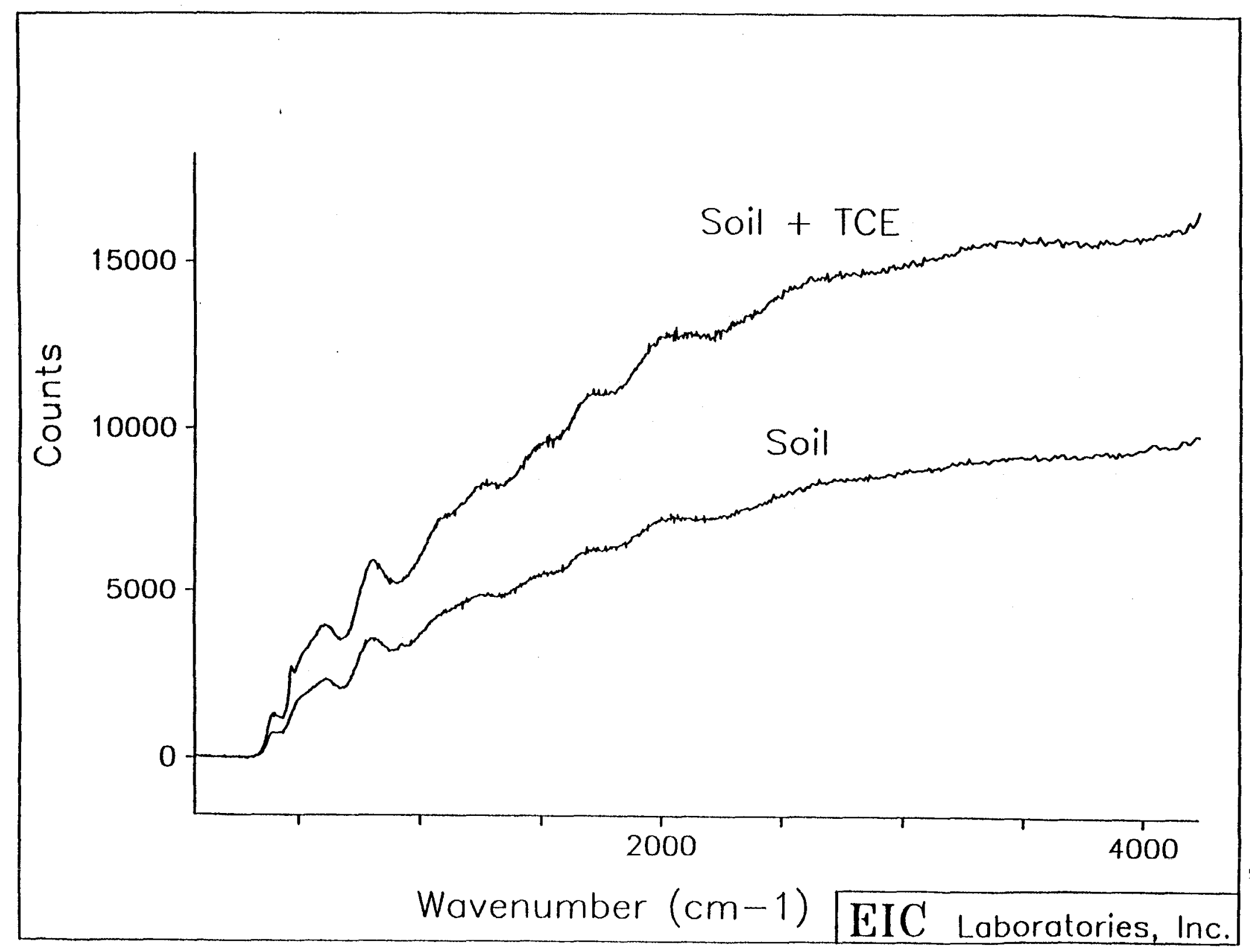

Figure 2.11 Fluorescence of Vermont clay soil both with and without TCE, showing increased fluorescence due to TCE. 


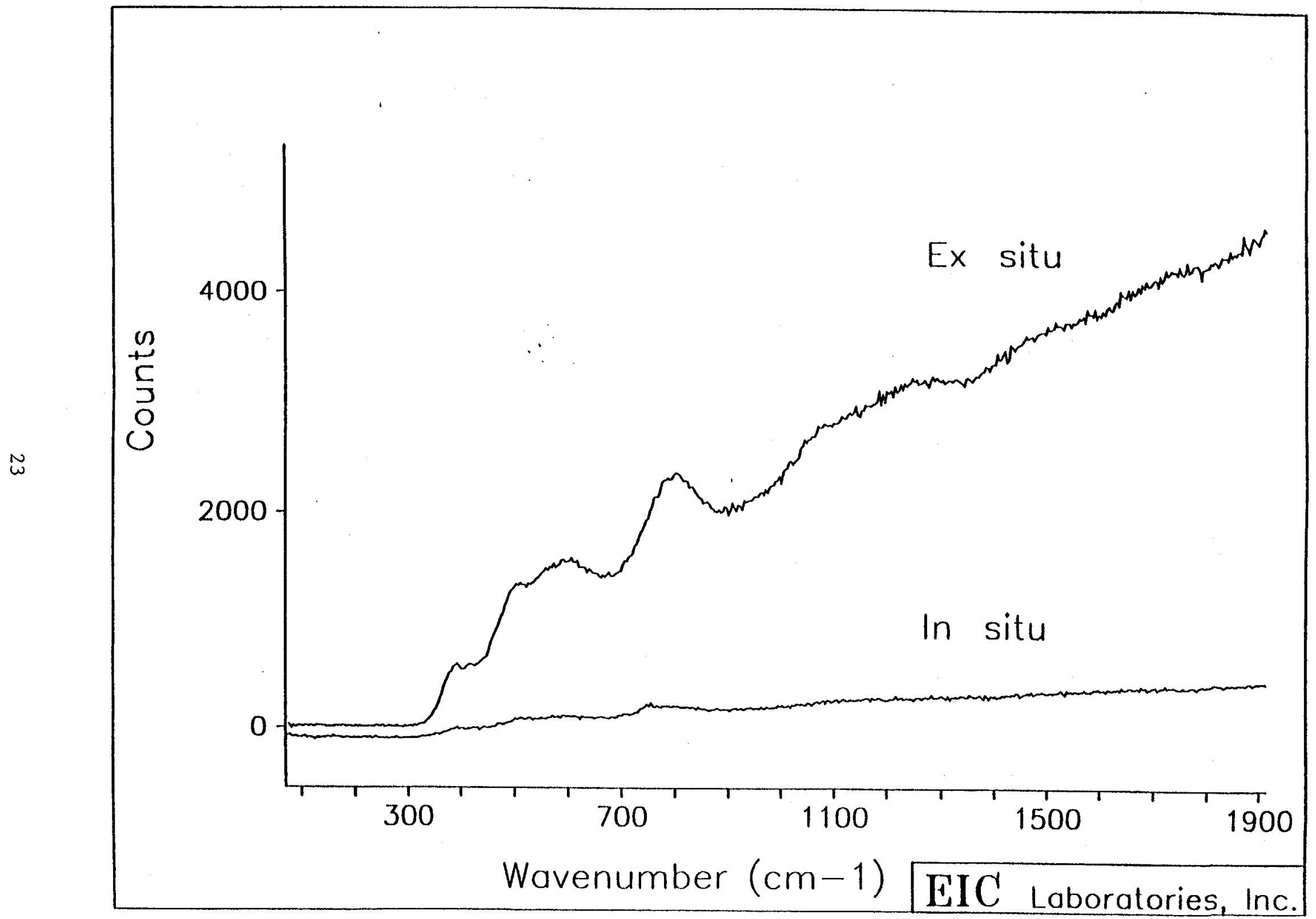

Figure 2.12 Fluorescence of a Vermont soil both in situ and after removal showing increased fluorescence after removal. 
A final objective met in the Vermont test was integration of the ARA on-truck computer with EIC's Raman computer. Raman data were successfully collected and transferred to the ARA computer for real-time display. Improved algorithms were developed by ARA programmers to record both background fluorescence levels and Raman peak values (background subtracted).

Based on the high level of background fluorescence observed for some of the soil samples tested, it was decided that the liquid extraction interface module described previously would be constructed prior to the SRS demonstration. The device was fabricated by ARA and tested at EIC using TCE and PCE saturated soils.

The module performed extremely well. Minimal suction was required to draw a sample into the detection reservoir, and even the most fluorescent soils did not produce extracts that fluoresced strongly enough to prevent NAPL detection. Figure 2.13 shows the spectrum of TCE extracted from a solvent saturated, highly fluorescent ARA local clay sample. 


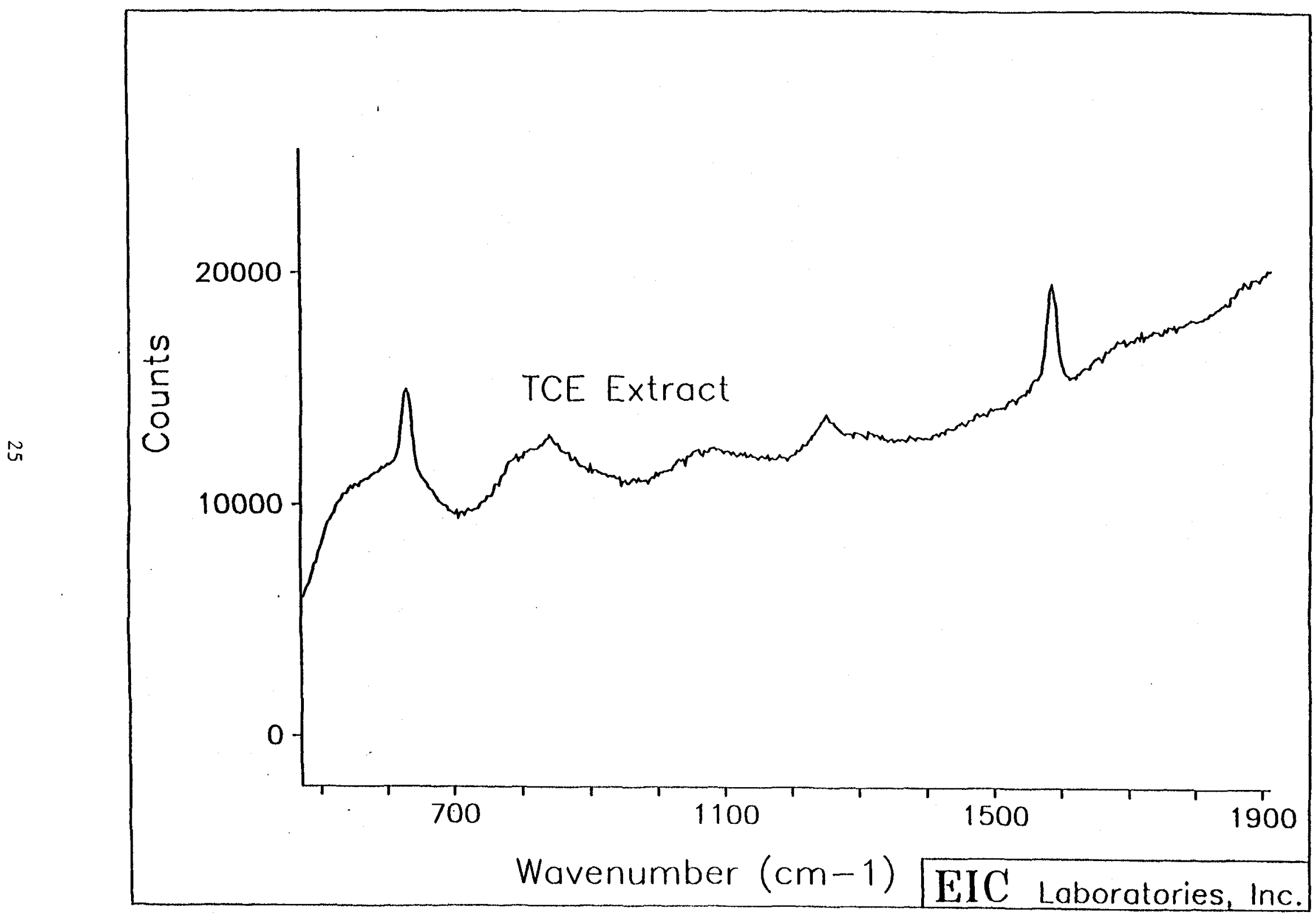

Figure 2.13 Raman spectra of a sample brought into the CPT for analysis. 


\section{SECTION 3 \\ FIELD DEMONSTRATION OF THE RAMAN/CPT SENSOR PACKAGE}

\subsection{INTRODUCTION}

To complete the development and obtain data to evaluate the Raman-CPT sensor package, a two week field demonstration was conducted at SRS. The demonstration was conducted between August 16 and 31, 1993. During the demonstration, 17 Raman-CPT profiles were conducted in the $\mathrm{A} / \mathrm{M}$ Area, to depths ranging from $60 \mathrm{ft}$ to $165 \mathrm{ft}$. In addition, a one day demonstration of the utility of the Raman-CPT system to detect fuels using fluorescence techniques, was also conducted at the Central Shops Area of SRS. During this demonstration at the Central Shops Area, two soil samples ( $16 \mathrm{ft}$ and $25 \mathrm{ft}$ ) were collected to verify the fluorescence results. Contained in Table 3.1 is a list of the CPT testing conducted at SRS in support of this project.

This section of the report begins with a discussion of standard CPT information describing how the test is conducted and the data are recorded. Also included is a brief discussion of the methods used to obtain both the Raman Spectroscopy and soil gas data.

\subsection{TECHNICAL APPROACH}

\subsubsection{Cone penetration testing}

The electronic cone penetrometer test (CPT) was originally developed for use in consolidated clay soils. Over the years, cone and push system designs have evolved to the point where they can now be used in strong cemented soils, and even soft rock. ARA's penetrometer consists of an instrumented probe which is forced into the ground using a hydraulic load frame mounted on a heavy truck, with the weight of the truck and supplemental ballast providing the necessary reaction mass (for this work, 30 tons). The probe has a conical tip and a friction sleeve which independently measures vertical resistance beneath the tip, as well as frictional resistance on the side of the probe, as a function of depth. A schematic view of the Raman-CPT penetrometer probe is shown in Figure 3.1, showing the location of the sapphire window and downhole optical probe. A pressure transducer in the cone is used to measure the pore water pressure as the probe is 
Table 3.1 Summary of Raman Project CPT Testing at SRS.

\begin{tabular}{|c|c|c|c|c|c|c|c|}
\hline TEST ID & DATE & DEPTH (FT) & TEST TYPE & LOCATION & NORTHING & EASTING & GROUND \\
\hline CPT-RAM-01 & $8 / 18 / 93$ & 118.0 & Piezo Raman * & M Basin & $102,196.49$ & $48,501.3$ & 358.4 \\
\hline CPT- RAM-02 & $8 / 20 / 93$ & 108.9 & Piezo Raman * & M Basin & & & \\
\hline CPT- RAM-03 & $8 / 21 / 93$ & 121.6 & Gas Raman & MBasin & $102,185.44$ & $48,468.42$ & 358.2 \\
\hline CPT- RAM-04 & $8 / 21 / 93$ & 113.2 & Sampling Raman & M Basin & $102,184.93$ & $48,449.63$ & 358.3 \\
\hline CPT- RAM-05 & $8 / 23 / 93$ & 117.8 & Sampling Raman & M Basin & $102,143.23$ & $48,215.67$ & 354.1 \\
\hline CPT- RAM-06 & $8 / 23 / 93$ & 164.7 & Sampling Raman & M Basin & $102,152.14$ & $48,034.97$ & 351.9 \\
\hline CPT- RAM-07 & $8 / 23 / 93$ & 125.1 & Sampling Raman & M Basin & & & \\
\hline CPT- RAM-08 & $8 / 24 / 93$ & 165.0 & Piezo Raman & M Basin & & & \\
\hline CPT-RAM-09 & $8 / 24 / 93$ & 164.8 & Piezo Raman & M Basin & & & \\
\hline CPT- RAM-10 & $8 / 25 / 93$ & 144.0 & Gas Raman & M Basin & & & \\
\hline CPT-RAM-11 & $8 / 25 / 93$ & 147.2 & Gas Raman & M Basin & & & \\
\hline CPT- RAM-14 & $8 / 26 / 93$ & 60 & Raman & Central Shop & & & \\
\hline SOIL SAMPLE & $8 / 26 / 93$ & 18.0 & Soil Sampling & Central Shop & & & \\
\hline SOIL SAMPLE & $8 / 26 / 93$ & 26.9 & Soil Sampling & Central Shop & & & \\
\hline CPT- RAM-12 & $8 / 26 / 93$ & 164.2 & Raman (Thru Auger) & M Basin & & & \\
\hline CPT- RAM-13 & $8 / 26 / 93$ & 112.2 & Gas Sampling & M Basin & & & \\
\hline CPT-RAM-15 & $8 / 30 / 93$ & 121.4 & Gas Sampling & M Basin & $102,459.42$ & $48,626.89$ & 360.2 \\
\hline CPT-RAM-16 & $8 / 30 / 93$ & 116.5 & Gas Sampling & M Basin & $102,372.82$ & $48,692.48$ & 357.6 \\
\hline СРT-RAM-17 & $8 / 31 / 93$ & 128.7 & Gas Sampling & M Basin & $102,064.04$ & $48,773.76$ & \\
\hline
\end{tabular}

* Fiber Damaged atter push and probe changed. Rest of Raman-CPT pushes conducted with same Raman probe. 


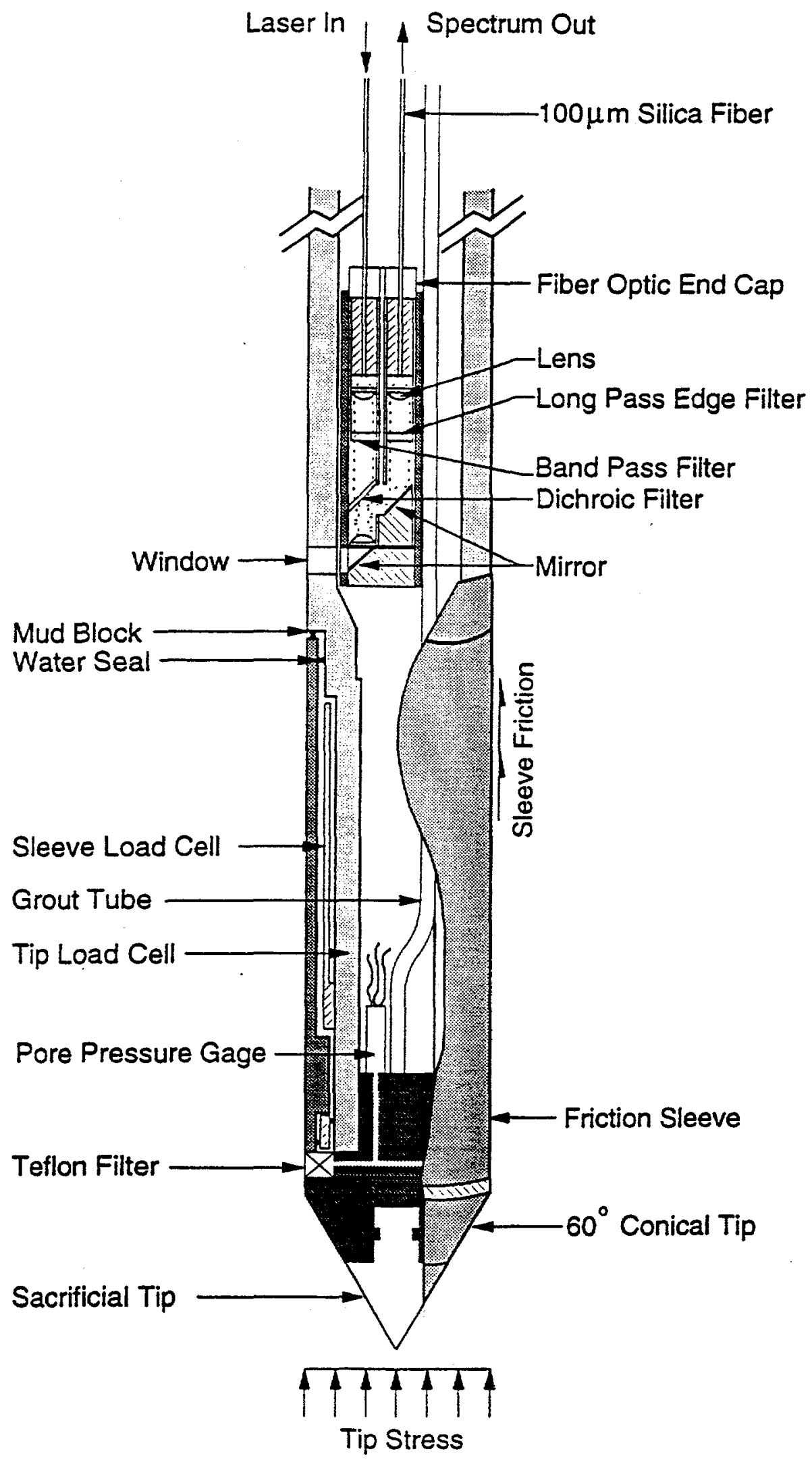

Figure 3.1 Schematic of CPT probe showing detail of the optics inside the Raman module. 
pushed into the ground (Piezo-CPT). For some of the soundings the pressure gage was removed and a soil gas sampling module inserted into the probe. Soil gas was pulled into the cone system through a dry pore pressure filter to a multi-gas monitor located in the CPT truck. The soil gas was pulled into the cone using a vacuum, and traveled up to the truck through a high density polyethylene tube for analysis in the CPT rig.

Cone Penetration Testing, by nature of the test, leaves an open hole. For a majority of the penetrations, PVC well materials (slotted and riser sections) were lowered down the open hole to establish a temporary monitoring well in the vadose zone for future use by Westinghouse Savannah River Site (WSRS) personnel. The penetrations not used as temporary wells were filled with 1/4-inch bentonite pellets or granular bentonite grout at the end of each day. Sealing the CPT holes in this manner was deemed adequate by WSRS personnel.

\subsubsection{Piezo Cone Penetration}

The cone penetrometer tests are conducted using the ARA penetrometer truck. The penetrometer equipment is mounted inside an $18 \mathrm{ft}$ van body attached to a ten-wheel truck chassis with a turbo-charged diesel engine. Ballast in the form of metal weights and a steel water tank, which can hold 5,000 lbs. of water, is added to the truck to achieve an overall push capability of over 60,000 lbs. Penetration force is supplied by a pair of large hydraulic cylinders bolted to the truck frame.

A 2.4 in $^{2}$ penetrometer probe was used for these explorations. This probe has a 1.75 -inch diameter, $60^{\circ}$ conical tip, and a 1.75 -inch diameter by 6.50 -inch long friction sleeve. The shoulder between the base of the tip and the porous filter is 0.08 in long. The penetrometer is normally advanced vertically into the soil at a constant rate of $2 \mathrm{~cm} / \mathrm{sec}$, although this rate must sometimes be reduced as hard layers are encountered and when Raman measurements in thin materials are being made. The electronic cone penetrometer test is conducted in accordance with ASTM D344186.

Inside the probe, two load cells independently measure the vertical resistance against the conical tip and the side friction along the sleeve. Each load cell is a cylinder of uniform cross section inside the probe, which is instrumented with four strain gages in a full-bridge circuit. Forces are sensed by the load cells, and the data is transmitted from the probe assembly via a cable 
running through the push tubes. The analog data is digitized, recorded, and plotted by computer in the penetrometer truck. A set of data is normally recorded each second, for a minimum resolution of about one data point every $0.8 \mathrm{in}$. of cone advance. The depth of penetration is measured using an extensiometer mounted inside one of the push cylinders.

As shown in Figure 3.1, the piezo-cone probe senses the pore pressure immediately behind the tip. Currently, there is no accepted standard for the location of the sensing element. ARA chose to locate the sensing element behind the tip, as the filter is protected from the direct thrust of the penetrometer, and the measured pore pressure can be used to correct the tip resistance data (discussed below) as recommended by Robertson and Campanella, 1988 (Ref. 4). The magnitude of the penetration pore pressure is a function of the soil compressibility and, most importantly, permeability. In freely draining soil layers, the measured pore pressures will be very close to the hydrostatic pressure computed from the elevation of the water table. When low permeability soil layers are encountered, excess pore pressures generated by the penetration process cannot dissipate rapidly and this results in measured pore pressures which are significantly higher than the hydrostatic pressures. Whenever the penetrometer is stopped to add another section of push tube, or when a pore pressure dissipation test is run, the excess pore pressure may begin to dissipate. When the penetration is resumed, the pore pressure quickly rises to the level measured before the penetrometer was stopped. This process causes some of the spikes that may appear in the penetration pore pressure data.

\subsubsection{Saturation of the Piezo-Cone}

As shown in Figure 3.1, penetration pore pressures are measured with a pressure transducer located behind the tip in the lower end of the probe. Water pressures in the soil are sensed through a 150 micron pore size, porous, polyethylene/polypropylene composite filter that is 0.25 -inch high and 0.202 -inch thick. The pressure transducer is connected to the porous filter through a pressure port as shown in Figure 3.1. The pressure port and the filter are filled with a high viscosity silicone oil.

For the pressure transducer to respond rapidly and correctly to changing pore pressures upon penetration, the filter and pressure port must be saturated with oil upon assembly of the probe. A vacuum pump is used to de-air the silicone oil before use, and also to saturate the porous filters with oil. The probe is assembled with the pressure transducer up and the cavity above the 
pressure transducer filled with de-aired oil. A previously saturated filter is then placed on a tip and oil is poured over the threads. When the cone tip is then screwed into place, excess oil is ejected through the pressure port and filter, thereby forcing out any trapped air.

Saturation of the piezo cone is verified with field calibrations performed before the probe is inserted into the ground. The high viscosity of the silicone oil, coupled with the small pore space in the filter, prevents the loss of saturation as the cone is pushed through dry soils. Saturation of the cone can be verified with a calibration check at the completion of the penetration. Extensive field experience has proven the reliability of this technique, with no known case where saturation of the piezo cone was lost.

\subsubsection{Raman Cone Penetrometer Test}

The Raman-CPT probe is used to make spectral measurements of soils excited by $514 \mathrm{~nm}$ light as the cone is inserted into the ground. The laser light is generated inside the penetrometer truck, using an argon laser system developed and packaged by EIC. The laser system consists of the laser and a custom interface for efficient coupling of the laser light. The fiber-optic bundle consists of one transmission fiber and one collection fiber. This bundle is used to guide the light to and from the Raman module located inside the CPT probe. The Raman system measures the generated spectrum from delta wave numbers of 0 to $4500 \mathrm{~cm}^{-1}$. The area under specified bandwidths are determined in real-time and transported to the CPT computer for display while the actual spectrum is recorded and stored on the Raman computer. These bandwidth areas are related to intensity, and are profiled versus depth for each of the Raman-CPT pushes.

\subsubsection{Data Acquisition}

Electronic data acquisition equipment for the cone penetrometer consists of an IBM compatible 486 computer with a graphics monitor and a rack of eight customized signal conditioners. Analog signals are transmitted from the probe to the signal conditioners where the CPT data is amplified and filtered at $1 \mathrm{~Hz}$. The digital data are then read into memory, plotted on a graphics monitor, and written to the internal hard disk for future processing. Data displayed on screen can be used to determine site layering as it is encountered. This allows important decisions to be made in real-time directly in the field. Upon completion of the test, the CPT and Raman data 
can be plotted for decision making purposes. Plots can typically be available within ten minutes of completing the test. Floppy disks containing the data are brought to ARA's New England Division in South Royalton, Vermont, for preparation of final report plots and analysis.

\subsubsection{Field Calibrations}

Many environmental factors can effectively change the calibration used to convert the raw instrument readouts, measured in volts, to units of force or pressure. As a quality control measure as well as a check for instrument damage, the load cells, the pressure transducer, and the resistivity sensor are routinely calibrated in the field. Calibrations are completed with the probe ready to insert into the ground so that any factor affecting any component of the instrumentation system will be included and detected during the calibration.

The tip and sleeve load cells are calibrated with the conical tip and friction sleeve in place on the probe. For each calibration, the probe is placed in the push frame and loaded onto a precision reference load cell. The reference load cell is periodically calibrated in ARA's laboratory against NIST traceable standards. To calibrate the pore pressure transducer, the saturated probe is inserted into a pressure chamber with air pressure supplied by the compressor on the truck. The reference transducer in the pressure chamber is also periodically calibrated against an NIST traceable instrument in ARA's laboratory. Additionally, the extensiometer used to measure the depth of penetration, is periodically checked against a tape measure.

Each instrument is calibrated using ARA's CALDAS software that displays the output from the reference device and the probe instrument in graphical form. During the calibration procedure, the operator checks for linearity and repeatability in the instrument output. At the completion of each calibration, the software computes the needed calibration factors using a linear regression algorithm. In general, each probe instrument is calibrated at the beginning of each day of field testing. Furthermore, the pressure transducer is recalibrated each time the porous filter is changed and the cone is resaturated. Calibrations are also performed to verify the operation of any instrument if damage is suspected.

Since the Raman sensor requires nearly pure product to generate enough signal for measurement, calibration in terms of concentration was not performed on this project. Daily system checks were performed by obtaining the Raman spectrum from a neat naphthalene sample, 
and comparing it to the known naphthalene spectrum for a mercury Argon lamp. Also, the laser power was monitored and maintained at approximately 65 milliwatts during the field demonstration. The location of the TCE and PCE spectral characteristics are fixed, based on the excitation wavelength and basic fundamental Raman principles.

\subsubsection{Penetration Data Correction}

A typical penetration profile from the SRS A/M Area is shown in Figure 3.2. Plotted as a function of depth are the measured tip resistance, sleeve friction, friction ratio, and pore pressure. When the surface elevation of the test location is unknown, the penetration data are plotted against depth.

Tip resistance, $\mathrm{q}_{c}\left(\mathrm{lb} / \mathrm{in}^{2}\right)$, is obtained by dividing the vertical force on the conical tip by the effective tip area (2.405 in 2 ). The tip resistance is then corrected for pore pressures acting behind the conical tip as discussed in the next section. The corrected tip resistance, $\mathrm{qT}_{\mathrm{T}}\left(\mathrm{lb} / \mathrm{in}^{2}\right)$, is plotted in the penetration profile. Sleeve friction, $\mathrm{f}_{\mathrm{s}}\left(\mathrm{lb} / \mathrm{in}^{2}\right)$, is obtained by dividing the total frictional force on the sleeve by the sleeve's surface area ( $\left.23.26 \mathrm{in}^{2}\right)$. The offset between the depth at the tip, and the depth at the friction sleeve, is corrected by shifting the sleeve friction profile downward so that it corresponds to the depth at the centroid of the tip. In addition to the tip resistance and sleeve friction, a friction ratio profile is plotted for each location. This ratio is simply the sleeve friction expressed as a percentage of the tip resistance at a given depth. In uncemented soils, the friction ratio can be correlated to soil type. The final profile shown in Figure 3.2 is the pore pressure that is measured as the probe is advanced. This measurement is useful for identifying clay layers as the pore pressure rises significantly above the hydrostatic level.

\subsubsection{Pore Pressure Correction of Tip Stress}

Cone penetrometers, by necessity, must have a joint between the tip and sleeve. Pore pressure acting behind the tip, decreases the total tip resistance that would be measured if the penetrometer was without joints. The influence of pore pressure in these joints is compensated for, by using the net area concept (Ref. 4). 

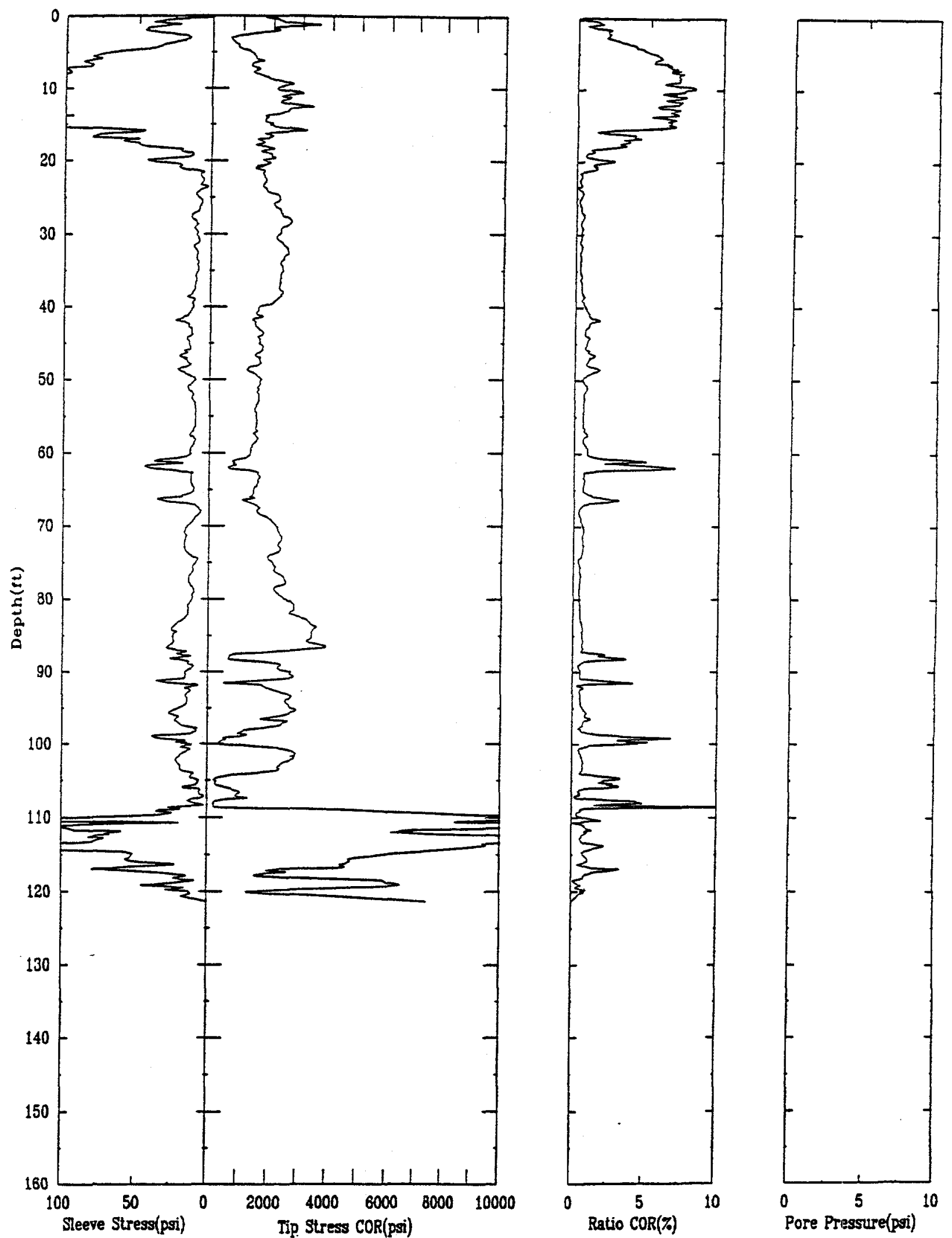

Figure 3.2 Typical Raman-CPT data profile from the SRS A/M site. 

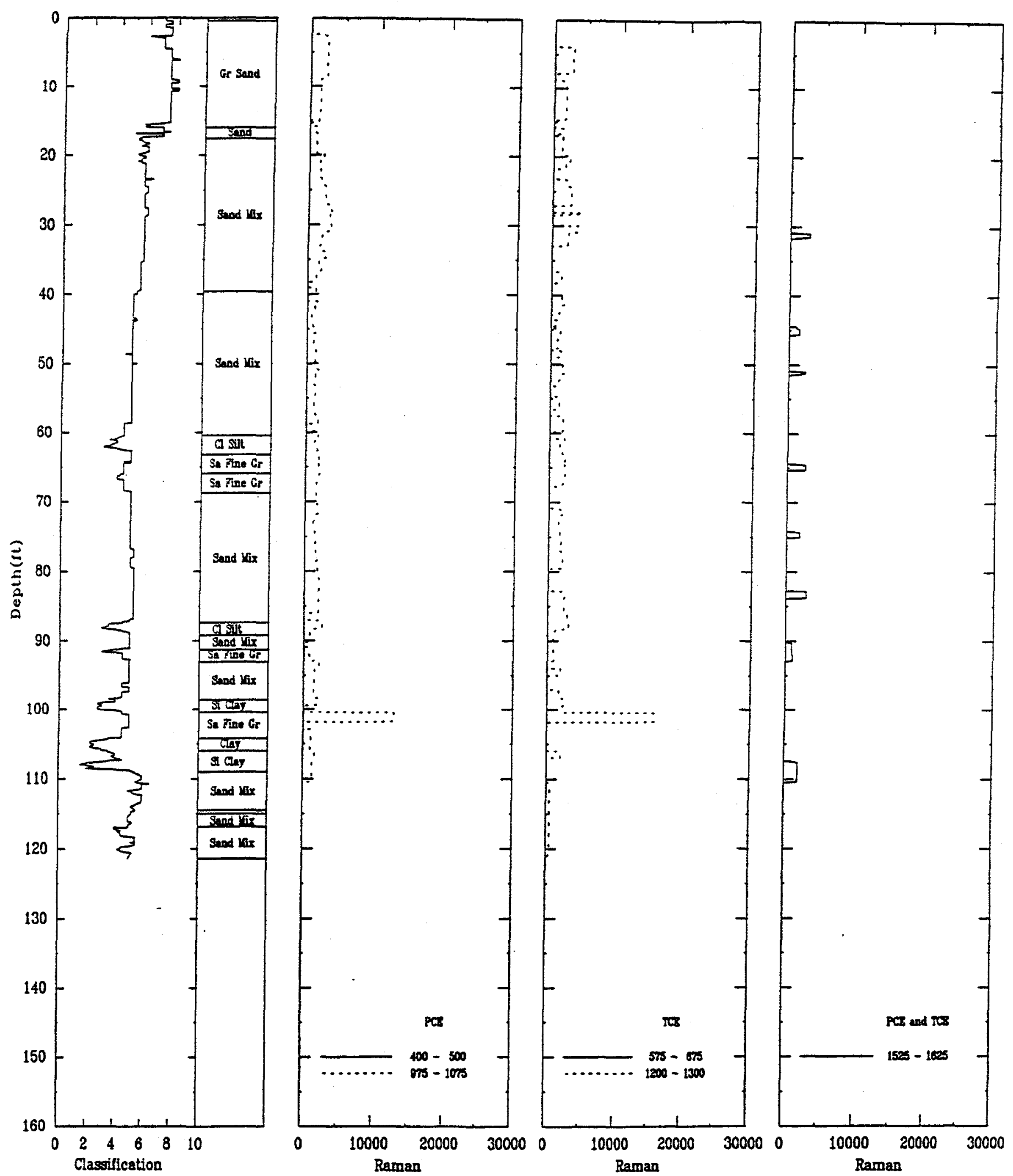

Figure 3.2 Typical Raman-CPT data from the SRS A/M site (cont.). 
The corrected tip resistance is given by:

$$
q_{T}=q_{c}+u\left(1-\frac{A_{a}}{A_{T}}\right)
$$

Where: $\mathrm{q}_{\mathrm{T}}=$ corrected tip resistance

$\mathrm{q}_{\mathrm{c}}=$ measured tip resistance

$\mathrm{u}=$ penetration pore pressure measured behind the tip

$A_{n}=$ net area behind the tip not subjected to the pore pressure (1.257 in2)

$\mathrm{A}_{\mathrm{T}}=$ projected area of the tip $\left(1.550 \mathrm{in}^{2}\right)$.

Hence, for the ARA cone design, the tip resistance is corrected as:

$$
\mathrm{q}_{\mathrm{r}}=\mathrm{q}_{\mathrm{c}}+\mathrm{u}(.1890)
$$

Laboratory calibrations have verified Equation 3.2 for ARA's piezo-cone design.

A joint also exists behind the top of the sleeve (see Figure 3.1). However, since the sleeve is designed to have the same cross sectional area on both ends, the pore pressures acting on the sleeve cancel out. Laboratory tests have verified that the sleeve is not subjected to unequal end area effects. Thus, no correction for pore pressure is needed for the sleeve friction data.

The net effect of applying the pore pressure correction is to increase the tip resistance and to decrease the friction ratio. Generally, this correction is only significant when the pore pressures are high, while measured tip resistance is very low.

\subsubsection{Depth Correction of the Penetration Data}

Any time that the cone penetrometer is stopped or pulled back during a test, misleading data can result. For instance, when the probe is stopped to add the next push rod section or when a pore pressure dissipation test is run, the excess pore pressures will dissipate toward the hydrostatic pore pressure. When the penetration is resumed, the pore pressure generally rises very quickly to the pressures experienced prior to the pause in the test. In addition, the probe is sometimes pulled back and cycled up and down at intervals in deep holes to reduce soil friction on the push tubes. 
This results in erroneous tip stress data when the cone is advanced in the previously penetrated hole.

To eliminate this misleading data from the penetration profile, the data is numerically edited before it is plotted or used in further analysis. Each time the penetrometer stops or backs up, as apparent from the depth data, the penetration data is not plotted. Plotting of successive data is resumed only after the tip is fully re-engaged in the soil by one tip length (1.52 in.) of new penetration. This algorithm also eliminates any data acquired at the ground surface before the tip has been completely inserted into the ground. The sleeve data is similarly treated and this results in the first data point not occurring at the ground surface, as can be seen in some tip and sleeve profiles. These procedures ensure that all of the penetration data that is plotted and used for analysis was acquired with the probe advancing fully into undisturbed soil.

\subsection{SOIL CLASSIFICATION FROM THE CPT}

The tip resistance, friction ratio, and pore pressure values from CPT profiles can be used to determine soil classification versus depth. The methodology used in this report to classify the soils is based on empirical correlations originally developed by Robinson (Ref. 4) and modified by Timian et al., 1992 (Ref. 5). The charts used to classify soils are shown in Figure 3.3. In general, clean, coarse grained soils have high strengths with relatively low sleeve friction, while finer grained soils have low strengths and high side friction (cohesion). Similarly, as shown in the second chart of Figure 3.3, a correlation exists between soil type and the ratio of tip stress to pore pressure response. Clean, coarse grained soils tend to have high strengths, but are permeable and develop little or no excess pore pressure during penetration. Fine grained soils are weak and impermeable and tend to develop high excess pore pressures during penetration.

Soil classification can be determined from the charts by comparing the normalized tip resistance to the pore pressure ratio or to the normalized friction ratio. The tip resistance is normalized according to:

$$
\mathrm{q}_{\mathrm{n}}=\frac{\mathrm{q}_{\mathrm{T}}-\sigma_{\mathrm{vo}}}{\sigma_{\mathrm{vo}_{\mathrm{O}}}}
$$


Where: $q_{n}=$ normalized tip stress

$\mathrm{q}_{\mathrm{T}}=$ corrected tip resistance from Equation 3.2

$\sigma_{\mathrm{vo}}=$ total overburden stress

$\sigma_{\mathrm{vo}}^{\prime}=$ effective overburden stress

The pore pressure ratio $\mathrm{Bq}$ is defined as:

$$
B q=\frac{u_{\text {mes }}-u_{0}}{q_{\tau}-\sigma_{v o}}
$$

Where: $u_{\text {meas }}=$ measured penetration pore pressure

$\mathfrak{u}_{\circ}=$ static pore pressure, determined from the water table elevation

and the normalized friction ratio, $f_{S N}$ is defined as:

$$
f_{s n}=\frac{f_{s}}{q_{T}-\sigma_{v o}} \times 100 \%
$$

The plot of any point of the $q_{n}$ versus $B_{q}$ or $f_{S N}$ value normally falls in a classification zone of Figure 3.3. The classification zone number corresponds to a soil type as shown in the figure. At some depths, the CPT data will fall outside of the range of the classification chart. When this occurs, no data is plotted and a break is seen in the classification profile.

The next step in developing the soil classification profile is reconciliation of the similarities and differences between the two soil classification methods shown in Figure 3.3 into a single unified estimate, as shown in the classification profile indicated in Figure 3.4. This profile represents a point by point weighted average of the two methods, with weighting factors based on 


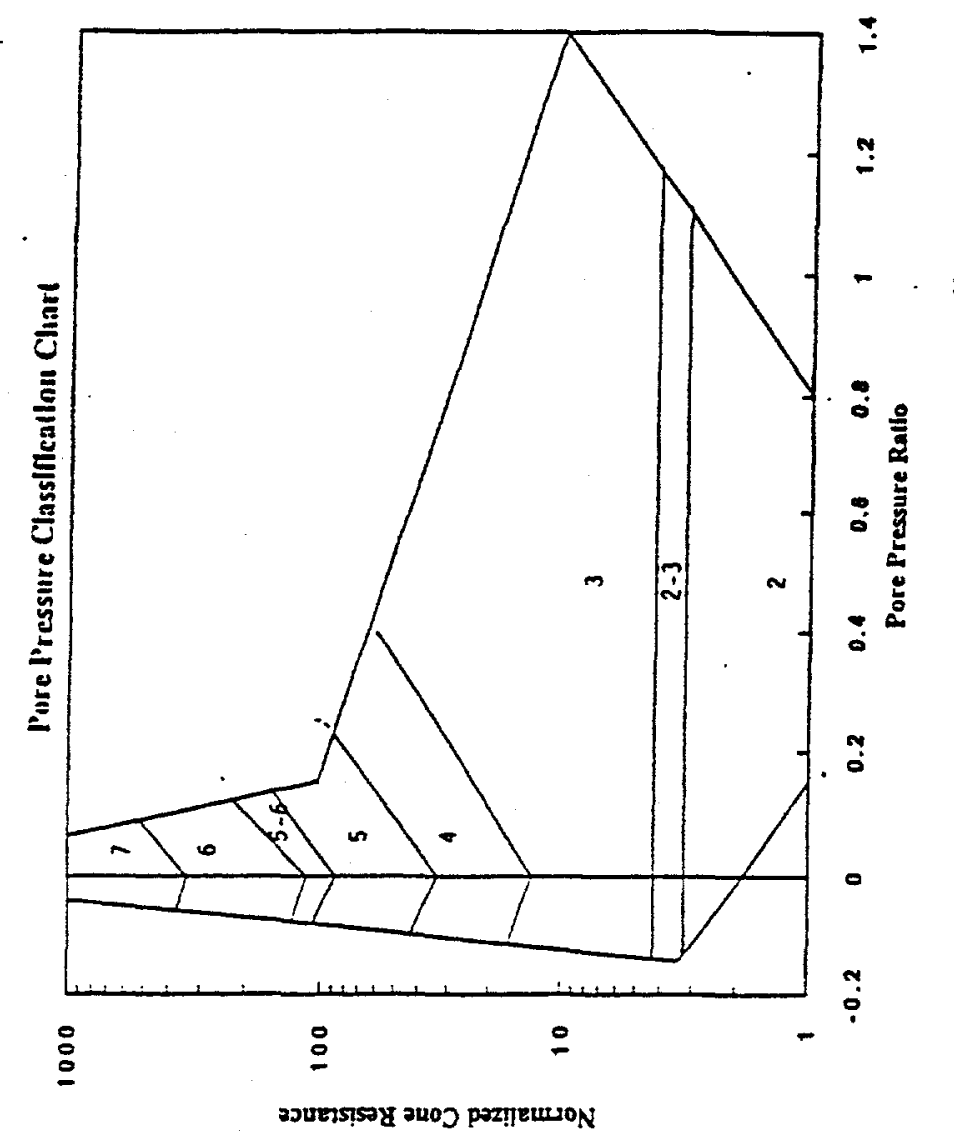

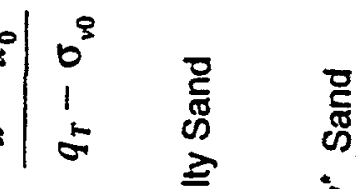

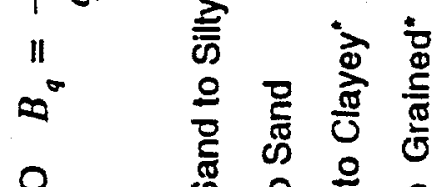

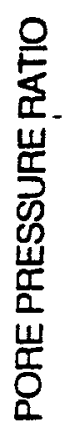

हึ

ฐ

i 言

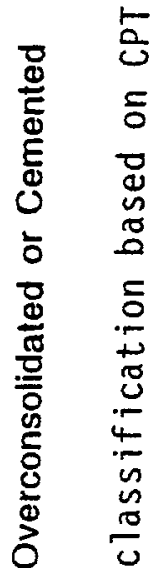

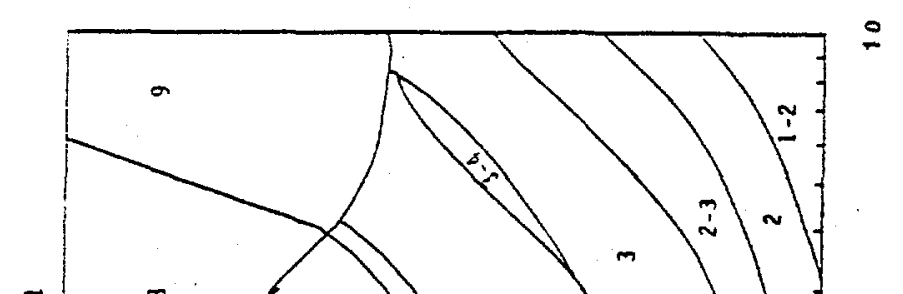

$\div$

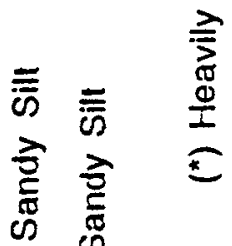

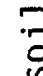

$\dot{0} \sim \dot{\sigma}$

$\frac{8}{8}$

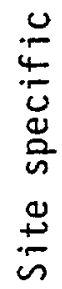

焉

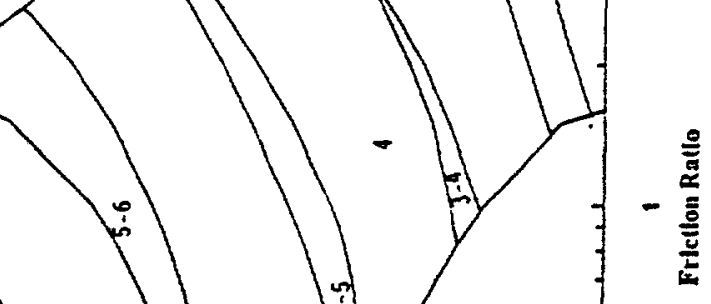

年

은

$\ddot{m}$

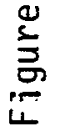



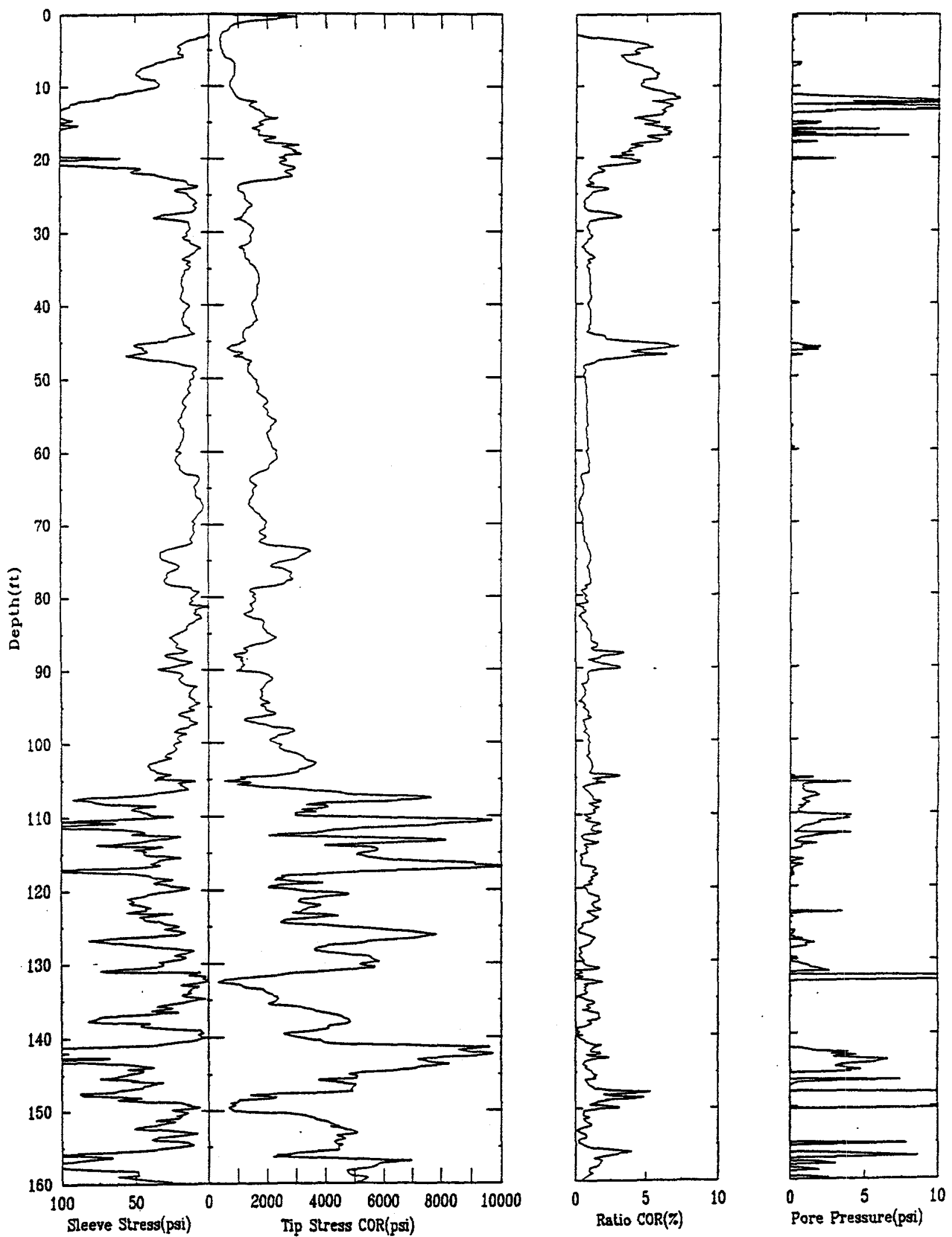

Figure 3.4 Typical CPT and Raman data from the SRS $A / M$ area. 

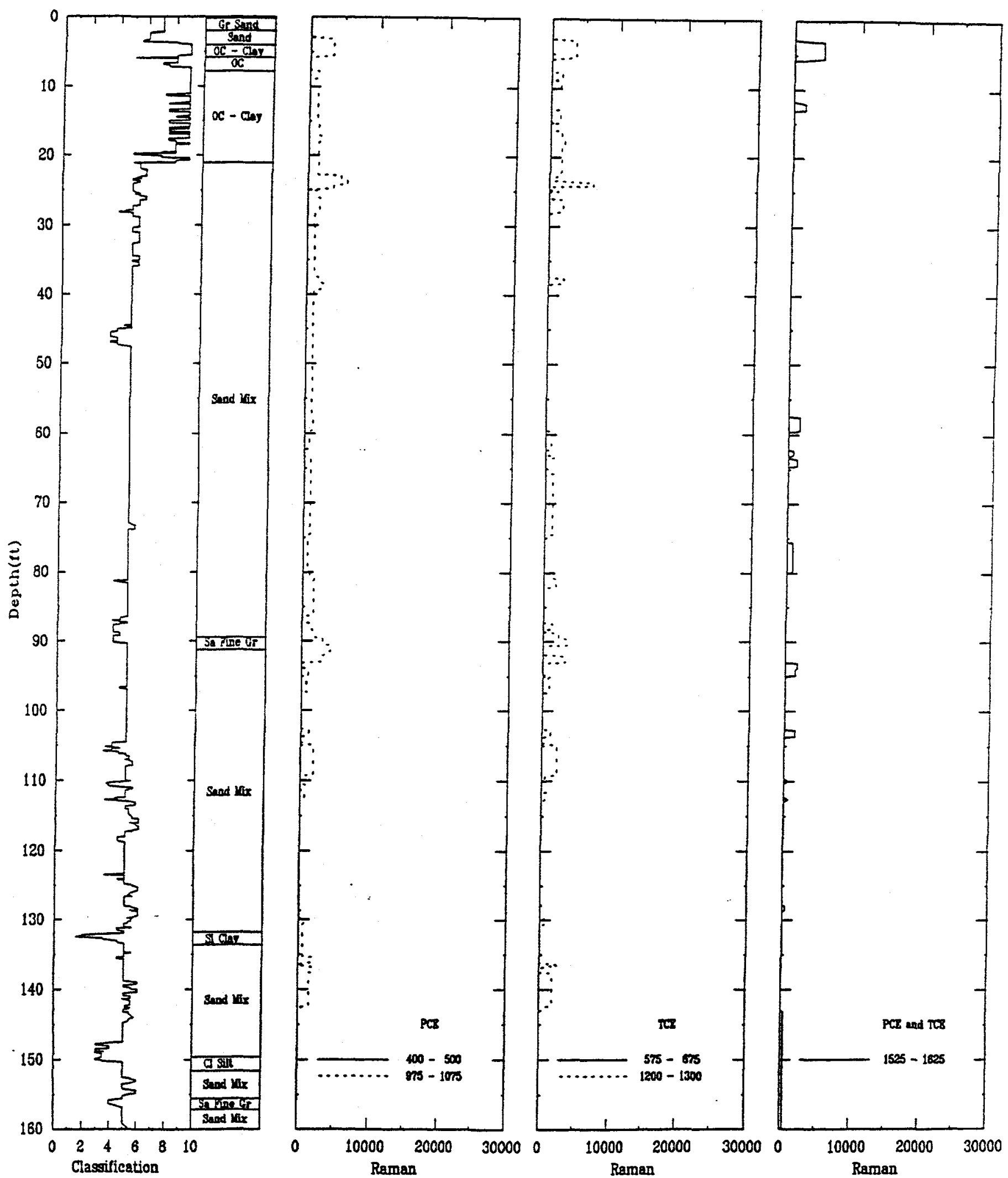

Figure 3.4 Typical CPT and Raman data from the SRS $A / M$ area (cont.). 
confidence levels established for each measurement used in the classifications. These confidence levels are based on measurement amplitudes, consistency, and engineering experience with CPT data.

The classification profiles are very detailed, frequently indicating significant variability in soil types over small changes in elevation. In order to provide a simplified soil stratigraphy for comparison to standard boring logs, a layering and generalized classification system was implemented (i.e., soil unit descriptions located to the right of the classification profile). A minimum layer thickness of 1.0 feet was selected. Layer thicknesses are determined based on the variability of the soil classification profile. The layer sequence is begun at the ground surface and layer thicknesses are determined based on deviation from the running mean of the soil classification number. Whenever an additional 6 inch increment deviates from the running mean by more than 0.50 in, a new layer is started, otherwise, this material is added to the layer above and the next 6 inch section is evaluated.

The soil type for the layer is determined by the mean value for the complete layer. The ten types are classified as:

\begin{tabular}{ll} 
Classification Range & Soil Type \\
\hline $1.00-2.25$ & Sensitive Clay \\
$2.25-2.75$ & Soft Clay \\
$2.75-3.25$ & Clay \\
$3.25-3.75$ & Silty Clay \\
$3.75-4.25$ & Clayey Silt \\
$4.25-4.75$ & Sandy Fine Grained \\
$4.75-5.75$ & Sand Mixture \\
$5.75-6.75$ & Sand \\
$6.75-7.50$ & Gravelly Sand \\
$7.50-9.00$ & Over Consolidated (OC)
\end{tabular}

Again, a more detailed classification can be determined from the classification profile plotted just to the left of the soil type (unit) layers. The layering provides a summary of the engineering classification of soil stratigraphy. 


\section{SECTION 4 \\ DATA ANALYSIS AND SENSOR EVALUATION}

\subsection{OVERVIEW}

During the two week demonstration a number of new CPT site characterization techniques were demonstrated and evaluated. While the major evaluation was of the Raman-CPT probe, additional evaluations were conducted of: 30 ton heavy weight CPT truck, Raman/Soil Gas CPT, location of heating fuel with the Raman-CPT probe, Sampling CPT-Raman analysis probe, CPT installed mini-wells, and CPT-soil sampling. Significant findings of the two week demonstration are summarized in Section 4.1, with analysis of the CPT and Raman data contained in Sections 4.2 through 4.6

\subsection{SUMMARY OF DEMONSTRATION PROGRAM}

The Raman system was designed to be a self contained, robust system which could be easily incorporated with the CPT truck. The system was contained in two shock isolated containers mounted on the CPT truck counter. About $6 \mathrm{ft}$ of bench space was required. Other requirements included 110 volt power, connection of a 94-bit communication cable between the CPT and Raman computers, and ducting of the cooling air to the outside. There were a number of startup difficulties which included: hooking up laser power, hooking up of the communication system incorrectly, damaging the CPT computer board, cutting the Raman probe fiber optic cable when the CPT rods were threaded together, and discovering water in the Raman probe after completing the first sounding requiring that the probe be replaced. These initial difficulties were solved and the demonstration program proceeded with a minimum of technical difficulties. A summary of significant findings during the two week demonstration is contained in Table 4.1. 
Table 4.1 Summary of Findings during the Raman-CPT Demonstration

\begin{tabular}{|l|l||}
\hline Raman Laser System & $\begin{array}{l}\text { The laser system worked well during the two week period } \\
\text { with no down time that could be attributed to the laser. } \\
\text { The system could be readily reconfigured and probes } \\
\text { easily changed. This was a major improvement over other } \\
\text { laser system demonstrations. }\end{array}$ \\
\hline Temperature Effects & $\begin{array}{l}\text { Ambient air temperatures during the demonstration were } \\
\text { as high as } 100^{\circ} \mathrm{F} . \text { As the laser system was air cooled, the } \\
\text { high temperatures during the demonstration program } \\
\text { caused a heating problem for the laser. Due to excessive } \\
\text { heat, the laser system was shut down for portions of the } \\
\text { CPT sounding. For this reason, continuous Raman } \\
\text { profiles were obtained on only five of the soundings. }\end{array}$ \\
\begin{tabular}{l|l} 
Increasing the cooling capacity of the CPT truck and/or \\
dedicating a cooler to the laser system would correct this \\
deficiency. The air cooled system is preferable to water \\
cooled due to its simplicity and ability to operate in cold \\
environments without special protection.
\end{tabular} \\
\hline CPT Probe leakage & $\begin{array}{l}\text { The seals which held the sapphire windows leaked after } \\
\text { the first day's testing and the Raman probe required } \\
\text { replacement. A simple redesign of the windows to be } \\
\text { more waterproof has corrected this problem. }\end{array}$ \\
\hline
\end{tabular}




\begin{tabular}{||l|l|}
\hline Sampling Raman Probe & $\begin{array}{l}\text { A special insert was made for the CPT which could draw } \\
\text { in a small fluid sample for testing. Laboratory tests } \\
\text { indicated that the high fluorescence background die to the } \\
\text { soil matrix effect was eliminated with this probe. During } \\
\text { the field testing, it was never certain if fluid entered the } \\
\text { probe. It appeared that the filter in the side of the CPT } \\
\text { probe tended to clog with soil. The internal Raman probe } \\
\text { should be redesigned to include a fluid sensor to ensure } \\
\text { that the probe contains the desired fluid, a purging system, } \\
\text { and a redesign of the filter to prevent clogging. }\end{array}$ \\
\hline 30-ton Push Capacity & $\begin{array}{l}\text { ARA's 30 ton CPT truck was used to conduct the CPT } \\
\text { soundings in an attempt to penetrate a very strong soil } \\
\text { layer at depths of 120 to 140 ft. The depth achieved by the } \\
\text { 30 ton push capacity trucks with 1.75-in probes was only } \\
\text { marginally greater than that achieved with a 20 ton truck } \\
\text { with 1.44-in probes. Successful penetration of this layer } \\
\text { may be accomplished with: (1) heavier weight CPT trucks; } \\
\text { (however rod support at the surface will have to be } \\
\text { increased through the use of surface casing to the first } \\
\text { strong layer); or (2) development of systems to assist the } \\
\text { CPT truck in penetrating these layers such as vibratory } \\
\text { systems or drilling systems. The vibratory systems are } \\
\text { more desirable as no drill waste is generated and worker } \\
\text { safety is greater, (no open drill holes which could emit } \\
\text { gasses). }\end{array}$ \\
\hline
\end{tabular}




\begin{tabular}{|l|l|l|}
\hline $\begin{array}{l}\text { Auger Advancement of CPT } \\
\text { Sounding }\end{array}$ & $\begin{array}{l}\text { An auger drill rig was mobilized to the site to penetrate the } \\
\text { hard layer at the } 120 \text { to } 140 \mathrm{ft} \text { depth interval and the CPT } \\
\text { sounding continued through the auger drill stem. This } \\
\text { worked successfully and a sounding was completed to a } \\
\text { depth of } 164 \mathrm{ft} . \text { The primary limitation of this method is } \\
\text { the increased cost associated with drilling the hole and } \\
\text { disposal of the drilling waste. Care must be taken to } \\
\text { ensure that the CPT rods receive sufficient lateral support } \\
\text { within the Auger flights. }\end{array}$ \\
\hline Soil Sampling with the CPT & $\begin{array}{l}\text { Two soil samples were obtained at the Central Shops site } \\
\text { to confirm the presence and absence of fuel in the two soil } \\
\text { layers. This system worked well and should be used in } \\
\text { conjunction with future investigations. Layers identified } \\
\text { by the CPT as being contaminated can be readily sampled } \\
\text { and confirmed with on-site analytical tests. This greatly } \\
\text { reduces the need for drilling. Before this technique can be } \\
\text { widely used at SRS, the CPT soil samplers need to be } \\
\text { made more robust. Commercially available samplers are } \\
\text { generally limited to soils weaker than those typical of the } \\
\text { SRS site. }\end{array}$ \\
\hline
\end{tabular}




\begin{tabular}{|l|l|}
\hline Soil gas/Raman-CPT Probe & $\begin{array}{l}\text { The piezo pressure gauge of the CPT probe was removed } \\
\text { and a soil gas sampling element installed. The soil gas } \\
\text { sampler was attached to a multi-gas monitor located in the } \\
\text { truck and gas samples obtained in the vadose zone. The } \\
\text { gas monitor had lower detection limits than the Raman } \\
\text { probe; however, the transfer of the gas from the CPT } \\
\text { probe to the monitor resulted in a delay which required a } \\
\text { correction. In addition, the gas monitor requires about 2 } \\
\text { minutes per analysis and cannot provide a continuous } \\
\text { profile. Operation of the Raman system to locate } \\
\text { significant zones of contamination and the gas monitor to } \\
\text { confirm contaminant concentration offers great potential } \\
\text { for future investigations. The soil gas filter requires } \\
\text { additional work to ensure that the filter does not become } \\
\text { clogged and reduce gas flow through the probe. }\end{array}$ \\
\hline Mini-Well Installation & $\begin{array}{l}\text { At eight locations, mini (.5 in I.D. ) wells were dropped } \\
\text { down the open CPT soundings to depths as great as 125 } \\
\text { ft. These wells are currently being used to obtain soil gas } \\
\text { samples and represent a very economical method of } \\
\text { obtaining additional long-term site monitoring data as the } \\
\text { need and expense of installing a drilled and cased well is } \\
\text { eliminated. }\end{array}$ \\
\hline
\end{tabular}

\subsection{SOIL STRATIGRAPHY ANALYSIS OF A TYPICAL PENETRATION PROFILE}

A typical penetration profile from the $\mathrm{A} / \mathrm{M}$ area of the Savannah River Site is presented in Figures 4.1 and 4.2. The CPT sounding presented in Figures 4.1 and 4.2 (CPT-RAM-8) was completed to a depth of $164 \mathrm{ft}$ and presents all of the geologic features present in the area. This data, as well as the other penetration data, is presented in Appendix A. Contained in Figure 4.1 is the sleeve stress, tip stress, friction ratio, and penetration pore pressures. Figure 4.2 contains the soil classification profile determined from the CPT data using the methods described in Section 

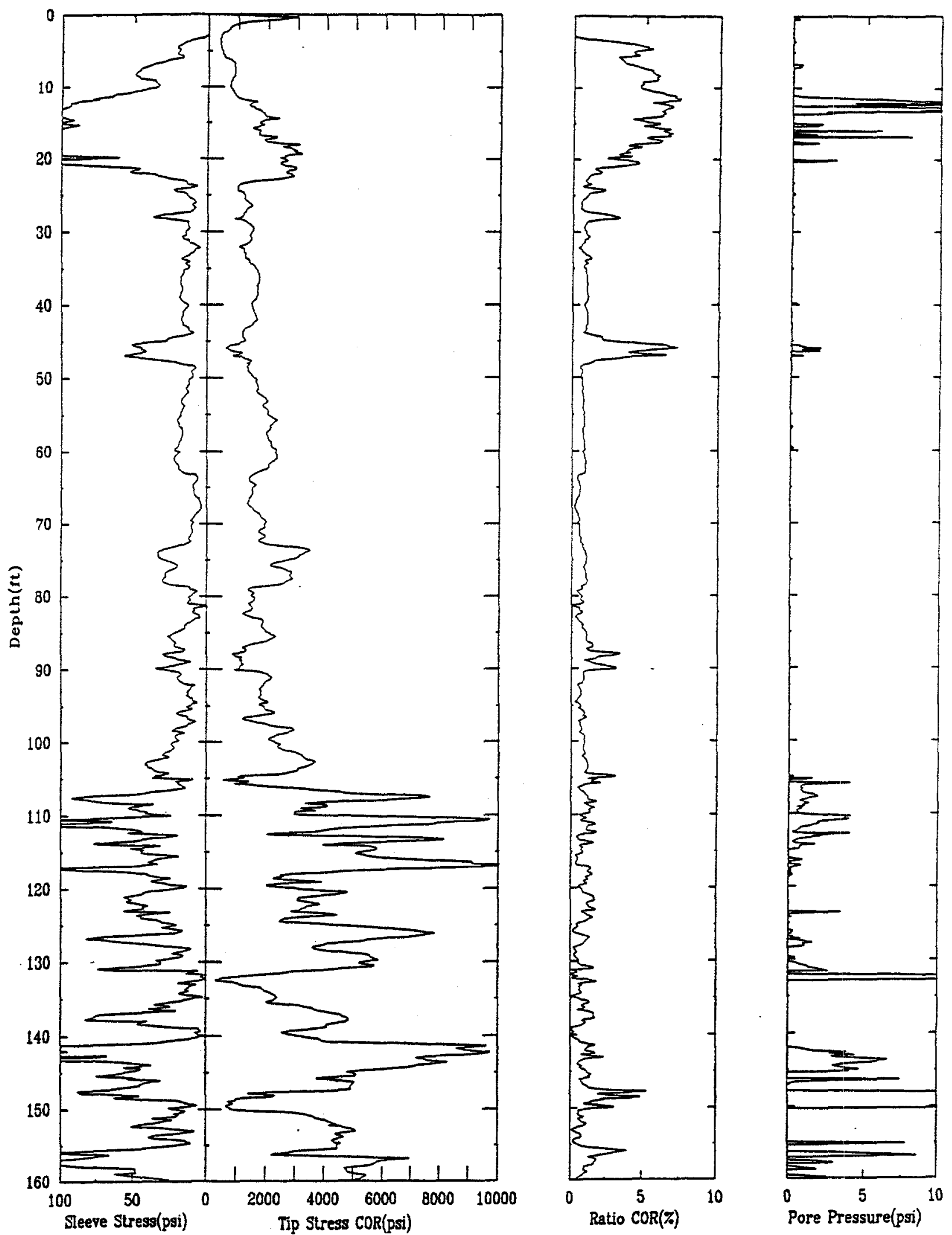

Figure 4.1 Typical CPT and Raman data from the SRS $A / M$ area. 

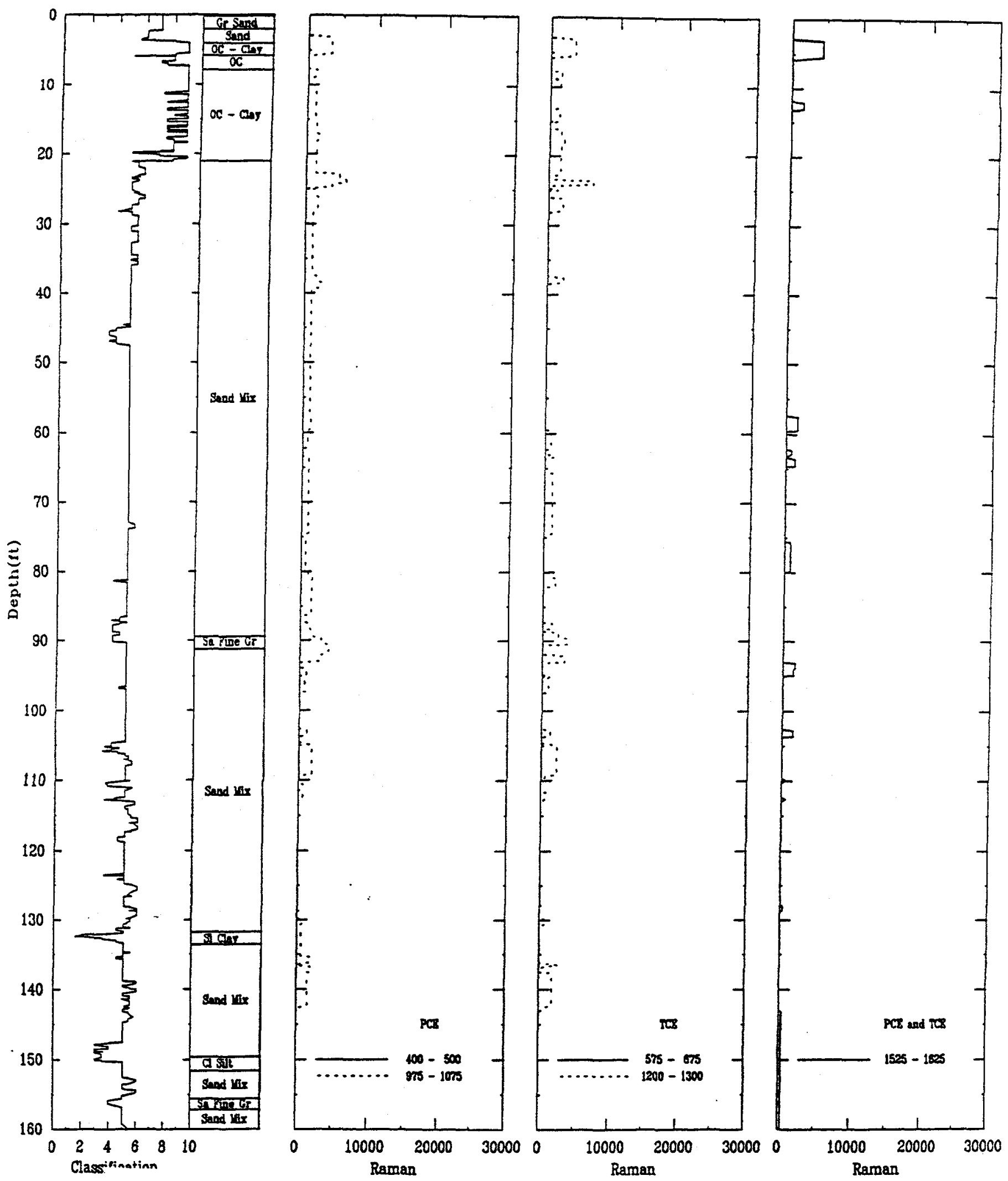

Figure 4.2 Typical CPT and Raman data from the SRS $A / M$ area (cont.). 
3.3, along with the Raman data that were measured during the test. The Raman plots are presented in three profiles adjacent to the soil classification profiles. Table 4.2 presents the Raman window displayed in each of the profiles. In all cases, the maximum intensity measured within the window is the value presented in the profiles:

Table 4.2 Contaminant Profiles

\begin{tabular}{|c|c|c|}
\hline $\begin{array}{c}\text { Raman Wave } \\
\text { Number Window } \\
(\mathbf{c m} \cdot \mathbf{1})\end{array}$ & Contaminant & Profile Number \\
\hline $400-500$ & PCE & 1 \\
\hline $575-675$ & TCE & 2 \\
\hline $975-1075$ & PCE & 1 \\
\hline $1200-1300$ & TCE & 2 \\
\hline $1525-1625$ & PCE, TCE & 3 \\
\hline
\end{tabular}

Both tip and sleeve resistance are strongly dependent upon the shear strength and stiffness of a soil. As the strength and stiffness of a soil increases, so will the tip resistance and sleeve stress. The friction ratio is also a function of strength and stiffness and is strongly influenced by the cohesive strength of the soil. In clayey soils, adhesion between the soil and sleeve increases the friction acting on the sleeve, resulting in an increase in the friction ratio. This effect is used to identify soil from the tip and friction ratio, with the tip stress decreasing and the friction ratio increasing as the clay content increases. The pore pressure profiles are also very useful for determining soil type as fine grained materials will generate excess pore pressures and sand will generally track on the hydrostatic line below the water table, with silty materials having penetration pore pressures less than the hydrostatic pressure.

Profile 8 was conducted on August 24th in the A/M Area of SRS. The upper $21 \mathrm{ft}$ of the profile consists of an overconsolidated silty clay. Over this depth interval the tip stress gradually increases to $3,000 \mathrm{psi}$ at a depth of $21 \mathrm{ft}$. The sleeve stresses are significant between 10 and $20 \mathrm{ft}$, 
averaging approximately $125 \mathrm{psi}$. The tip and sleeve responses combine to produce a friction ratio of 5 to 7 through this layer, indicating a clayey soil.

From a depth of 21 to $105 \mathrm{ft}$, the soils are primarily a mixture of sand and fine grained soils (i.e. clay and silt). Over this depth interval the tip stress varies between 2,000 to 3,000 psi and the sleeve stress varies between 10 and 20 psi. These values result in average friction ratio of approximately one, which is typical of a sand or sandy soil. No excess pore pressures were encountered in this material, except for the silty clay material present between 45 and $48 \mathrm{ft}$. Although this layer was not thick enough for the soil stratigraphy software to mark a separate layer, the presence of the layer can be seen in both the friction ratio and pore pressure profiles (see Figure 4.1) and the soil classification number profile (see Figure 4.2). A second silty clay seam is also present from a depth of 87 to $90 \mathrm{ft}$. Once again this material can be detected by noticing the drop in tip stress and concurrent rise in the sleeve stress. These attributes result in an increase in the friction ratio. Generally a rise in the pore pressure will also be present, although it did not occur in this material, indicating that this layer may not be very moist.

From a depth of $105 \mathrm{ft}$ to the end of the penetration profile, the soils become highly interbedded, with the most common material being a silt and sand mixture. A distinct increase in the tip stress is observed, with peak tip stresses as high as 10,000 psi indicating very strong, overconsolidated soils. Higher sleeve stresses are also observed in the lower portion of the profile, also indicating a more consolidated soil. The silty seams in this material are very thin (i.e. less than a $0.5 \mathrm{ft}$ ) and are very frequent, as evident by the rapid fluctuation in the tip stress and also the pore pressure indicating that these materials contain some moisture.

\subsection{ANALYSIS OF RAMAN SYSTEM PERFORMANCE}

Both Raman spectral data and Raman profile information were collected during each penetration test. The Raman profile data consisted of the maximum intensity value with each window for a series of five windows. Table 4.2 presents the Raman window range for each of the five windows, along with the method used to display and present this data. The purpose of making these measurements was two-fold. First, they represent a simplified method for displaying the important aspects of each of the Raman spectra as a function of depth. Second, the measurements allow the display of these profiles in real-time in the CPT truck. This allows the CPT operators to stop the probe in a contaminated zone for additional analysis of the Raman 
response in the region. The first Raman profile in Figure 4.2 presents the Raman PCE response. Although the second curve and the longer Raman shift indicates some response, this is most likely background signal. There are occasional rises in this signal, especially at $25 \mathrm{ft}$ and $92 \mathrm{ft}$, although not significant enough to conclude that contamination is present. Based on the analysis of both of these and the spectral results which are discussed below, the measured responses are either the result of lower concentrations of PCE or an interference effect due to the background nature of the soil environment. The second Raman profile in Figure 4.2 presents the characteristic Raman values for TCE. Once again the longer Raman shifts exhibit some background reading, whereas the shorter Raman shift does not. The differences are so small that contamination cannot be conclusively identified from the profile that was displayed in the CPT truck. The final profile represents a common Raman shift that exists for both TCE and PCE. Once again separation of the contaminant spectrum from soil induced fluorescence cannot be conclusively identified.

In addition to Raman profile plots displayed in the CPT truck for real-time analysis, the complete spectral information file was also collected for analysis at the completion of the sounding. As discussed in Section 4.1, high ambient air temperatures caused concerns about overheating of the laser system. Spectral data versus depth were obtained on only four of the soundings in the MBasin and the sounding at Central Shops. (Even for these soundings, in some zones the laser was turned off over selected depth intervals). Typical spectral data at three depths for sounding CPTRAM-8 are plotted in Figure 4.3. Spectra are plotted from a delta wave number of $200 \mathrm{~cm}^{-1}$ $(\lambda=519 \mathrm{~nm})$ to $2000 \mathrm{~cm}^{-1}(\lambda=572 \mathrm{~nm})$. The raw data show several spectral peaks from $200 \mathrm{~cm}^{-1}$ to about $400 \mathrm{~cm}^{-1}$, which is characteristic of incomplete filtering of the laser light. These delta wave numbers contain no useful data. For the spectral data presented in the remainder of this report, these wave numbers were eliminated.

The intensity of the fluorescence emission plotted in Figure 4.3 increases as the delta wave number increases. This increase can be caused by a combination of soil induced fluorescence and the presence of a contaminant, as discussed in Section 2. It had been expected that sharp spectral peaks at wave numbers characteristic of TCE and PCE would be observed. However, no sharp spectral peaks were ever observed in the Raman data. As the laboratory tests on SRS soils (see Figure 2.7 through 2.9 ) indicated, the background fluorescence intensity was dependent upon both 
APPLIED RESEARCH ASSOCIATES, INC.

CPT Raman 8

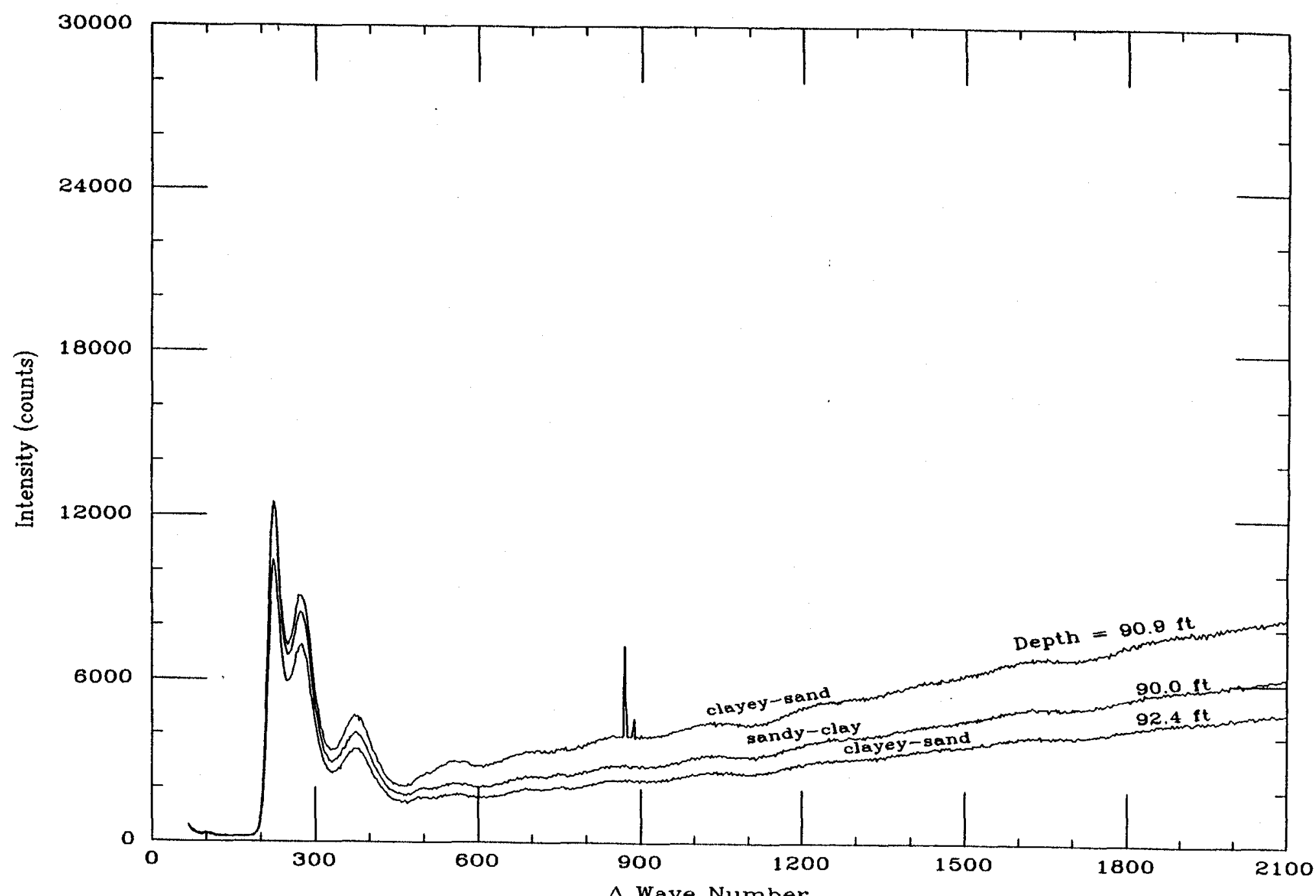

Figure 4.3 Raman spectral data from CPT-RAM-8 and three depths. 
the soil type and contaminant. The laboratory examination of the data was made to determine if this effect could be used to located solvent contaminated soils.

The data plotted in Figure 4.3 show that the fluorescence background increases at a depth of $90.9 \mathrm{ft}$. As can be seen from Figure 4.1, the soils at a depth interval of $90 \mathrm{ft}$ to $92.4 \mathrm{ft}$ change form a sandy clay to clayey sand. The variation in the spectral intensity over this $90 \mathrm{ft}$ to $92.4 \mathrm{ft}$ depth interval was first attributed to soil type variation. However, the sandy-clay at the $90 \mathrm{ft}$ depth would have been expected to have higher fluorescence intensity than both of the clayey sand soils at depths of 90.9 and $92.4 \mathrm{ft}$. Instead, the sandy-clay was only higher than the clayey-sand at 92.4 $\mathrm{ft}$ but not the clayey-sand at $90.9 \mathrm{ft}$. This increased fluorescence at the $90.9 \mathrm{ft}$ depth interval may be due to DNAPL. As this minor variation in the spectrum was not identified during the field activity, no soil samples were obtained to confirm or deny the presence of a DNAPL at this depth interval.

To assist in locating zones with increased intensity, intensity versus depth was plotted for delta wave numbers where spectral responses were expected due to Raman scattering. These data are plotted in Figures 4.4 through 4.7 for soundings CPTRAM-8, 1, 2, and 3. Delta wave numbers of $625 \mathrm{~cm}^{-1}, 1250 \mathrm{~cm}^{-1}$ and $1575 \mathrm{~cm}^{-1}$ are plotted. These represent the TCE spectral peaks for profile CPTRAM- 8 increases in intensity observed at depths of $24 \mathrm{ft}$ and $91 \mathrm{ft}$. The increase at the $24 \mathrm{ft}$ depth is associated with an increase in the clay content and may be solely due to the clay. As previously discussed the layer at $91 \mathrm{ft}$ may be due to either soil effects or DNAPL.

Sounding CPTRAM-1 contains significantly more character than the other profiles. This test was conducted with a different probe which was discovered to be water saturated after completion. The increased character in this sounding may be due to the probe and the data may be suspect. Sounding CPTRAM-2 shows high intensities near surface, with no significant signals below a depth of $11 \mathrm{ft}$. The near surface signals are most likely due to soil matrix effects. For sounding CPTRAM-3 an increase in intensity is observed at the $28 \mathrm{ft}$ depth, and another large increase observed at the $100 \mathrm{ft}$ depth. At the $28 \mathrm{ft}$ depth, no significant difference in soil type was observed and the increase in intensity does not appear to be due to a change in soil type. At the $100 \mathrm{ft}$ depth, a thin clay seam was penetrated and the increase in the fluorescence signal maybe due to soil fluorescence. It should be noted that within the vadose zone, DNAPL's are expected to be located in the clays, and separation of clay and DNAPL induced fluorescence is difficult. Again the reader is reminded that the DNAPL induced fluorescence is not a direct signal, but is due to an 
Raman CPT 8

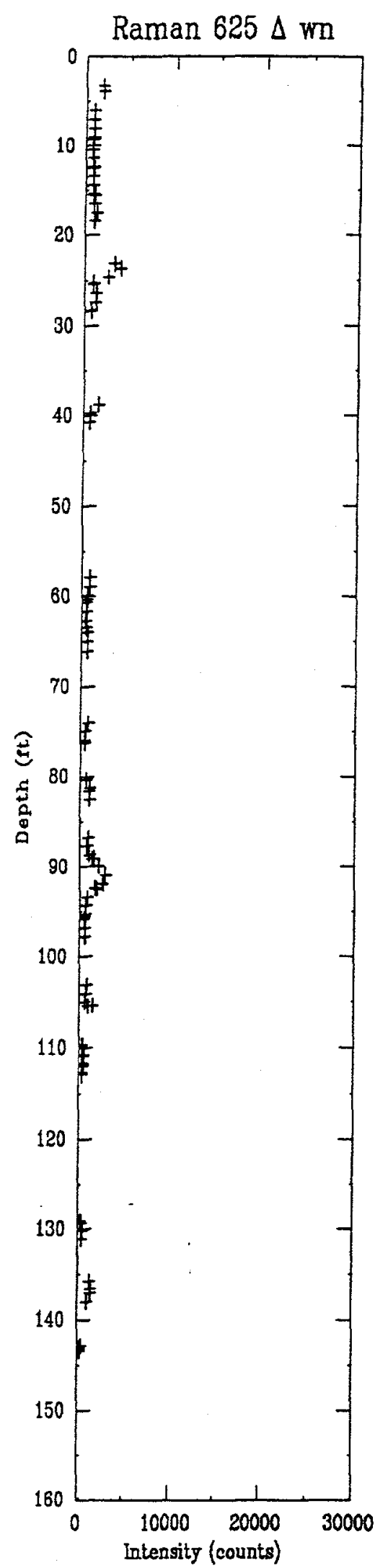

APPLIED RESEARCH ASSOCIATES, INC.

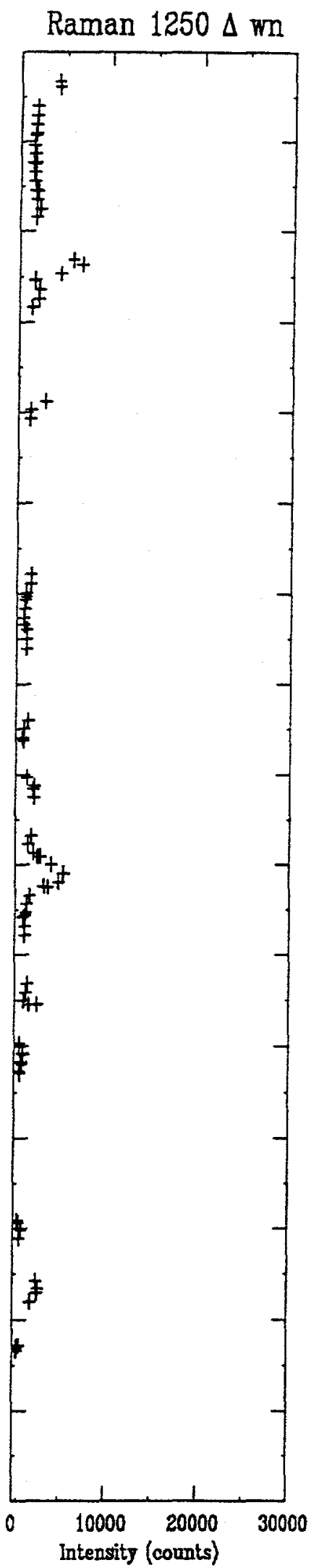

Raman $1575 \Delta$ wn

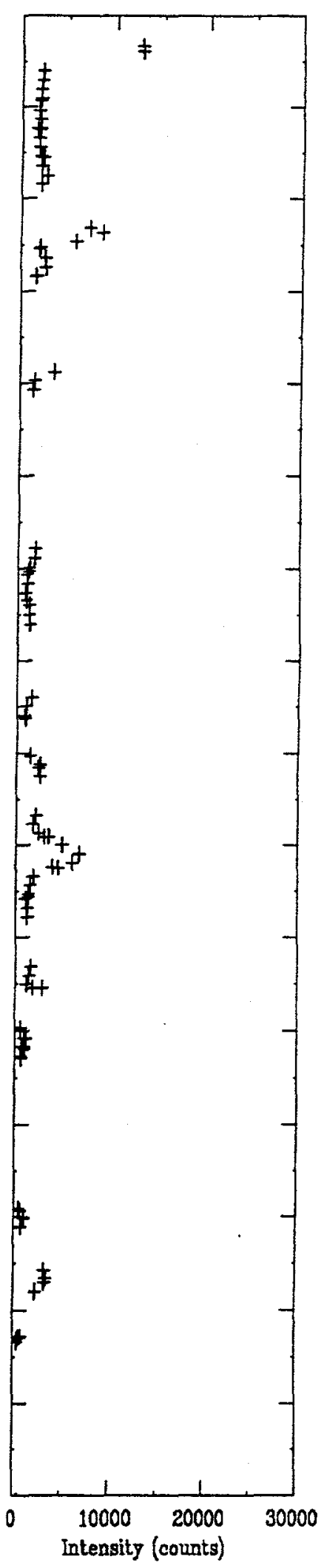

Figure 4.4 Spectral peaks for RAMAN

CPT 8 
Raman CPT 1

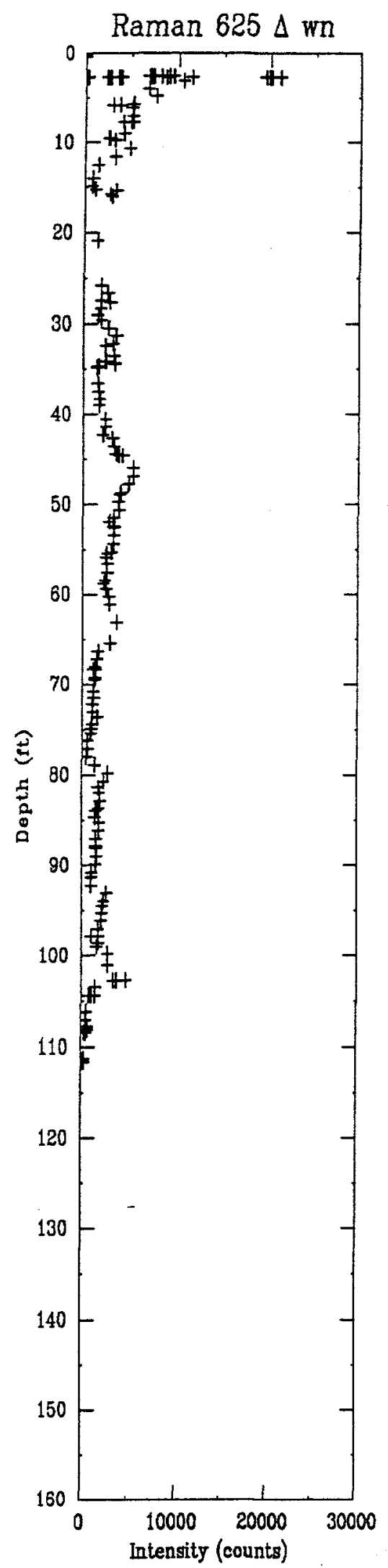

APPLIED RESEARCH ASSOCIATES, INC.

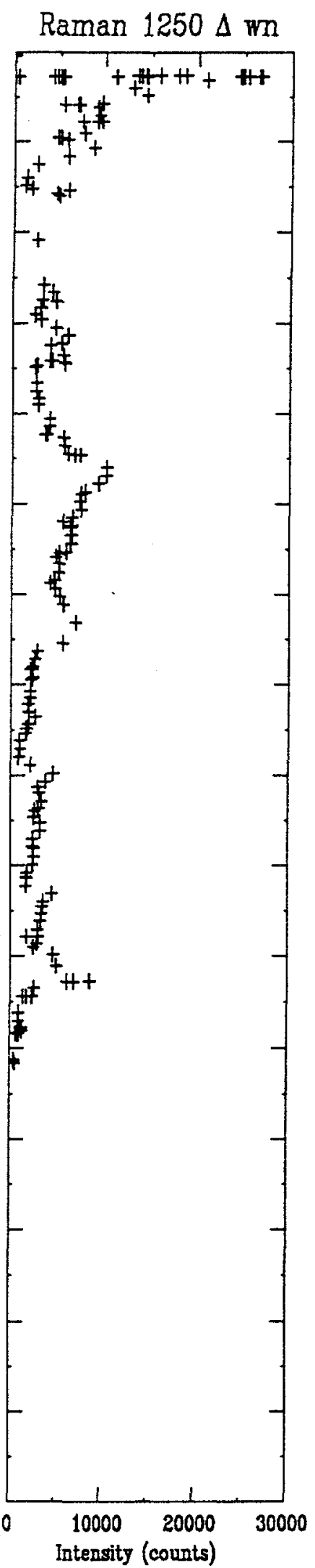

Raman $1575 \Delta$ wn

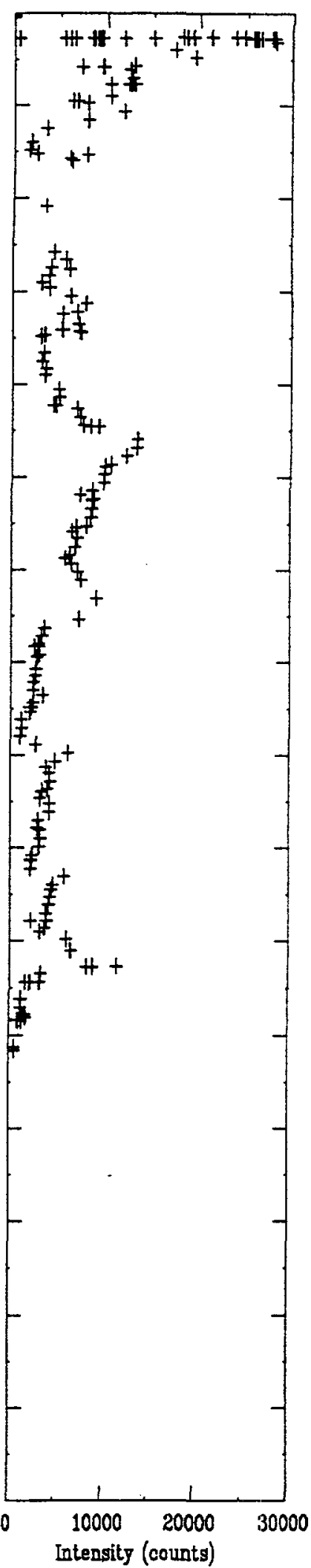

Figure 4.5 Spectral peaks for RAMAN CPT 1 
Raman CPT 3

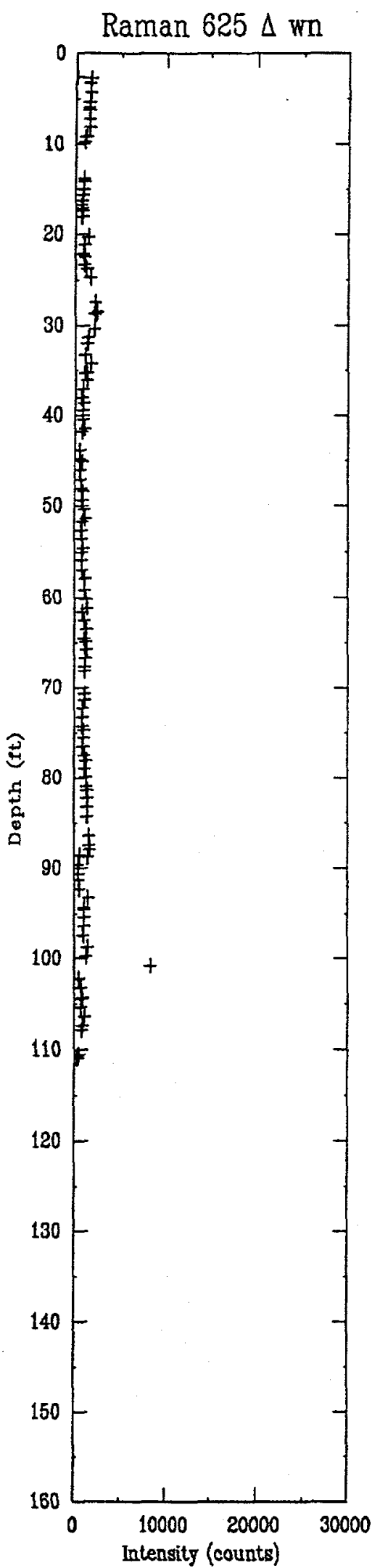

APPLIED RESEARCH ASSOCIATES, INC.

Raman $1250 \Delta w n$

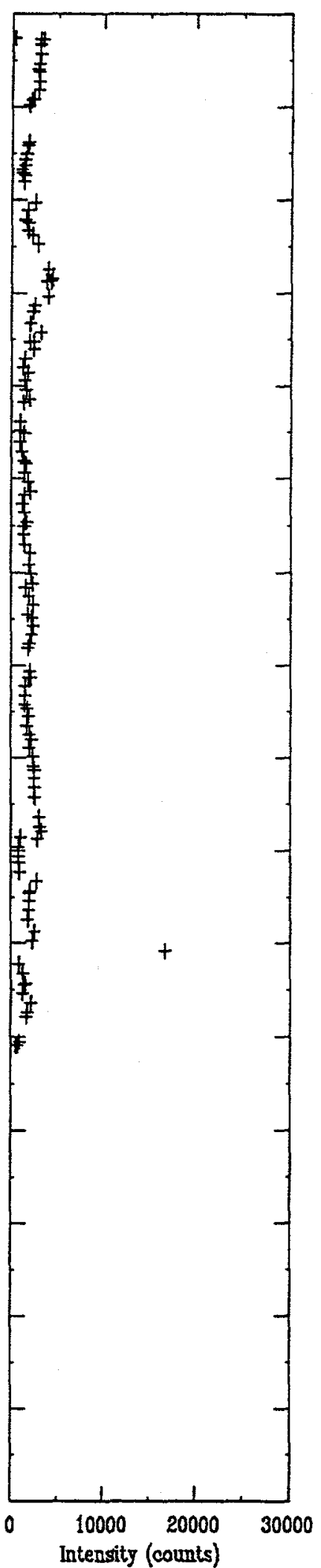

Raman $1575 \Delta$ wn

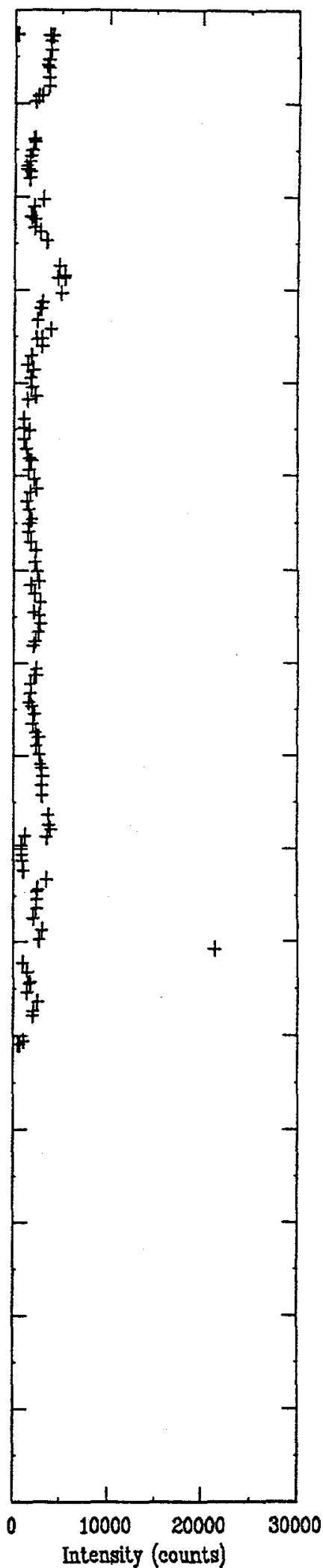

Figure 4.7 Spectral peaks for RAMAN CPT 3 
Raman CPT 3

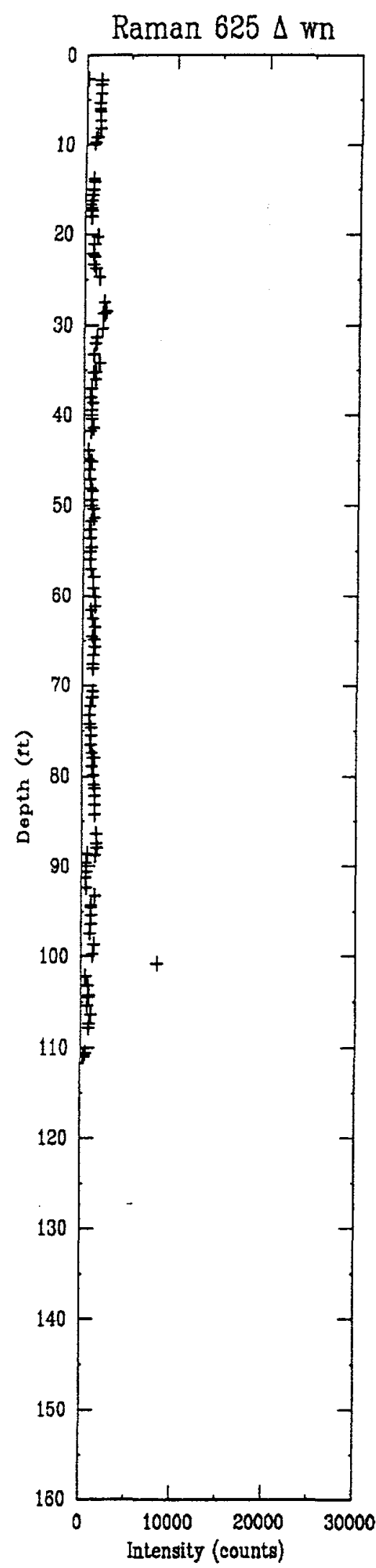

APPLIED RESEARCH ASSOCIATES, INC.

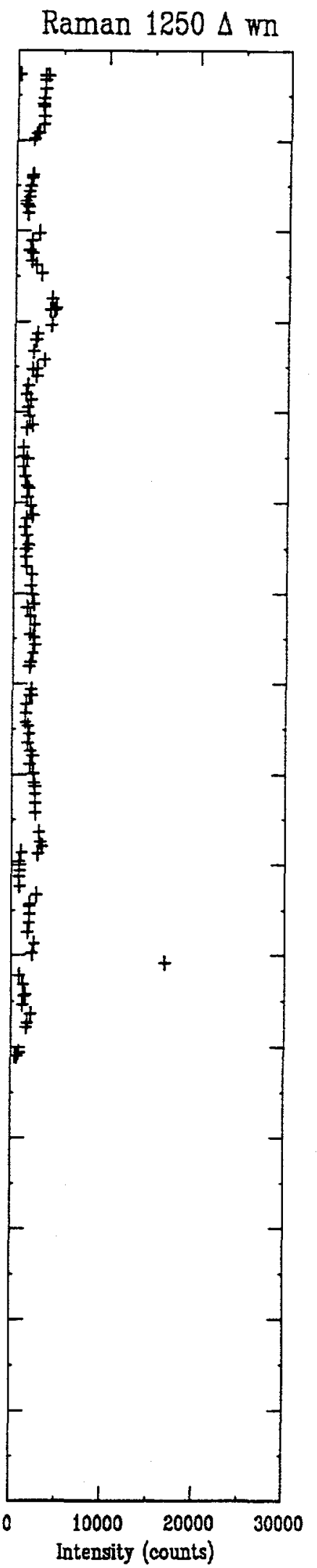

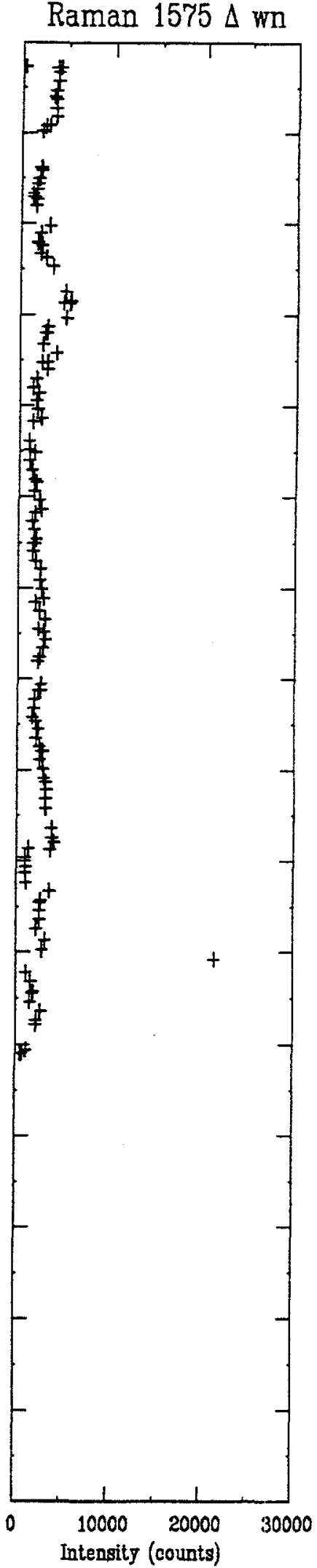

Figure 4.7 Spectral peaks for RAMAN CPT 3 
interaction of the DNAPL and soil which is not understood. Pure Dnapl do not produce a fluorescence signal from the excitation wavelength used in this study.

The complete spectral data versus depth are plotted as color intensity plots and are presented in Figure 4.8 through 4.11 for locations CPTRAM 8, 1,2 and 3. The objective of these plots was to present the entire collected spectra for all depths. The intensity of the spectra is represented by the color, with blue representing the baseline and yellow a very high intensity. The gray shaded zones are areas in which the laser was turned off to cool and contain no spectral data. These plots assist in determining if other spectral intervals are indicating significant responses that should be considered. Taking CPT-RAM-8 as a typical example (Figure 4.8), two interesting items can be noted. First, there are the regions of high responses at long wave numbers for various depths. These high response regions appear to be related to changes in soil type. Second, the intensity of the longer wave numbers are always higher than the shorter wave numbers, as previously presented in Figure 4.3. In all cases there exists a gradual rise in the baseline with wave number, causing the longer wave numbers to have higher values. The increase in spectral intensity at the $90.9 \mathrm{ft}$ depth, as previously discussed, may be due to DNAPL

The spectral information by itself does not appear to indicate that any regions of pure product were encountered. The spectra information is consistent, however, with the results obtained in Vermont, in that the in situ fluorescence backgrounds in SRS soils at depths more than a few feet were significantly lower than those measured in the laboratory. Integration times of 1060 seconds were used during the demonstration, it appears unlikely that simple examination of the spectral data will allow location of TCE or PCE Napl due to soil induced fluorescence. As will be discussed in a later section, an integration time of $\mathbf{3 0}$ seconds, was typically used to optimize signal-to-noise. Based on the results obtained from this field demonstrations with high power NIR laser system indicated that Napl can be located using Raman spectroscopy techniques.

Two notable exceptions to the low soil fluorescence in the M Area Basin occurred. First, in the holes where refusal was reached at about $118 \mathrm{ft}$, there was an increased fluorescence in the 60-80 ft range. As shown in Figure 4.12 for CPTRAM-7, there is a correlation between fluorescence and increase in the IR-PAS measurement made using the multi-gas monitor. As shown in Figure 4.13, the fluorescence intensity for sounding CPTRAM-6 increases dramatically at the $150 \mathrm{ft}$ depth, which correlates with the increased IR-PAS response. It is not certain that 


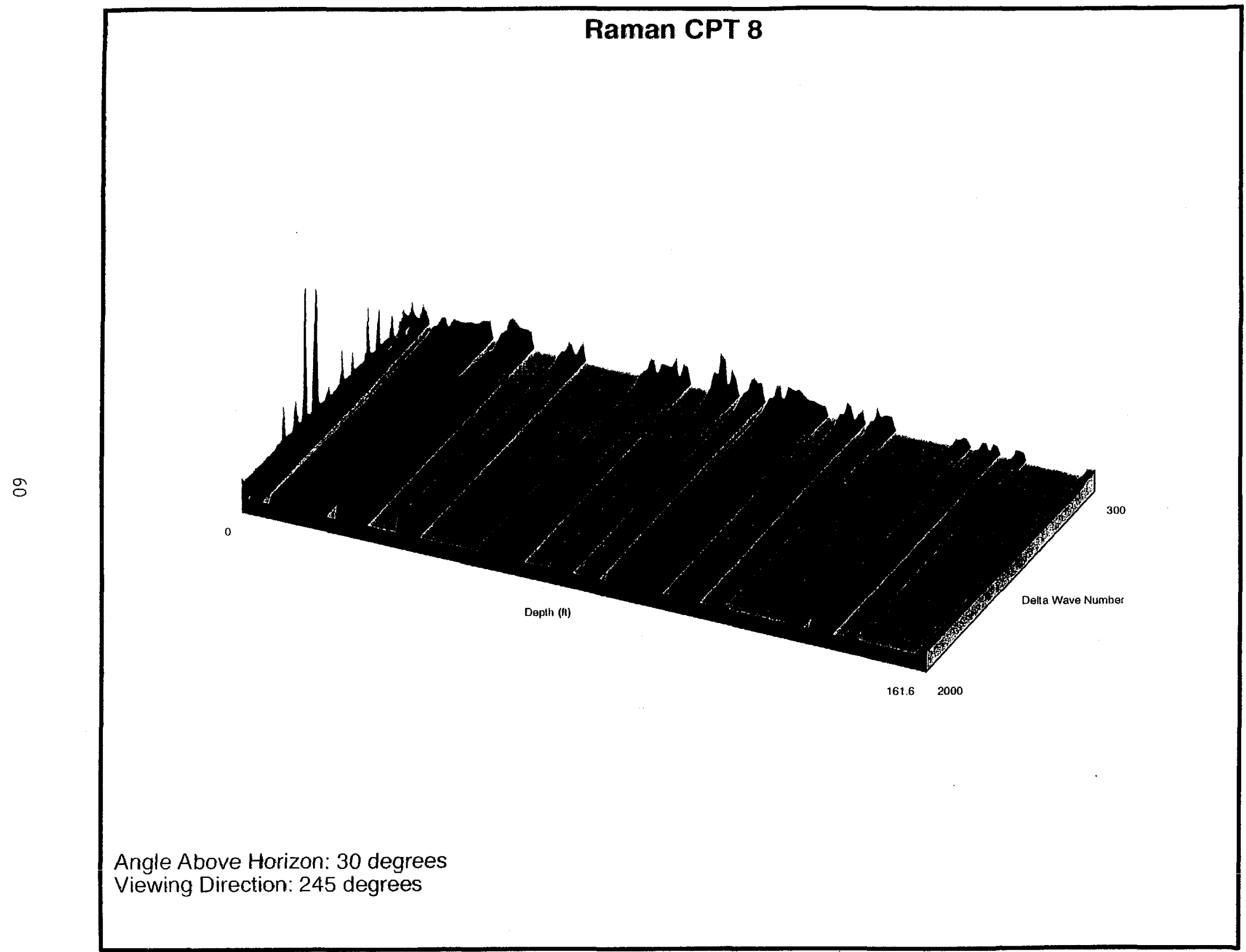

Figure 4.8 Three dimensional presentation of spectral data versus depth for CPT-RAM-8. 


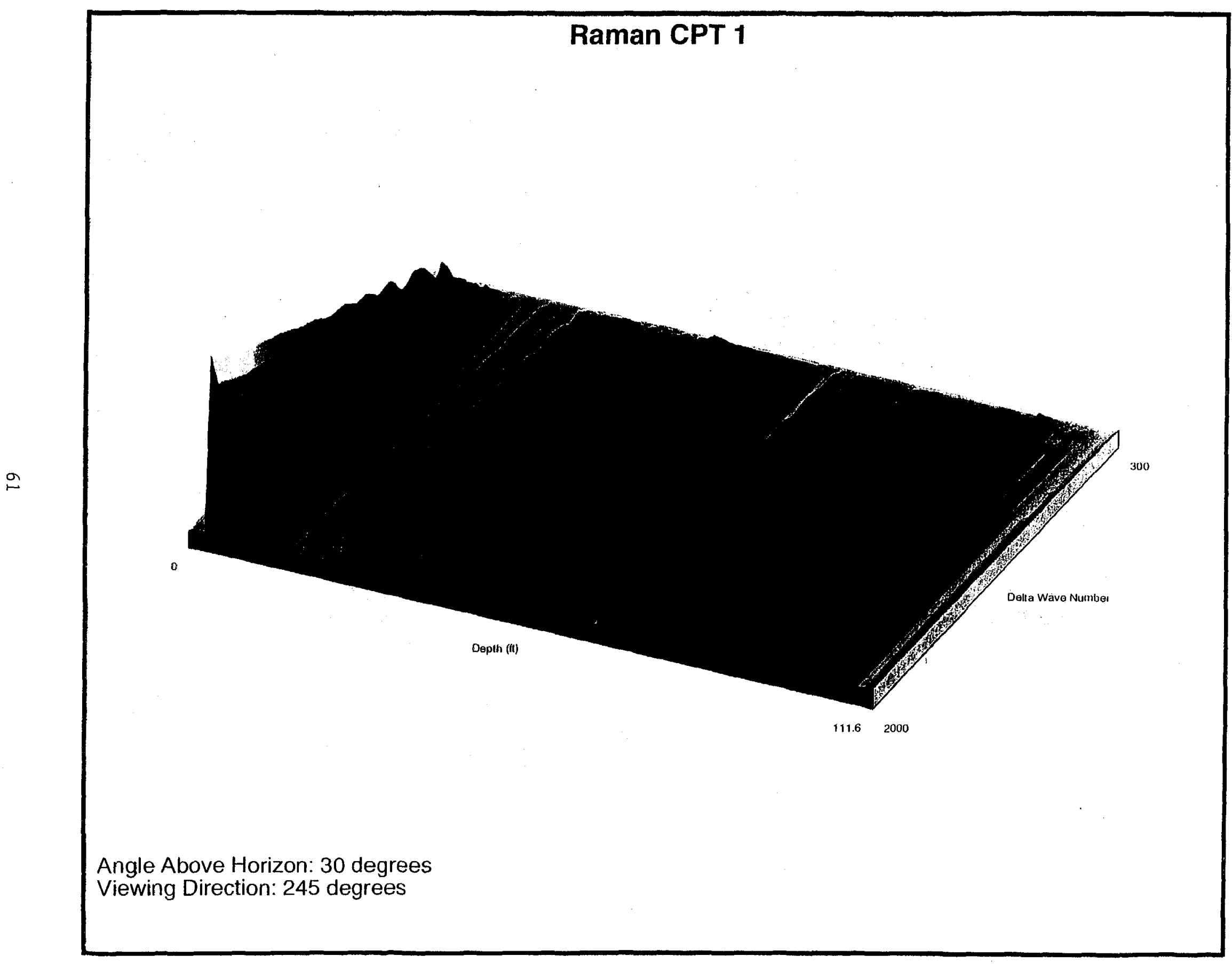

Figure 4.9 Three dimensional presentation of spectral data versus depth for CPT-RAM-1. 


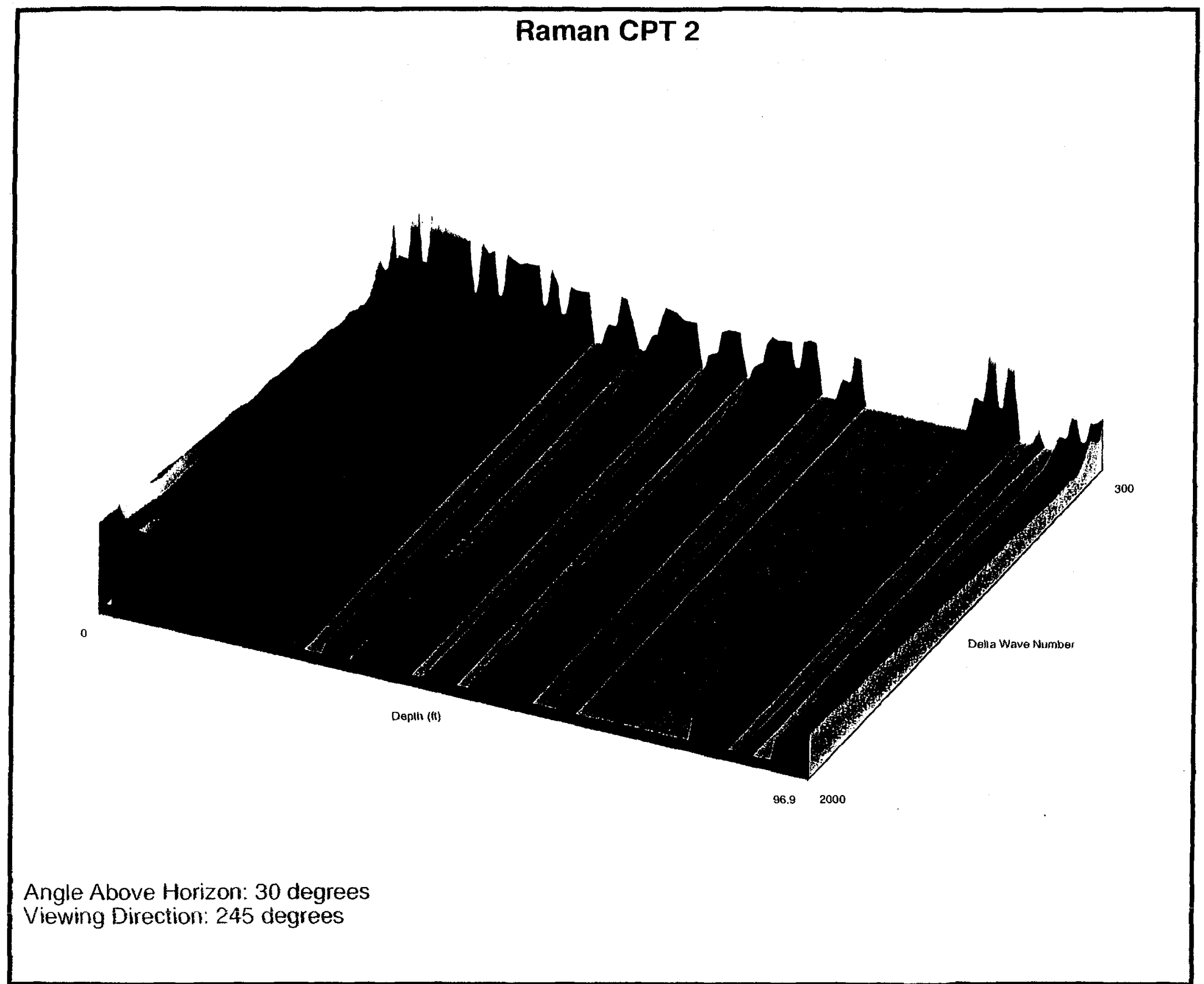

Figure 4.10 Three dimensional presentation of spectral data versus depth for CPT-RAM-2. 


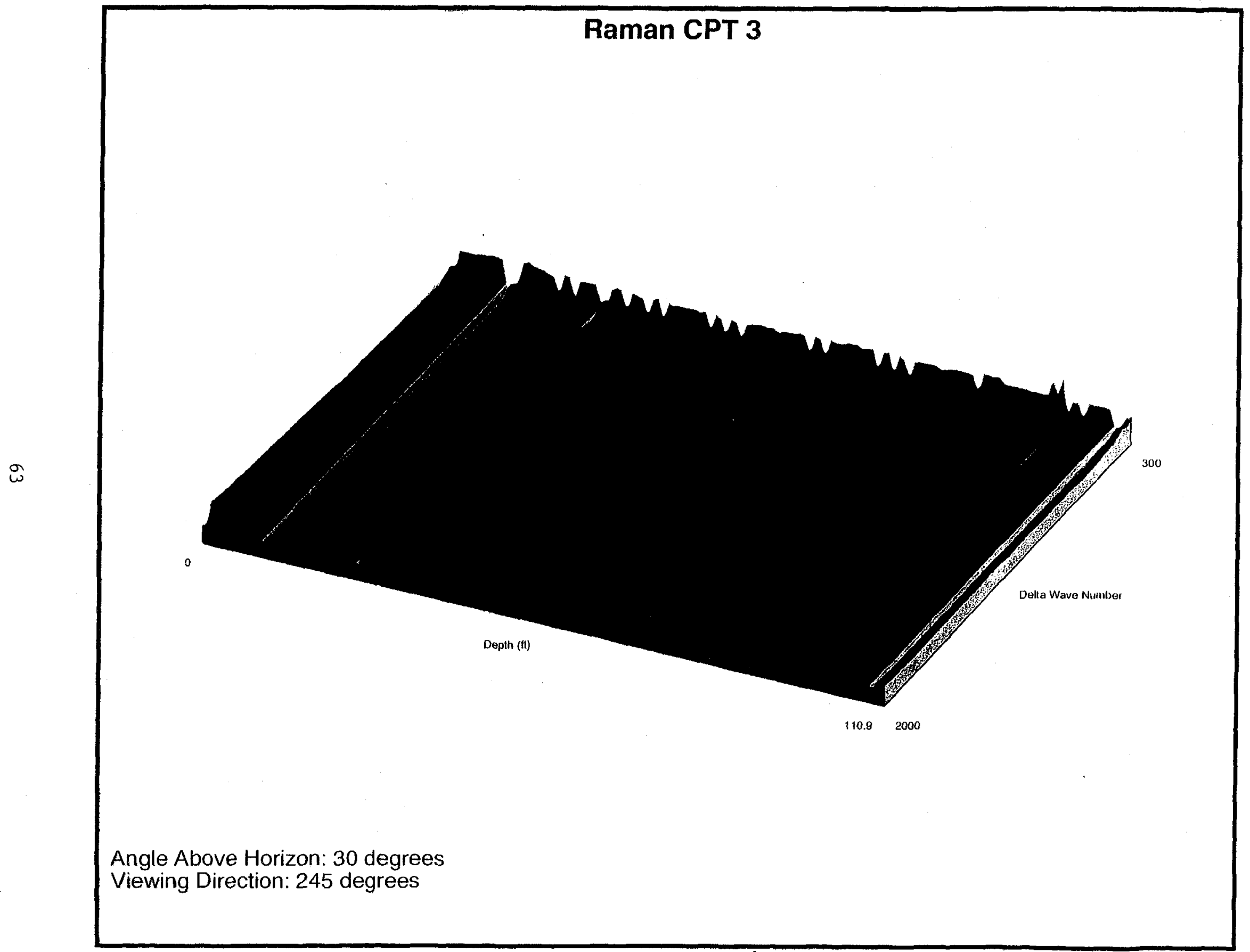

Figure 4.11 Three dimensional presentation of spectral data versus depth for CPT-RAM-3. 


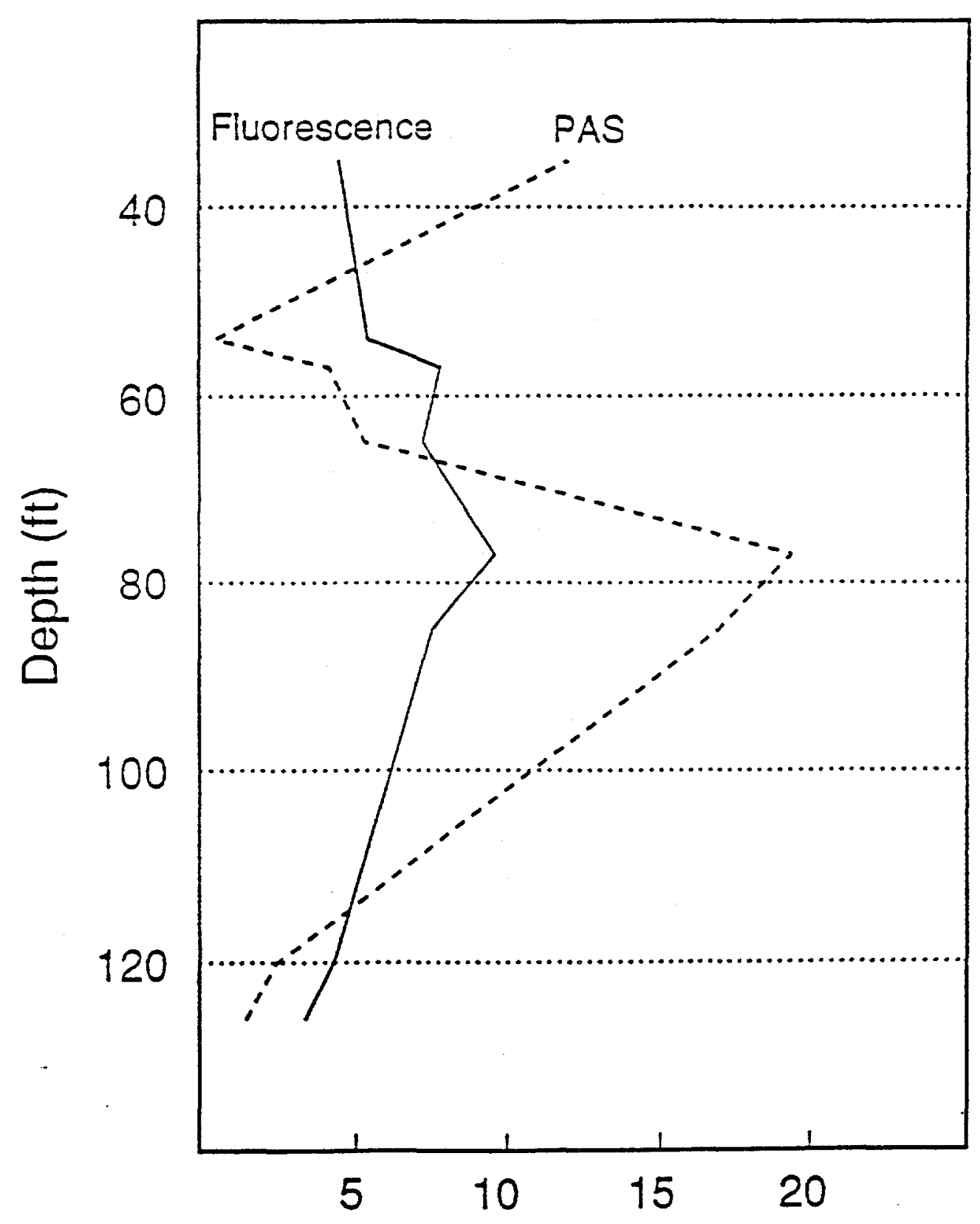

\section{Relative Response}

Figure 4.12 Fluorescence and IR-PAS responses

from CPT-RAM-7 with peaks near $80 \mathrm{ft}$. (RAMAN a $1,000 \mathrm{~cm}^{-1}$ ) 


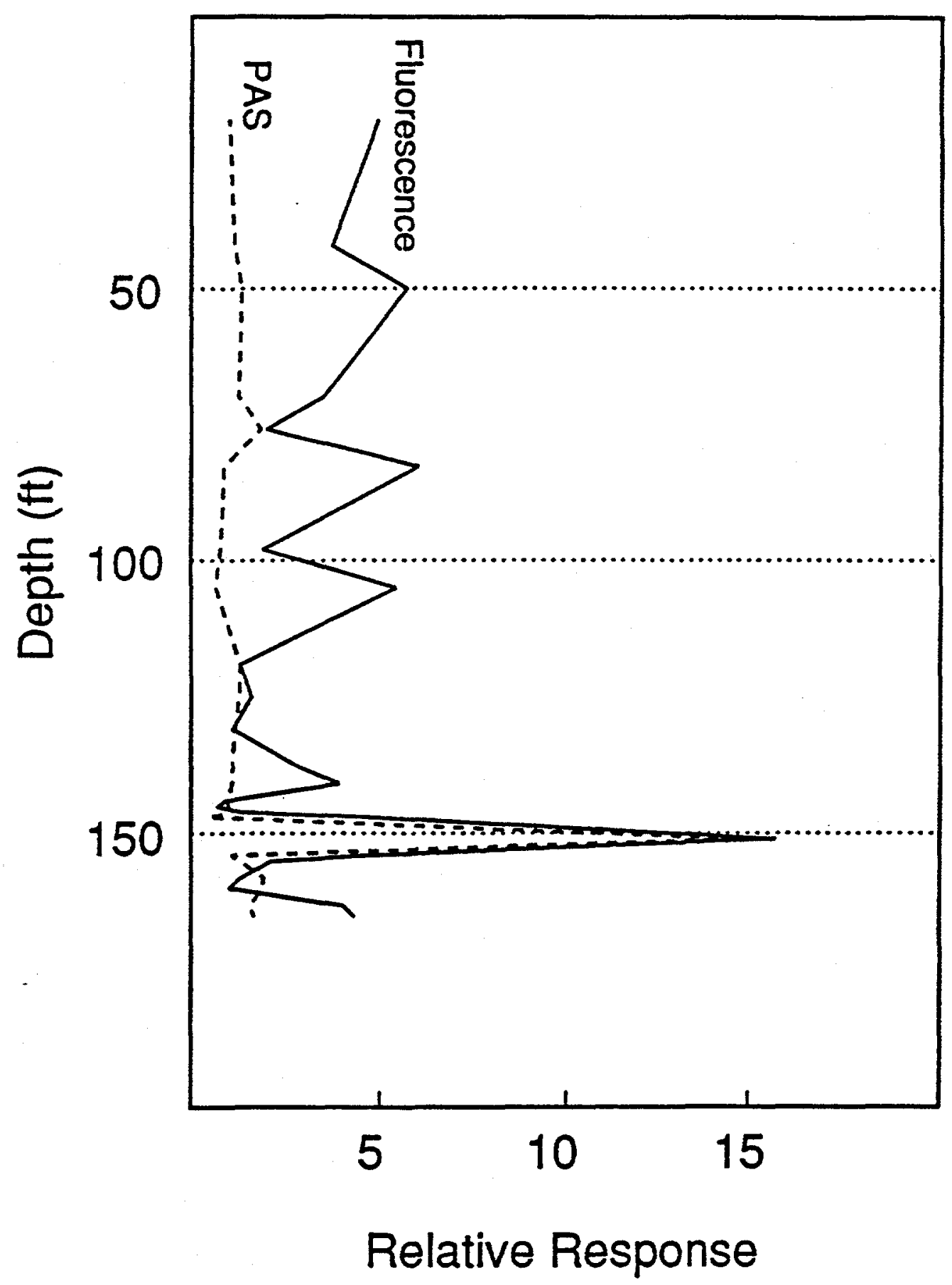

Figure 4.13 Fluorescence and IR-PAS responses from CPT-RAM-6 with peak at $150 \mathrm{ft}$. (RAMAN @ $1,000 \mathrm{~cm}^{-1}$ ) 
It is not certain that NAPLs were encountered near 80 and $150 \mathrm{ft}$; changes in soil type (i.e. the silt clay that is present at $150 \mathrm{ft}$. at CPT-RAM-6) or perhaps even the presence of some other solvent might be responsible for the observed differences. However, Figures 4.12 and 4.13 tend to indicate that there is a relationship between increased fluorescence and possible DNAPL contamination. The effect of soil background fluorescence must be understood before this effect can be used to located NAPL contamination.

Using the liquid sampling probe did not provide any measureable Raman signal for confirmation of NAPL presence. It should be noted that there was not clear evidence that sufficient liquid was being drawn through the frit (measured vapor flows were often negligible). It was certain, however, that there was never any "residual" solvent in the cone module or in the vacuum lines leading to it when the cone was brought to the surface. This would have indicated that free product was encountered. Confirmation by some other method is needed along with further testing of the liquid sampling cone to ensure that it can successfully extract NAPLS from subsurface soils.

\subsection{CENTRAL SHOPS HEATING FUEL DEMONSTRATION}

In addition to the testing performed at the AM area of SRS, a one day demonstration was conducted of the Raman system's ability to detect fluorescence from fuel contamination. This demonstration took place at the Central Shops Area of SRS, where a significant heating oil plume is known to exist near the surface. Fluorescence monitoring results to a depth of $60 \mathrm{ft}$ are presented in Figure 4.14. Clearly visible are two regions of NAPL contamination at about $15 \mathrm{ft}$. and $35 \mathrm{ft}$. The presence of NAPL was easily confirmed in this case because free product was found in the Raman probe-cone interface (the fuel had dissolved some of the epoxy used to glue the sapphire window). In addition, a sample collected at $16.2 \mathrm{ft}$. was wet with product and smelled strongly of diesel, whereas a sample from a depth of $25.1 \mathrm{ft}$. had only a faint fuel odor and was dry. Based on this limited demonstration, the Raman system is able to detect fuel contamination using a fluorescence measurement.

Two sets of post-demonstration tests on the Central Shops soil samples were conducted to further evaluate the results measured during the field demonstration and also to assist in determining recommendations for further advancement of the system. First, the two SRS Central Shops soil samples were analyzed using EIC's laboratory Raman/fluorescence spectrometer. Even after a week in a plastic bag the sample from the $16 \mathrm{ft}$. depth fluoresced very strongly, whereas the $25 \mathrm{ft}$. sample fluoresced at background levels. Results for the two samples are compared in Figure 4.15. While distinct spectral peaks are not evident, as in the Raman signal, we do see a large increase in fluorescence from the $16 \mathrm{ft}$. sample compared to the $25 \mathrm{ft}$. sample. This fluorescence increase can provide a clear method for locating fuel contaminated soils in situ, although more effort is required to separate the effect of natural background soil fluorescence and contaminated soil fluorescence. 


\subsection{POST DEMONSTRATION EVALUATION OF AN NIR LASER SYSTEM}

The field testing demonstrated that soil induced fluorescence limited the usefulness of Raman spectroscopy with an excitation wavelength of $514 \mathrm{~nm}$. Upon completion of the field demonstration, EIC obtained a more powerful NIR laser, which was not available before the field demonstration. Limited laboratory testing conducted before the field test had indicated that a longer wavelength laser source may cause less background soil fluorescence and improve the detection of NAPLs by Raman spectroscopy. However, these laser sources delivered less energy or were less stable than the $514 \mathrm{~nm}$ Argon laser source.

Upon completion of the field testing, additional laboratory tests were conducted with a new NIR laser source to determine the feasibility of enhancing Raman performance and to evaluate the fluorescence of contaminants at visible wavelengths. The primary motivation for this work was the future availability of a powerful and stable laser source that overcomes the limitations of the diode lasers tested in the early stages of this project. For these tests, a new air-cooled krypton laser, currently being evaluated by EIC for Omnichrome, was used to analyze many of the samples evaluated in the previous laboratory study (see Section II). The Omnichrome laser is capable of delivering about $15 \mathrm{~mW}$ of $752 \mathrm{~nm}$ exciting light to the sample. A future version of the laser is expected to provide more than ten times that power.

The first sample tested was a fluorescent SRS Brown soil. Results for TCE and PCE spiked samples measured with $752 \mathrm{~nm}$ excitation wavelength and then with a 514 $\mathrm{nm}$ excitation wavelength are given in Figures 4.16 and 4.17, respectively. Using a 60 second exposure time, the two contaminants are readily detected suing the NIR (752nm) excitation (see Figure 4.16). With the green excitation (514nm), soil fluorescence masks the DNAPL contamination almost completely (see Figure 4.17). It is concluded that with a more powerful NIR source, detection of TCE and PCE in this soil could be accomplished in a few seconds. Figure 4.18 shows that NIR excitation offers no advantage over visible excitation in the liquid sampling cone. Decreased Raman scattering efficiency and detector sensitivity overwhelms the benefit of a reduced fluorescence background for the extracts.

1. Gasoline and diesel fuel NAPL layers on water were also evaluated at these two wavelengths. With visible excitation $(514 \mathrm{~nm})$, both fuels fluoresced, the diesel more intensely and at longer wave numbers than gasoline, as shown in Figure 4.19. With NIR excitation the diesel fuel still fluoresced, but with a different profile and less intensely as expected. (see Figure 4.20). Gasoline (as an LNAPL), on the other hand, produces an identifiable Raman spectrum with $752 \mathrm{~nm}$ excitation as Figure 4.21 clearly shows, allowing it to be easily discriminated from diesel as shown in Figure 4.20. This Raman response for gasoline that is present with the $752 \mathrm{~nm}$ excitation is not present with $514 \mathrm{~nm}$ and provides additional benefit to a longer excitation wavelength source. Features in the gasoline Raman spectrum are dominated by alkylbenzenes, especially in the $100 \mathrm{~cm}-1$ region. 


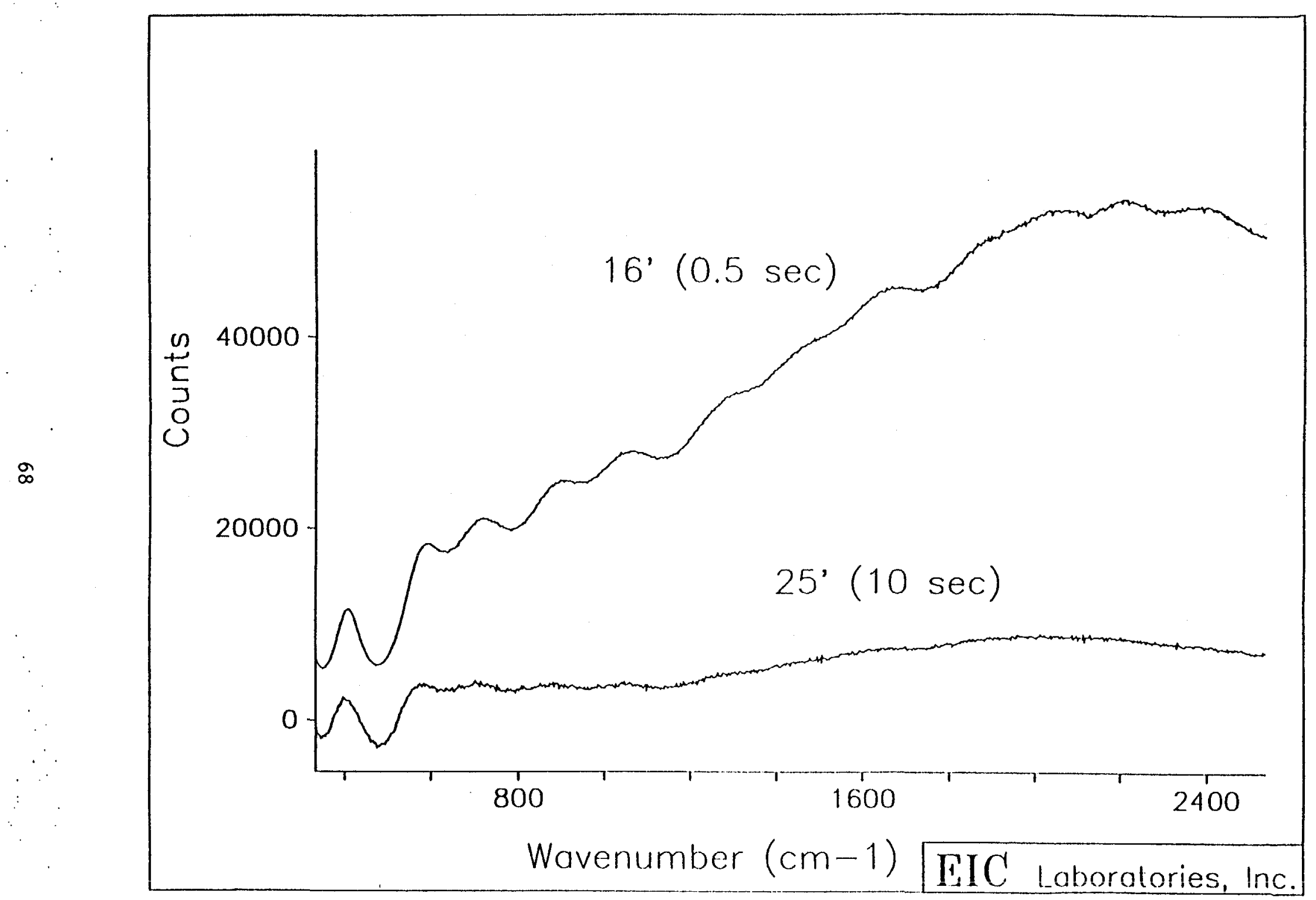

Figure 4.15 Fluorescence of SRS bag samples from 16 and 25 feet at the Central Shops Area. 


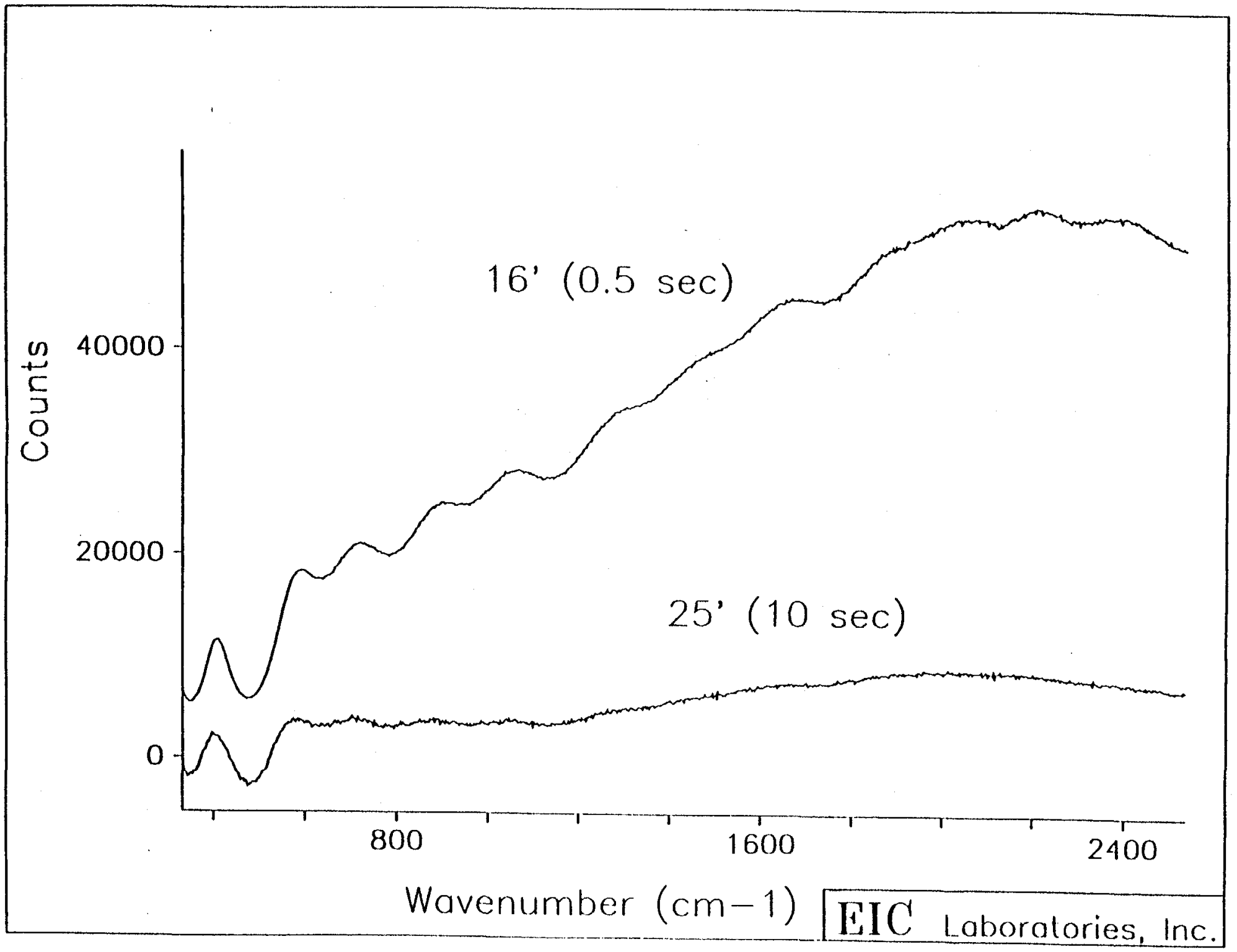

Figure 4.15 Fluorescence of SRS bay samples from 16 and 25 feet at the Centrai Shops Area. 


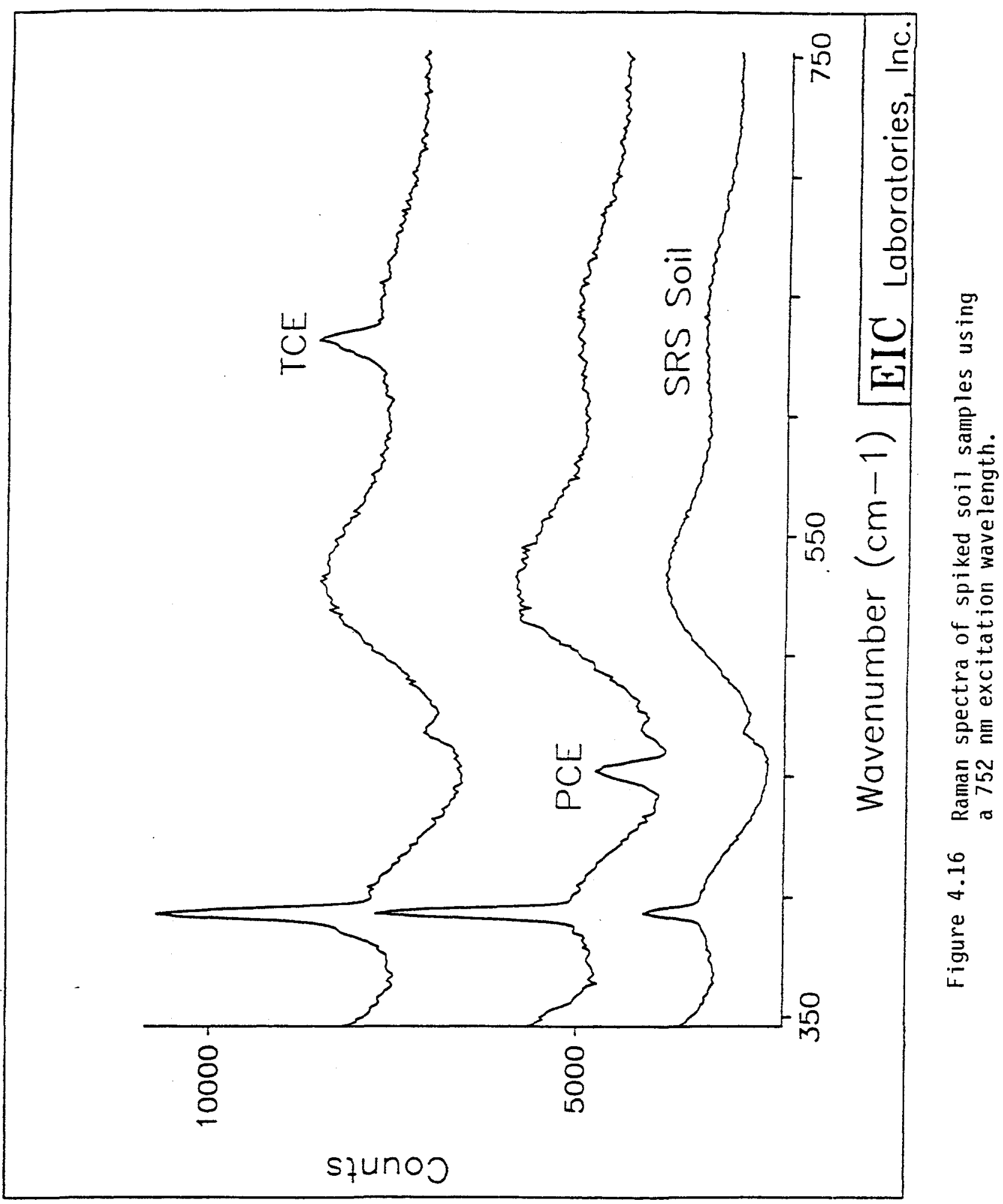




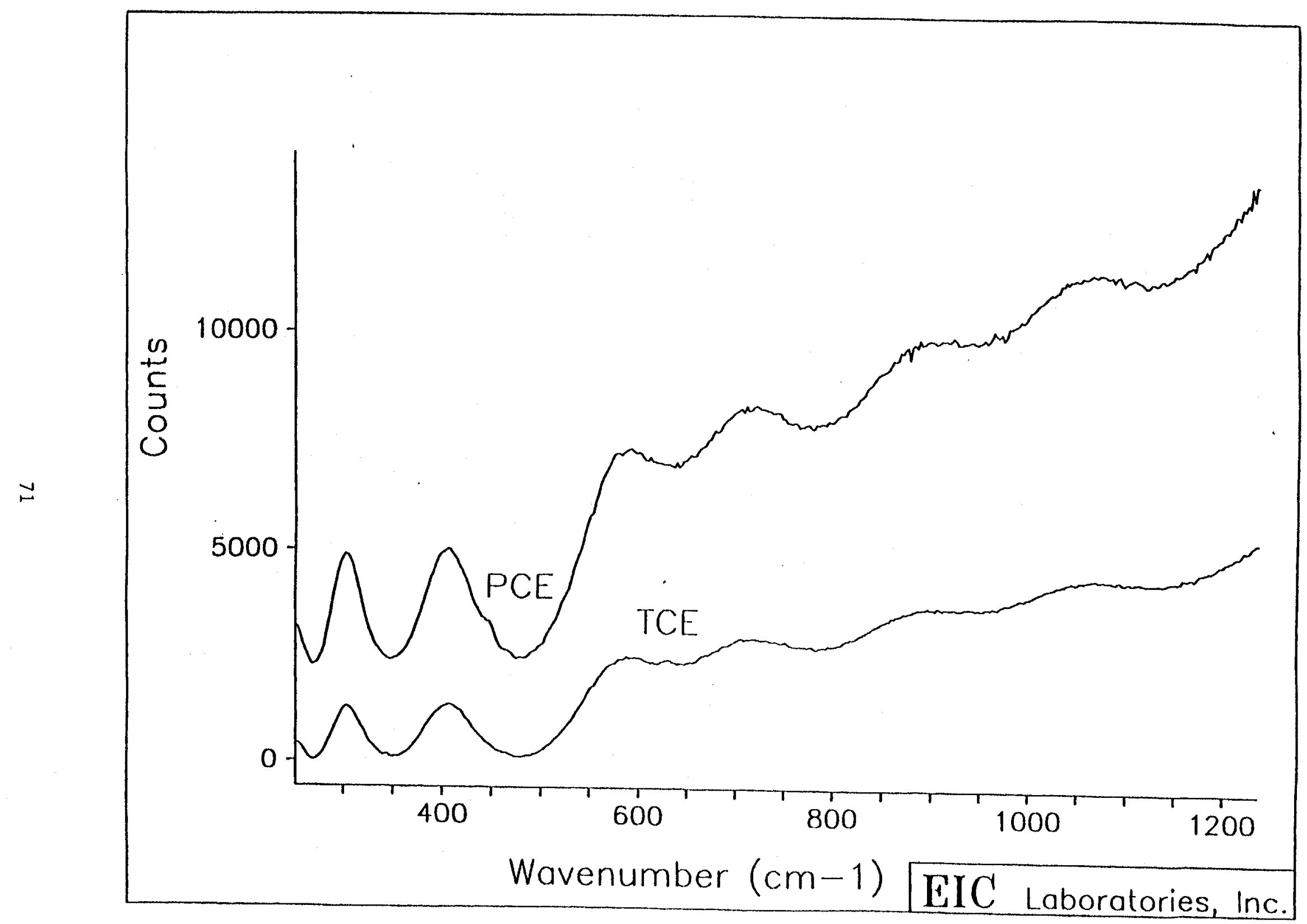

Figure 4.17 Raman spectra of spiked soil samples tested using a $514 \mathrm{~nm}$ excitation wavelength. 


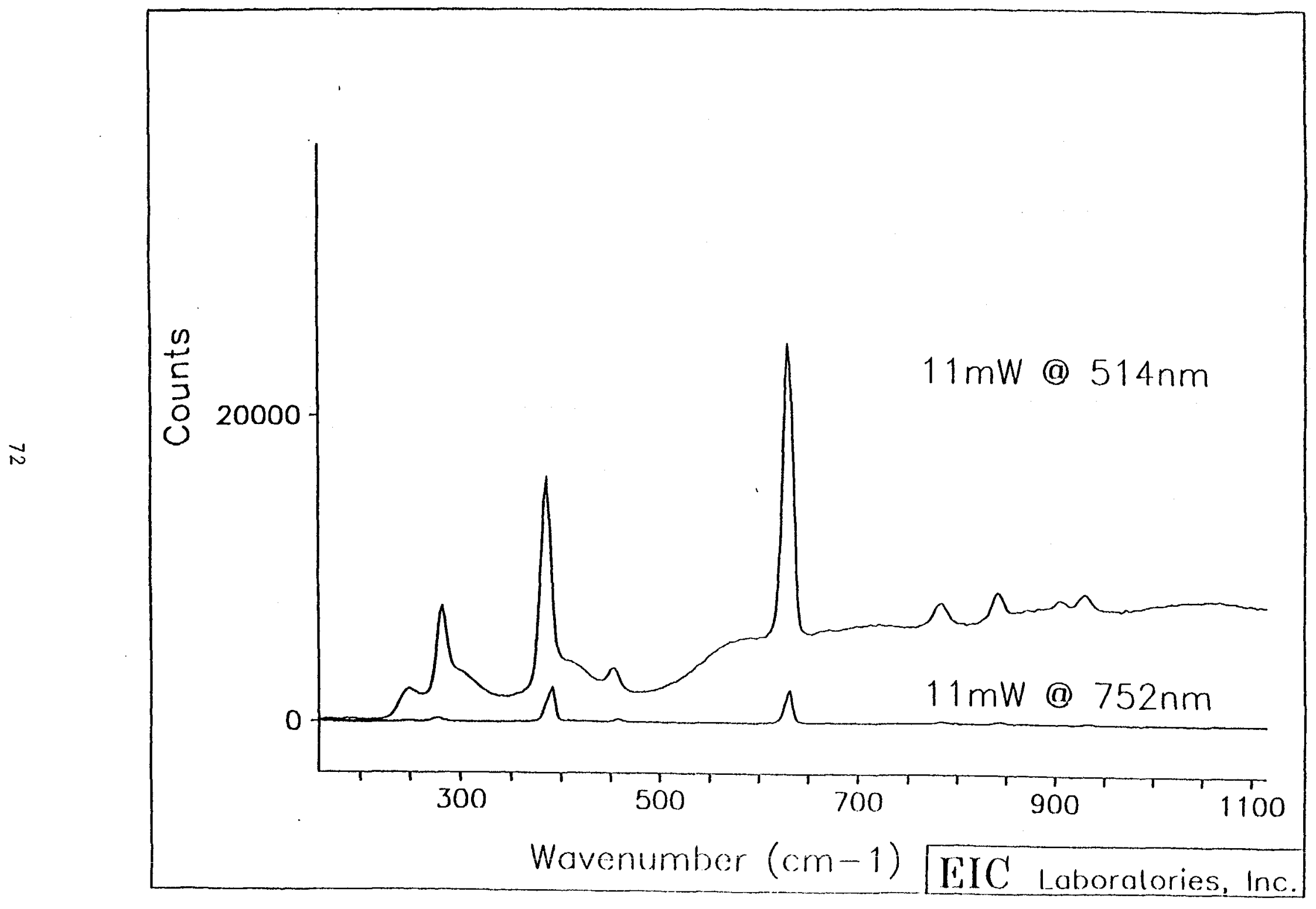

Figure 4.18 Raman spectra of an aqueous sample using both 514 and 752 nm excitation wavelengths. 


\subsection{RAMAN/SOIL GAS-CPT SENSOR EVALUATION}

Although no samples other than two taken at the Central Shops Area, were taken and chemically analyzed for confirmation of the Raman-CPT results, an in situ gas monitor was used in conjunction with the Raman-CPT to provide an indication of the presence of contamination. The soil gas monitor used on this project was obtained and operated by WSRC personnel. The gas monitor was a Bruel \& Kjaer (B\&K) Multi-gas Monitor type 1302. The instrument was configured and calibrated to measure both TCE and PCE with a lower detection limit on the order of $1.0 \mathrm{ppmv}$. The gas monitor is based on the photo-acoustic infra-red detection principle (IR-PAS). By installing appropriate optical filters the B\&K device can selectively measure the concentration of up to five component gases and water vapor in any air sample. The gas samples were obtained using a metal bellows vacuum pump to draw soil gas through a dry pore pressure filter and into the high density polypropylene tubing used to transport the gas to the B\&K sensor. The measurement results along with the flow rates were recorded and time stamped using a data logging instrument. These results were then compared to the CPT data files which are also time stamped, and the final sample depths determined considering the measured flow rates by WSRC personnel. An example plot of the TCE and PCE soil gas concentrations is presented in figure 4.22. All the additional profiles from other locations where the B\&K instrument was used, are presented in Appendix B. 


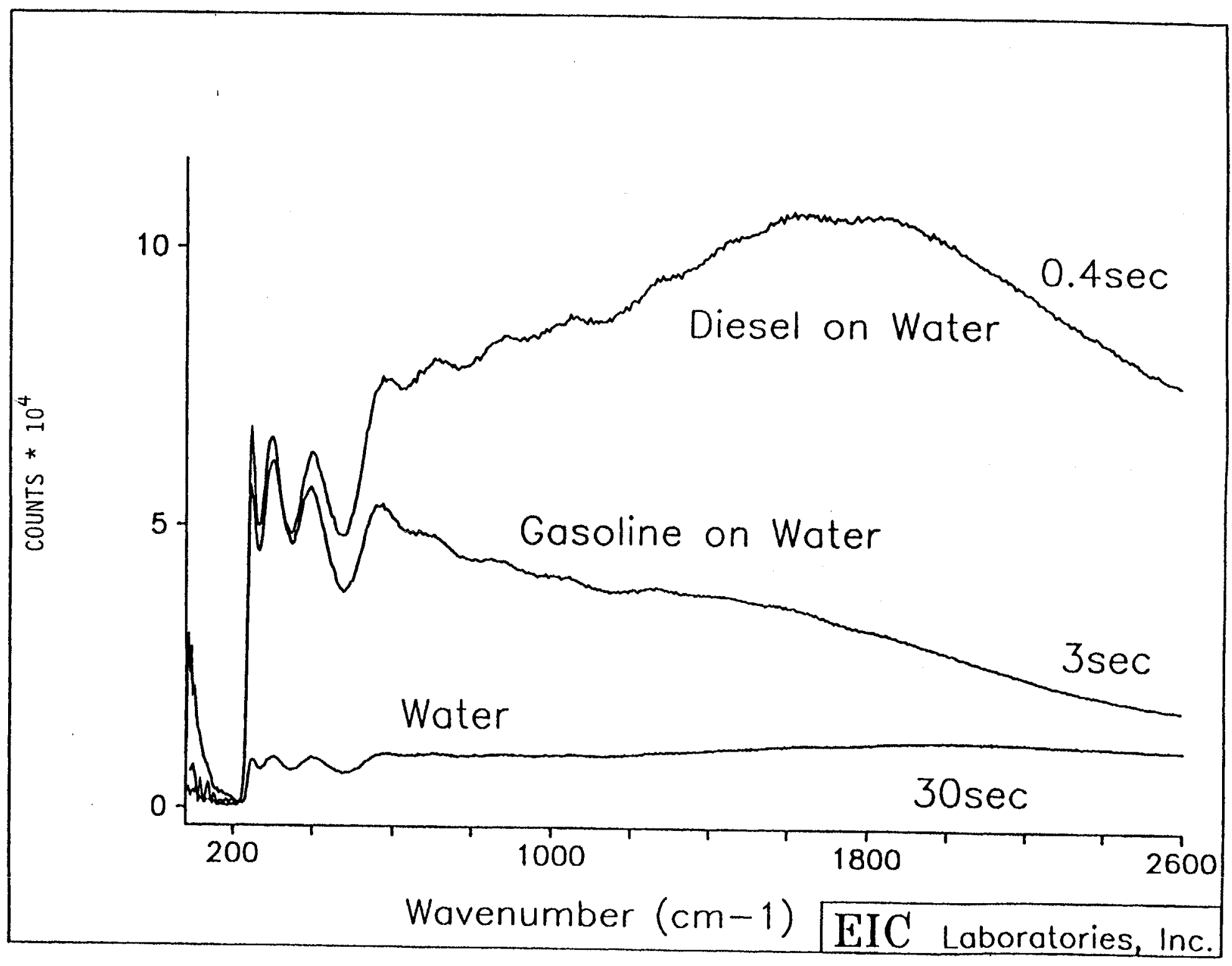

Figure 4.19 Fluorescence of aqueous samples using $514 \mathrm{~nm}$ excitation wave length. 


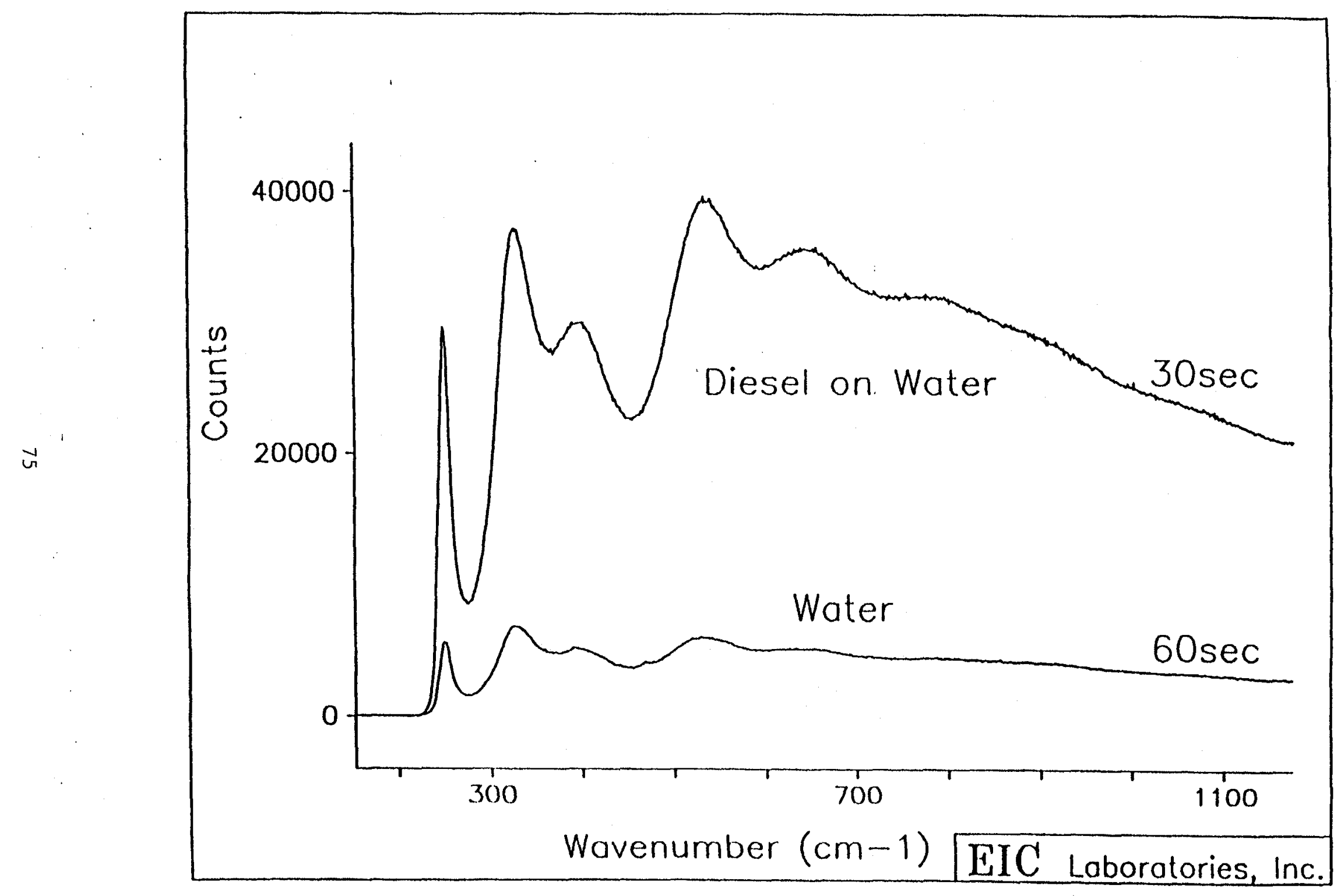

Figure 4.20 Fluorescence of aqueous samples using a $752 \mathrm{~nm}$ excitation wavelength. 


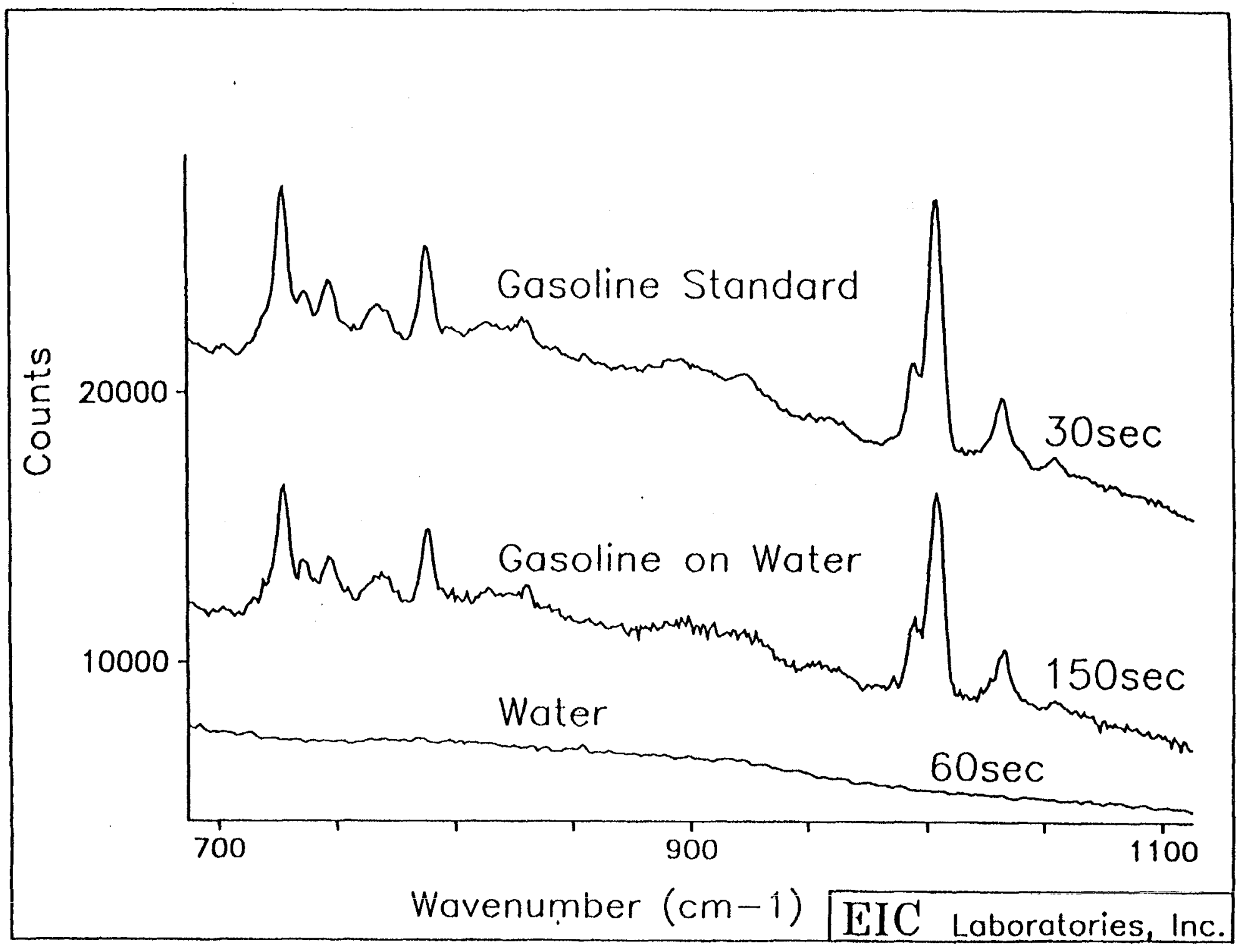

Figure 4.21 Raman spectra for gasoline samples using a $752 \mathrm{~nm}$ excitation wavelength. 
APPLIED RESEARCH ASSOCIATES, INC.

CPT Raman 3

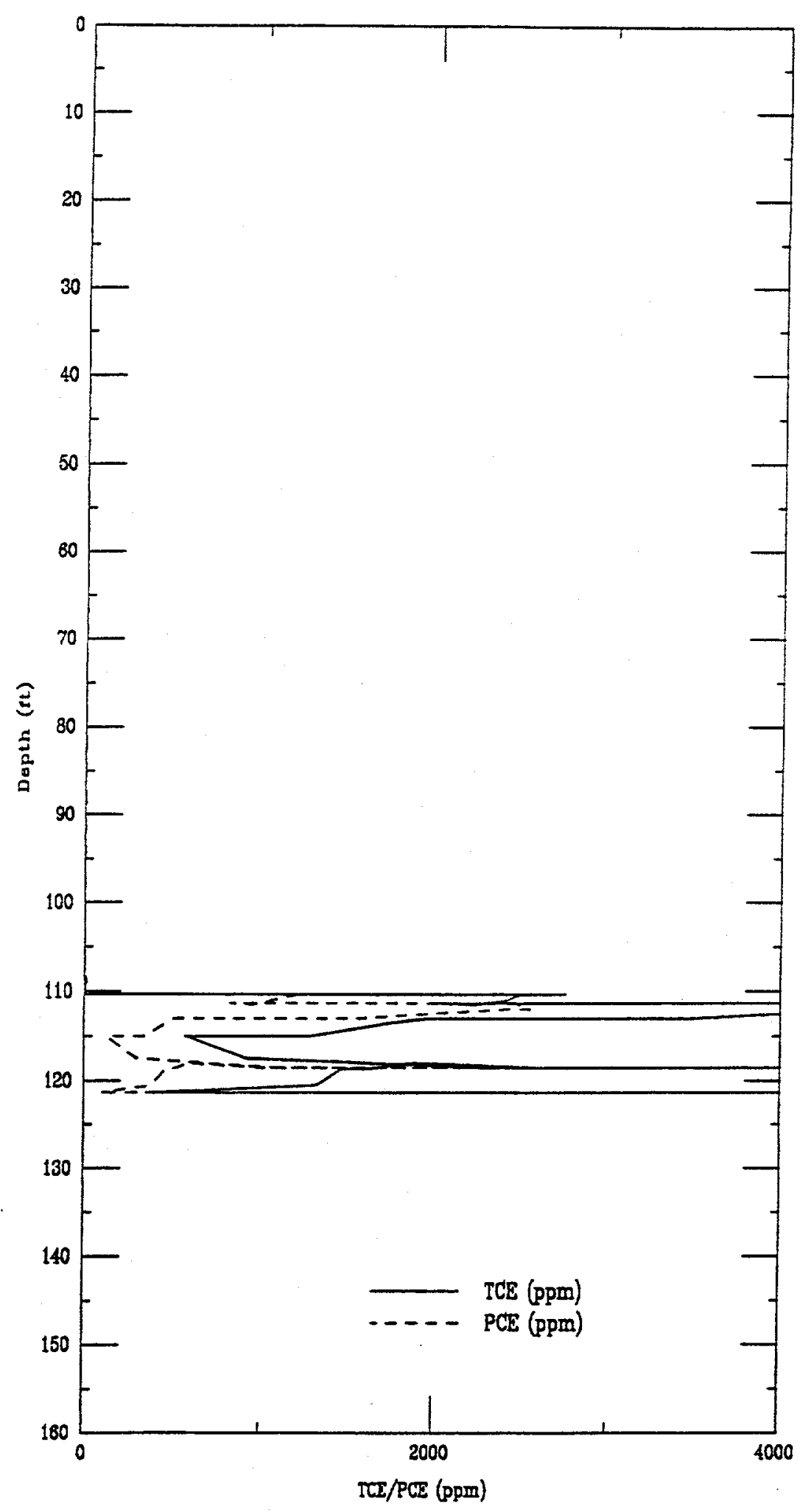

Figure 4.22 Soil gas concentrations measured using the $B \& K$ instrument at location CPT-RAM-3. 
presented in Appendix B.

Several considerations must be kept in mind when reviewing this data. First and foremost is that the $B \& K$ is measuring soil gas and the Raman sensor requires high concentrations of a liquid form to be present. The Raman and B\&K use two different measurement concepts. The $B \& K$ can sample a large volume of gas in sandy soils which is an advantage. However, in low permeability soils, the gas volume is greatly reduced and the sample zone smaller. Hence concentrations in the soils are not directly related to the $B \& K$ measurement. The Raman optical technique measures contamination only in direct contact with the probe. Thus the measurement zone is reduced. However, the Raman signal is directly proportional to the amount of contamination. The very high concentrations measured using the B\&K sensor are a good indicator of a nearby source. However, it does not guarantee that pure product came in contact with the CPT. An additional difference is that the $\mathrm{B} \& \mathrm{~K}$ measures gas concentrations to $1.0 \mathrm{ppm}$. These detection limits are significantly lower than the Raman sensor which is designed to respond to product in a soil matrix.

The B\&K monitor indicated three locations with significant contamination where a response might be expected on the CPT-Raman sensor. These locations were CPT-RAM-3, CPTRAM-7, and CPT-RAM-16. For location CPT-RAM-3, the B\&K sensor indicated contamination from 110 to $121 \mathrm{ft}$. The soil material at this depth is a silty sand mixture which immediately underlies a clay seam from 105 to $110 \mathrm{ft}$ in depth. The Raman-CPT sensor during the same test recorded a thin layer of potential contamination from 100 to $102 \mathrm{ft}$. The soil types for 100 to $105 \mathrm{ft}$ represent a sandy fine grained material. It is encouraging that both sensors produce a response in this region, although they were at different depths. There are two reasons why the B\&K data may be slightly deeper than expected. First, very little gas flow occurred in the clay materials present from 105 to $110 \mathrm{ft}$. Once the gas sampling port reached $110 \mathrm{ft}$, the flow rate increased, flushing the gas out of the sampling line. Second, the depths for the B\&K monitor are based on calculations of flow rates and time stamps, through $250 \mathrm{ft}$ of tubing. There exists the possibility for errors in the depth determinations, since the sensor is located at the surface and the sampling point downhole. The Raman-CPT sensor is downhole and depths can be accurately determined from the extensiometer in the push cylinders.

At location CPT-RAM-16 \& 17 periodic measurements were made using the $B \& \mathrm{~K}$ monitor. For this location the sampling port was stopped at a measurement depth and the tubing 
purged to ensure that the sample came from the desired depth. While this operation method does not provide as much profiling information and pauses CPT operations from 5 to 7 minutes to make a measurement, the quality of the depth data is significantly enhanced. From the B\&K monitor, significant levels of TCE and PCE contamination appear to be present over large depth intervals. The Raman-CPT sensor on the other hand, did not indicate contamination during the entire profile. The soil type present at the location consists of a sand and silt mixture from 69 to $87 \mathrm{ft}$ and a soft clay material from 87 to $92 \mathrm{ft}$.

Based on the analysis of these three locations, it appears that the Raman-CPT did enter some zones of high concentration of TCE and PCE vapors, although pure product may not have been directly encountered. In two out of the three cases, the Raman data did not show any significant signals above the background level. In one case, there are indications that the RamanCPT probe was responding to the presence of TCE and PCE, although the response was not as high as expected. These results are encouraging and additional effort is warranted, especially if actual soil samples can be obtained and analyzed in the regions where the Raman-CPT probe is producing a response. In addition, the ability to use fluorescence as an indicator of contamination is encouraging based on previously presented results. A clear understanding of the soil matrix effect on the Raman signal is required. 


\section{SECTION 5 \\ SUMMARY, CONCLUSIONS AND RECOMMENDATIONS}

\subsection{SUMMARY}

Under contract to the Argonne National Laboratory and funding from Westinghouse Savannah River Company, Applied Research Associates, Inc. and EIC Laboratory, Inc. developed a Raman-CPT probe. The primary objective of the project was to develop a minimally invasive system to locate Dense Non Aqueous Phase Liquid (DNAPL) contaminants. The Dnapl are particularly difficult to locate as they are heavier than water, sink below the water table, and travel readily due to their low viscosity. In the saturated zone, DNAPL's tend to pool on top of an aquitard until a fracture or crack is encountered, and then propagate downward toward the next aquitard. Small pockets of DNAPL remain at the shallower location, and can be a source for long term contamination. Unlike Light Non Aqueous Phase Liquid (LNAPL) such as gasoline, diesel and heating fuels which float on top of the water table and are easily located, Dnapl are difficult to locate because they can be found at great depths, in small pockets and are widely dispersed. To date, location of these dispersed pockets of DNAPL has relied upon drilling technology, and the success of this method for locating DNAPL pockets has been limited.

\section{Integration of Applied Research Associates' CPT with EIC Laboratories' Raman} spectroscopy system has resulted in a system which is minimally invasive, generates little or no hazardous drilling spoils, and is rapid. In a production mode, up to several hundred feet of penetration testing per day are possible. Under this project, a prototype Raman-CPT system was developed, and field demonstrated during a two week site investigation program at the $\mathrm{A} / \mathrm{M}$ Area of Savannah River Site. The project consisted of two major phases: (1) development and bench top testing of the system, and (2) demonstration and evaluation of the system.

Upon completion of the system development, a series of bench top experiments and limited field testing was conducted at the New England Division. These tests indicated that many of the soils developed an intense fluorescence signal when solvents such as TCE and PCE were added. The source of the fluorescence is not known, but is suspected to be due to either extraction or solvation of humic acid from the soils by the solvents. Fluorescence of the soils was so intense, that the Raman spectrum could not be discriminated from the background fluorescence. Based on the results of these tests, two versions of the Raman-CPT probe were tested. The first was the 
side looking probe with an optical window, and the second was a modified version in which a small volume of groundwater was drawn into a chamber inside the CPT probe. Tests of this system, with extracts from TCE and PCE spiked soils, provided Raman spectrum that could be used to identify the contaminants. These tests seemed to indicate that the source of the solventinduced fluorescence was contained within the soil and not in the aqueous phase.

A two week demonstration of the system was conducted at the Savannah River Site from August 16 to August 31, 1993. A total of 17 Raman-CPT soundings were conducted. Upon completion of a sounding, the hole was either grouted or a small diameter PVC well inserted into the CPT hole to serve as a soil gas monitoring location. For a portion of the testing, the CPT pore pressure gage was removed, and a modified CPT tip used to collect soil gas samples as the RamanCPT probe was advanced. The soil gases were drawn under a vacuum to an on-board soil gas analyzer, which was used to determine if either TCE or PCE contamination was present. The soil gas system indicated that both TCE and PCE were present at several depths in high concentrations. The Raman-CPT system, which is designed to locate DNAPL contamination, indicated possible contamination at only one of these locations.

Raman-CPT soundings were also conducted at the Central Shops Site where heating fuel contamination was known to exist. The Raman-CPT system detected the contamination using fluorescence effects. These findings were confirmed by soil samples obtained by the CPT.

Soil fluorescence at the SRS site provided a significant source of background noise during the demonstration. Upon completion of the field test program, a laboratory testing program was conducted in which an NIR (752 nm) laser was used to excite the soil samples. Tests were conducted on the same samples which demonstrated a high degree of fluorescence when excited with the $514 \mathrm{~nm}$ laser. For the NIR laser system, the fluorescence level was decreased and Raman spectrum in the spiked soil were obtained which clearly showed the TCE and PCE Raman bands.

\subsection{CONCLUSIONS}

Based on the results obtained during this demonstration, the following conclusions can be drawn concerning the Raman system: 
1. Because of the limitations imposed by some soils (absorbance of excitation light, background fluorescence, etc.), and by a $514 \mathrm{~nm}$ laser, it was difficult to detect Dnapl by Raman spectroscopy in a continuous monitoring mode at typical CPT penetration speeds. The Raman technique is probably better suited for measurement when the cone is stationary; however, a single spectrum can be collected quickly, (in a few seconds or less), for screening purposes. Continuous monitoring is more feasible if contamination zones are at least several inches thick or if the soil fluorescence background is low.

2. The use of NIR excitation ( $752 \mathrm{~nm}$ ) is a promising alternative to visible $514 \mathrm{~nm}$ excitation with the CPT. Generally, fluorescence backgrounds of all the soils tested were lower with $752 \mathrm{~nm}$ excitation than with $514 \mathrm{~nm}$ excitation, providing better Raman identification of Napl. However, current fieldable laser sources (diode lasers, air-cooled krypton lasers) are too unstable and lack the power needed to make measurements rapidly. EIC is now developing a stable and powerful NIR laser that overcomes these limitations.

3. The liquid sampling cone may be a better alternative to the side-looking probe in some cases. In laboratory tests it worked extremely well and could be used readily with visible excitation. Additional controlled testing is needed to validate its performance in the field, especially with additional soil types.

4. Locating and identifying fuels by fluorescence induced by visible light was demonstrated on this project. The results obtained at SRS Central Shops clearly demonstrated the capabilities of this approach. Large, expensive, and difficult to operate UV lasers traditionally used in this method may not be needed to locate fuel Napl. Also, because the fluorescence from fuels such as gasoline and diesel is so strong, continuous monitoring can be utilized. Light and heavy fuels can be differentiated based on their fluorescence wavelength maxima, or by utilizing NIR excitation (the light fuels produce Raman spectra whereas the heavy fuels still fluoresce).

5. From these tests, it was inconclusive whether or not Dnapl were encountered in the $M$ Area Basin at SRS. The lack of Raman peaks in the spectra collected from the various holes using both cone modules, and the relatively low fluorescence backgrounds, suggests that Dnapl were not met. It may be that DNAPL is present at about $150 \mathrm{ft}$, where a marked increase in fluorescence background was detected (and detected by the soil gas monitor 
(IR-PAS) system). This needs to be validated however, and could instead be related to a change in soil type. Use of NIR excitation might prove useful to diminish the fluorescence at this sample depth.

\subsection{RECOMMENDATIONS}

In the course of this project several new opportunities for development were identified and are recommended for further investigation:

1. NIR Raman: Once complete, it is recommended that EIC's new laser be evaluated for NAPL detection. If significant advantages are demonstrated in the laboratory, then a return trip to the SRS M Area Basin would be useful. It would also be helpful to have more extensive analytical testing equipment on site to validate the test results.

2. Liquid sampling cone: Performance of the liquid sampling cone should be validated in the subsurface. Modifications should be made as needed. This device too, could be demonstrated on a follow-up visit to SRS.

3. Fuel detection. The use of visible and NIR excitation should be further tested. A return trip to SRS Central Shops to map the contamination over a wider area, and to a greater depth is recommended. The technique should also be validated at another better characterized site (or in conjunction with extensive conventional characterization of the Central Shops Site).

4. Probe-cone interface: Although the current design is adequate, it is recommended that an improved probe-cone interface that is easier to assemble and disassemble, and better protect the Raman probe from water and/or solvents, be developed for future field work.

5. Increased push capacity: On many of the pushes during this project the 30 ton CPT rig was only able to reach the upper regions of the contamination. Only once did the cone reach the green clay layer near the M Settling Basin. Additional push capacity in the form of a 40 tom CPT or vibratory assisted penetration should be investigated to increase the utility of the Raman system. 


\section{SECTION VI}

\section{REFERENCES}

1. Bianchi, J.C., W.L. Bratton "Development of a Multi-sensor Cone Penetrometer", Applied Research Associates, Inc., Nov. 1993.

2. Bratton, W. L., J.D. Shinn II, S. M. Timian, "The Air Force Site Characterization and Analysis Penetrometer System (AFSCAPS): Laser Induced Fluorescence Cone Penetrometer", Applied Research Associates, Inc., Feb. 1993.

3. Cassem, B.R., "Demonstration of a Heavyweight Cone Penetrometer at the Hanford Site", Westinghouse Hanford company, WHC-SD-EN-TRP-003, Dec. 1992.

4. Robertson, P.K., R.G. Campanella," Guidelines for Using the CPT, CPTU and Marchetti DMT for Geotechnical Design: Vol. II-Using CPT and CPTU Data," Civil Engineering Dept., University of British Columbia, March 1988.

5. Timian, D.A., W.L. Bratton, B.E. Fisk, "Piezo Electric Cone Penetration Tests in Support of Geotechnical Investigations at Sections $6 / 7$ and $1 / 9$ of Fresh Kills Landfill, Staten Island, New York-Development of Correlation for Soil Classification and In Situ Properties", Applied Research Associates, Inc., Contract No. 5693, May, 1992. 
APPENDIX A 

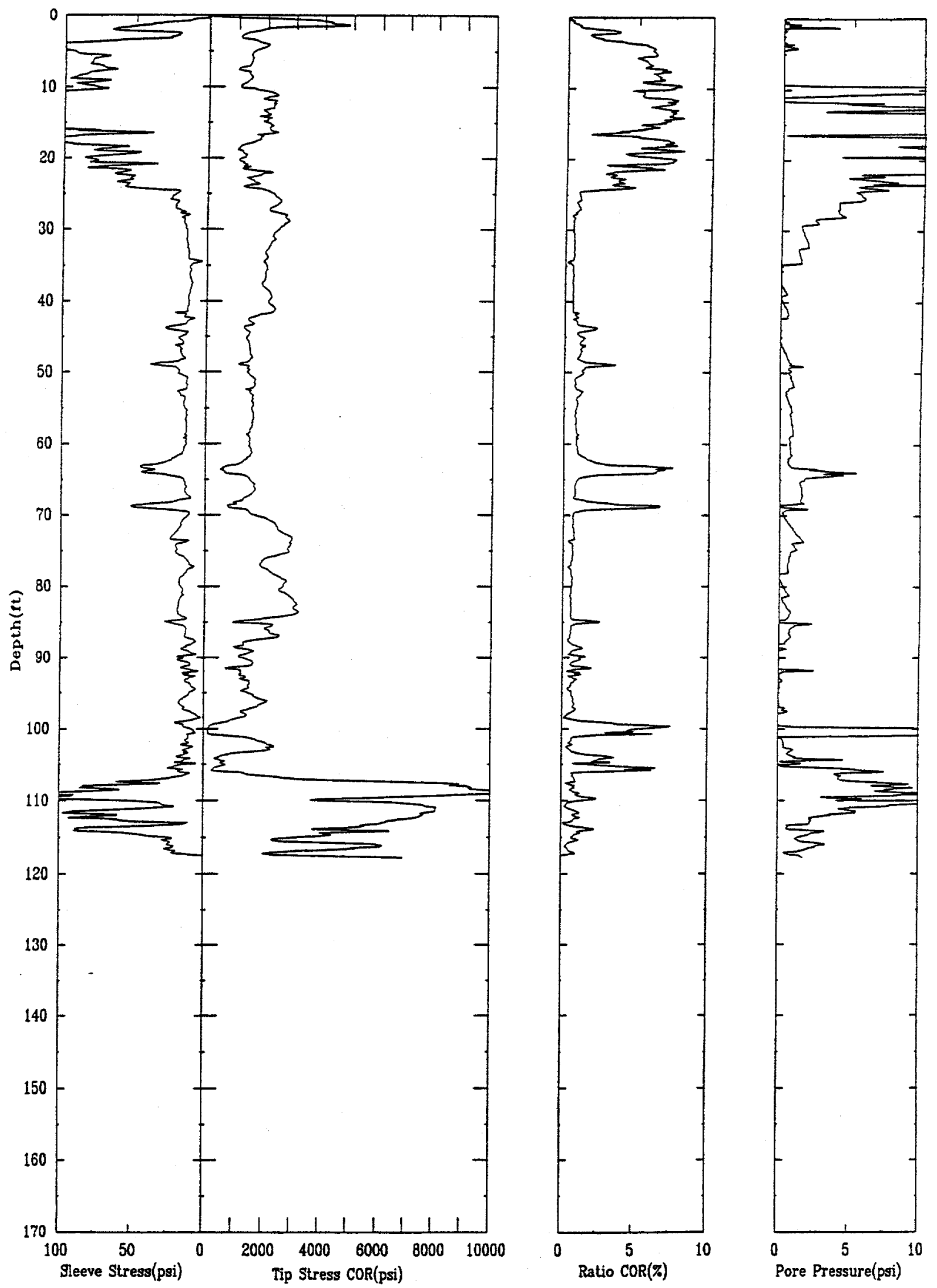

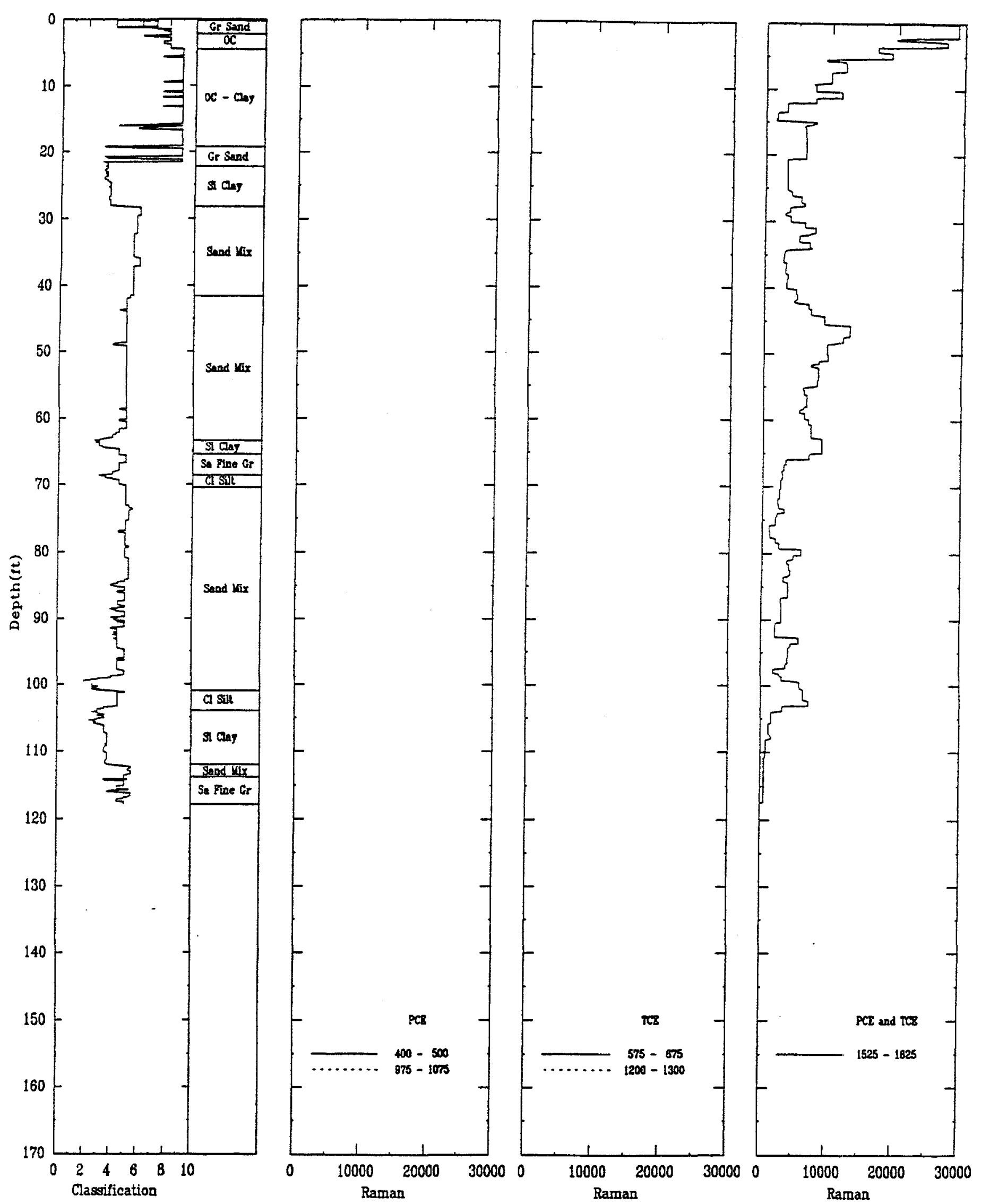


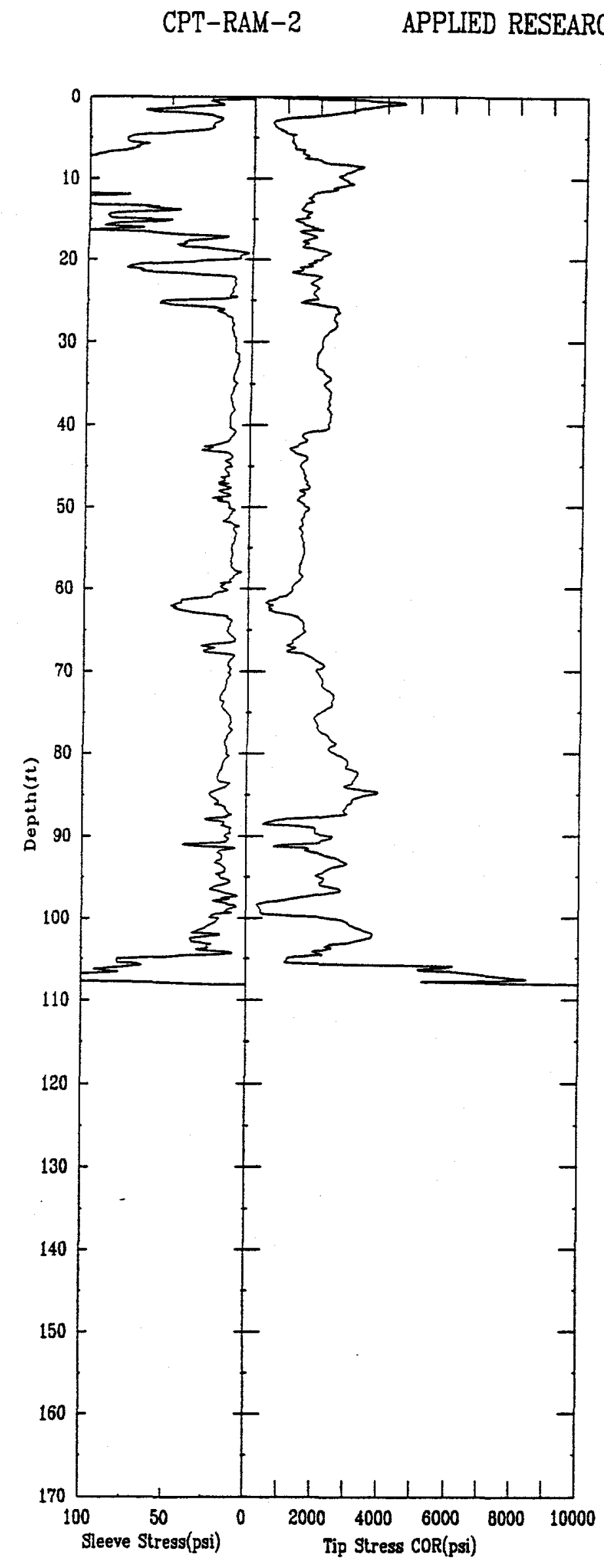

ASSOCIATES, INC.

$08 / 20 / 93$
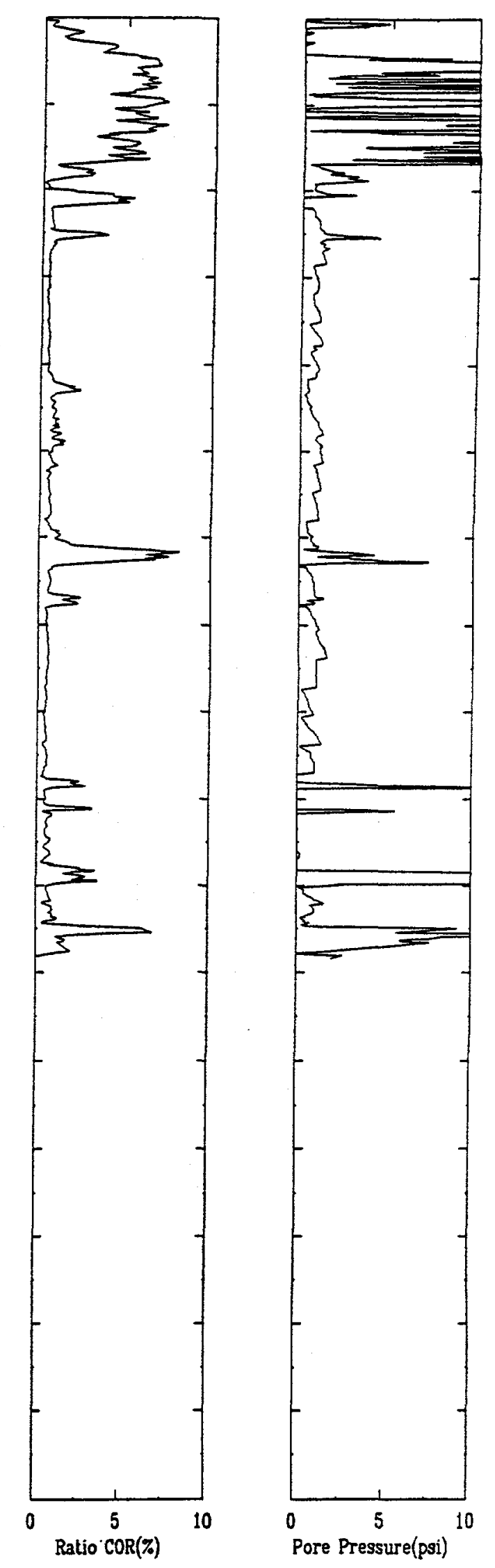
CPT-RAM-2

APPLIED RESEARCH ASSOCIATES, INC.

$08 / 20 / 93$
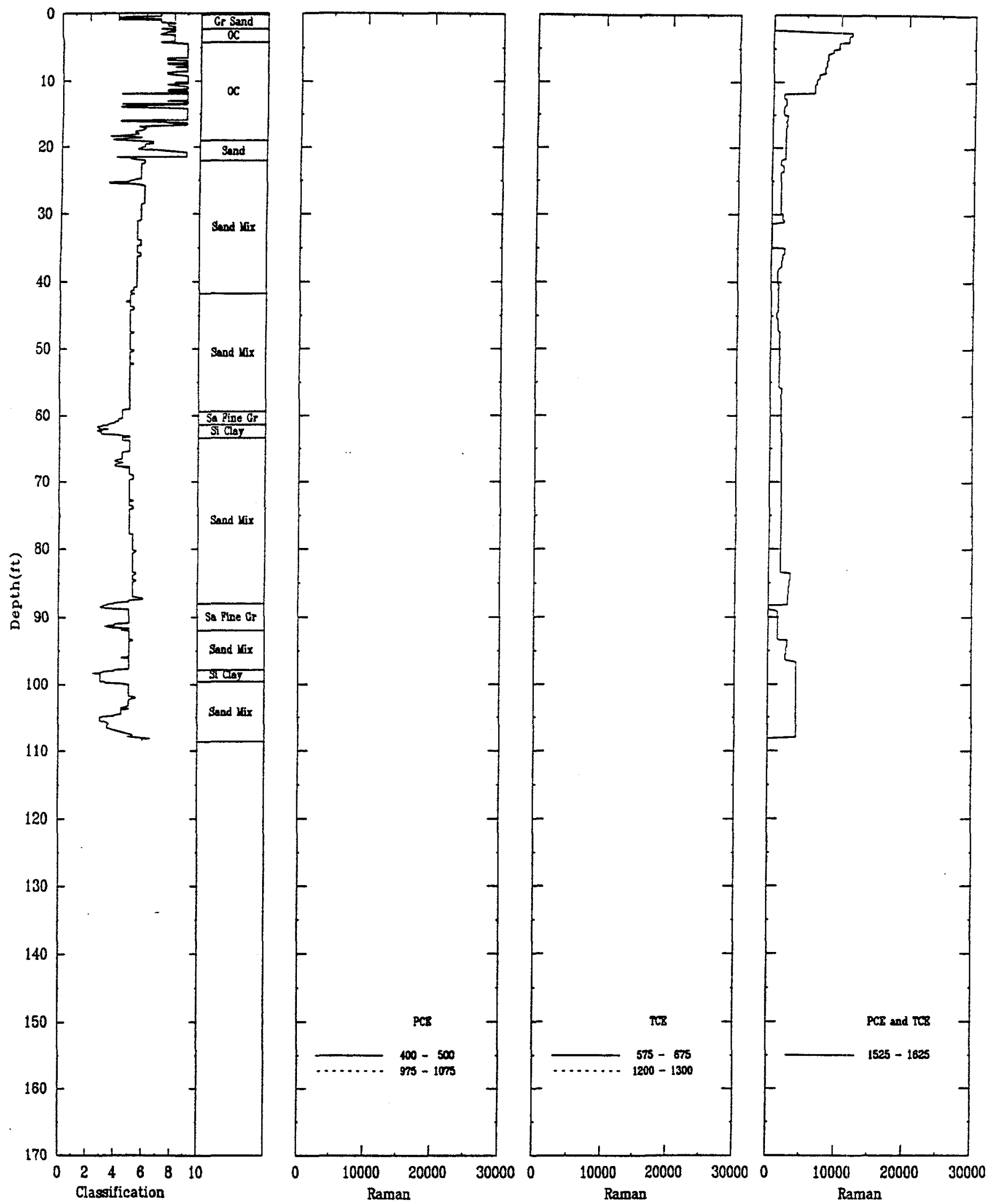

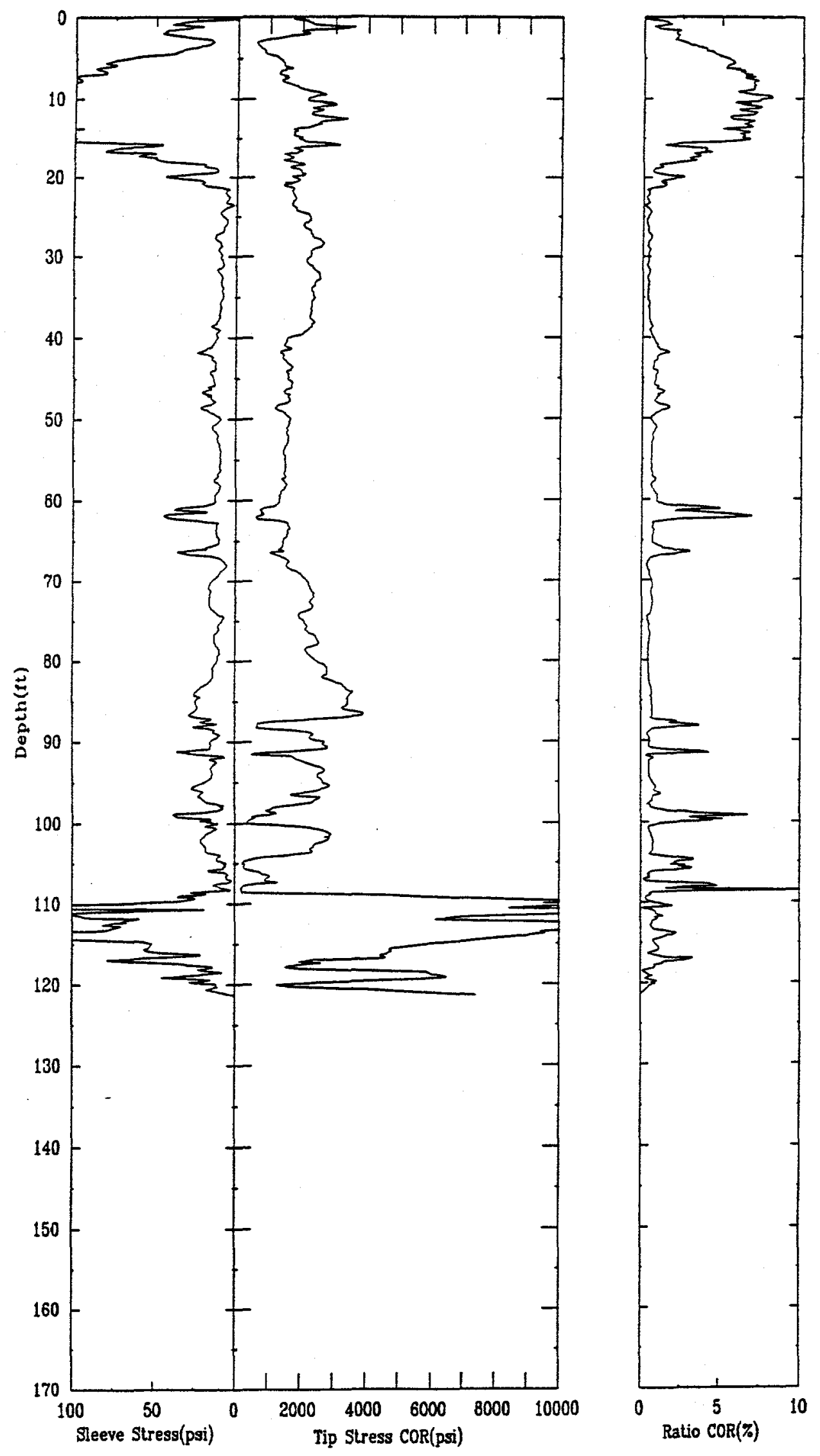

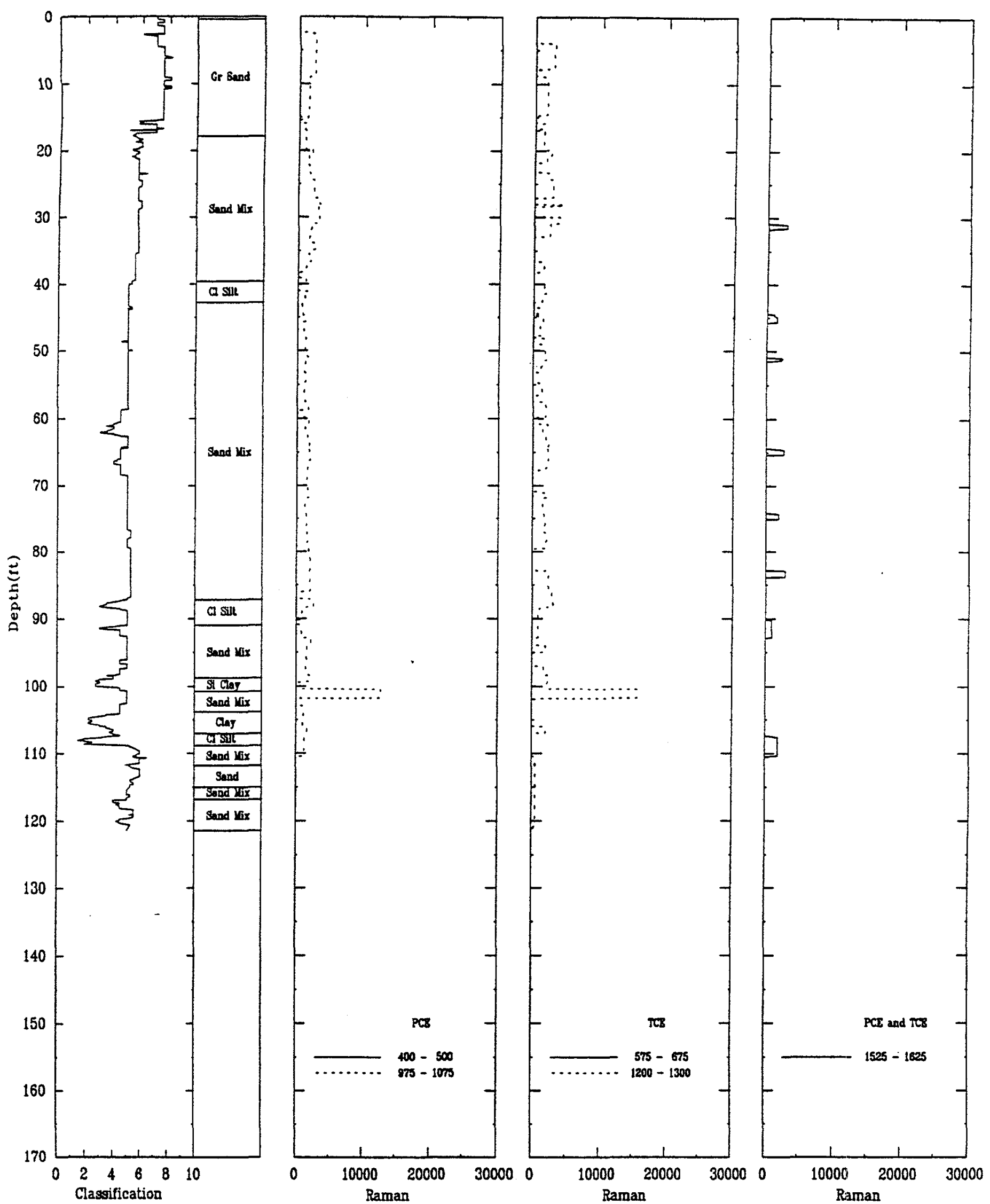

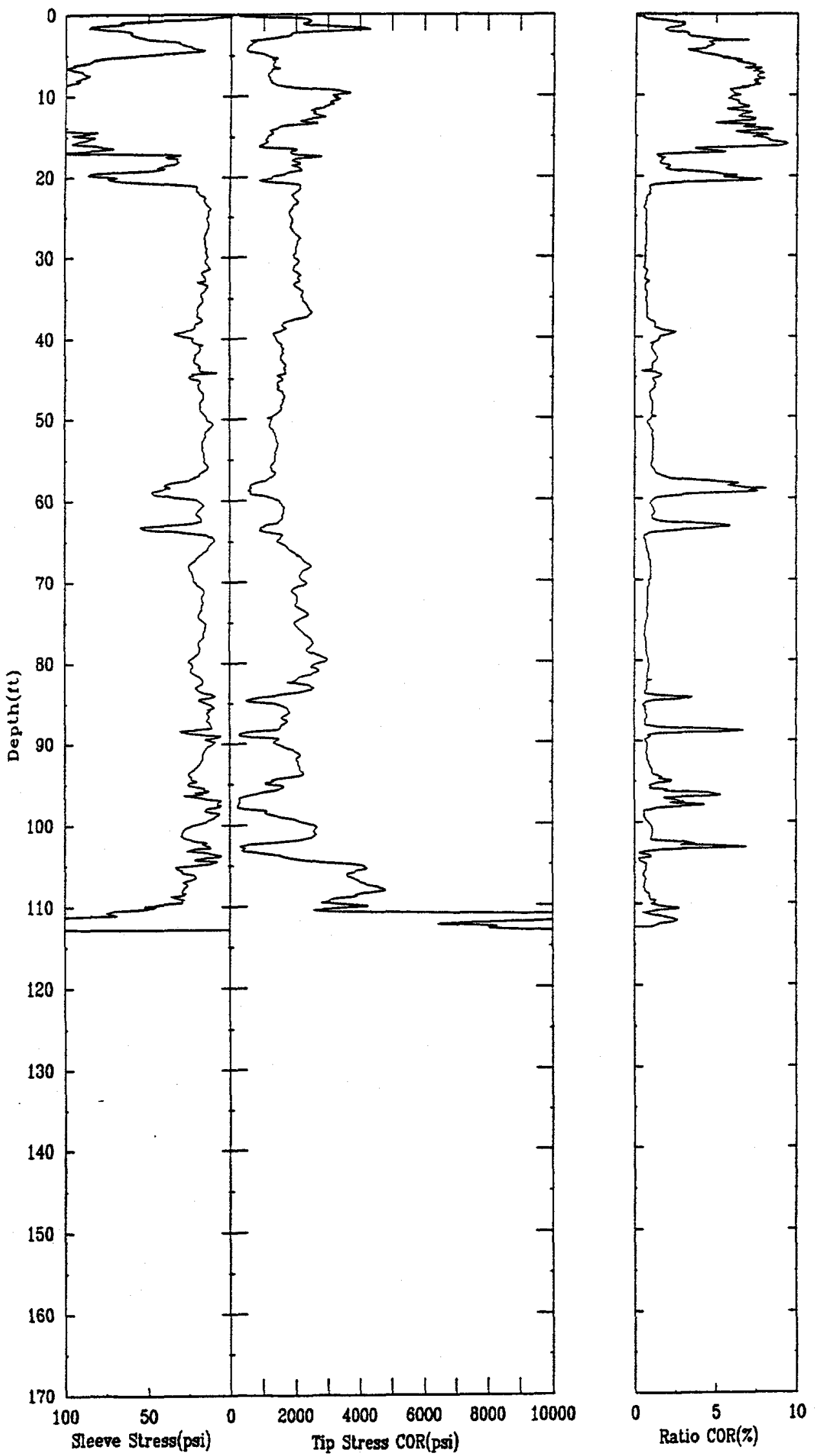

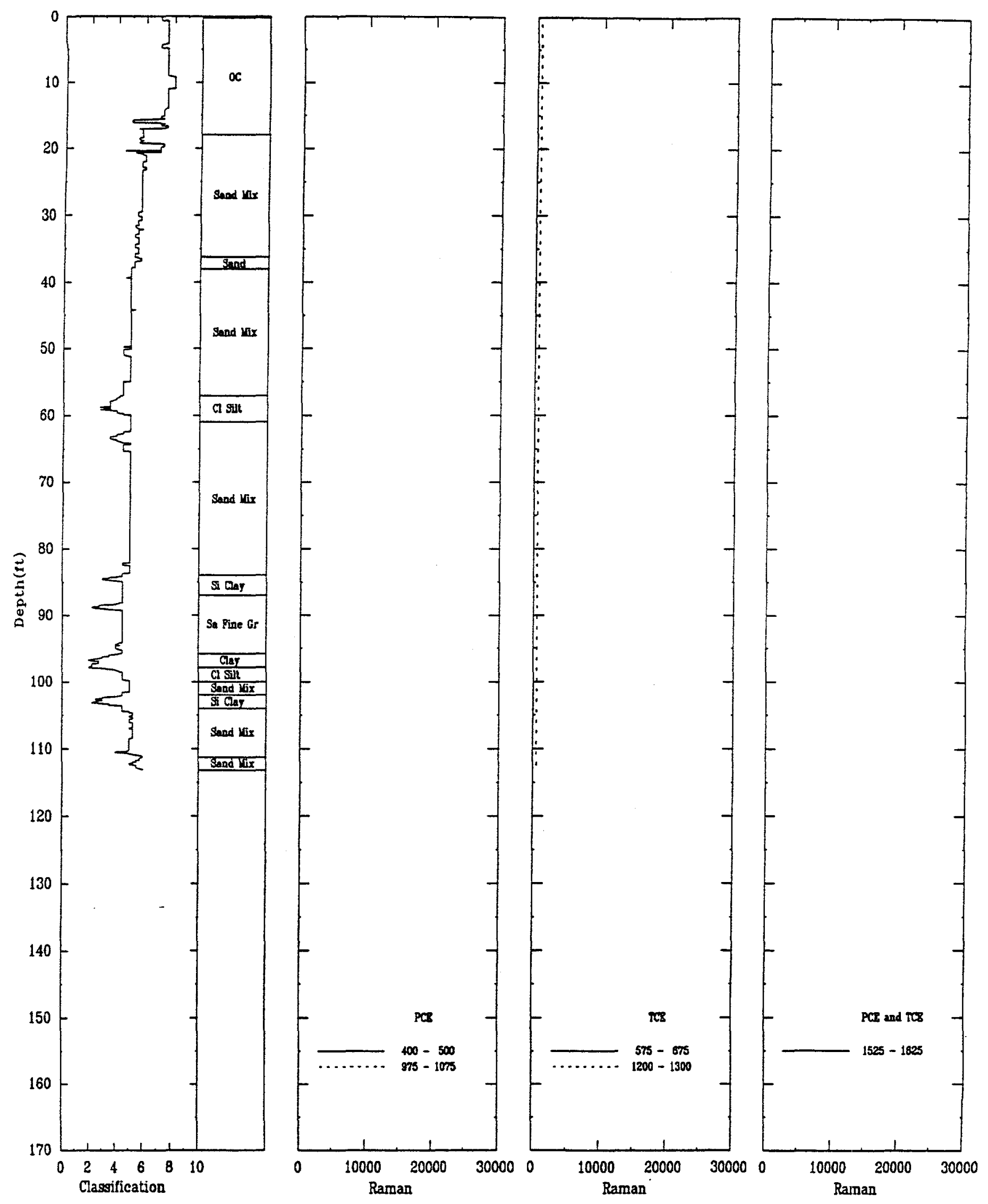


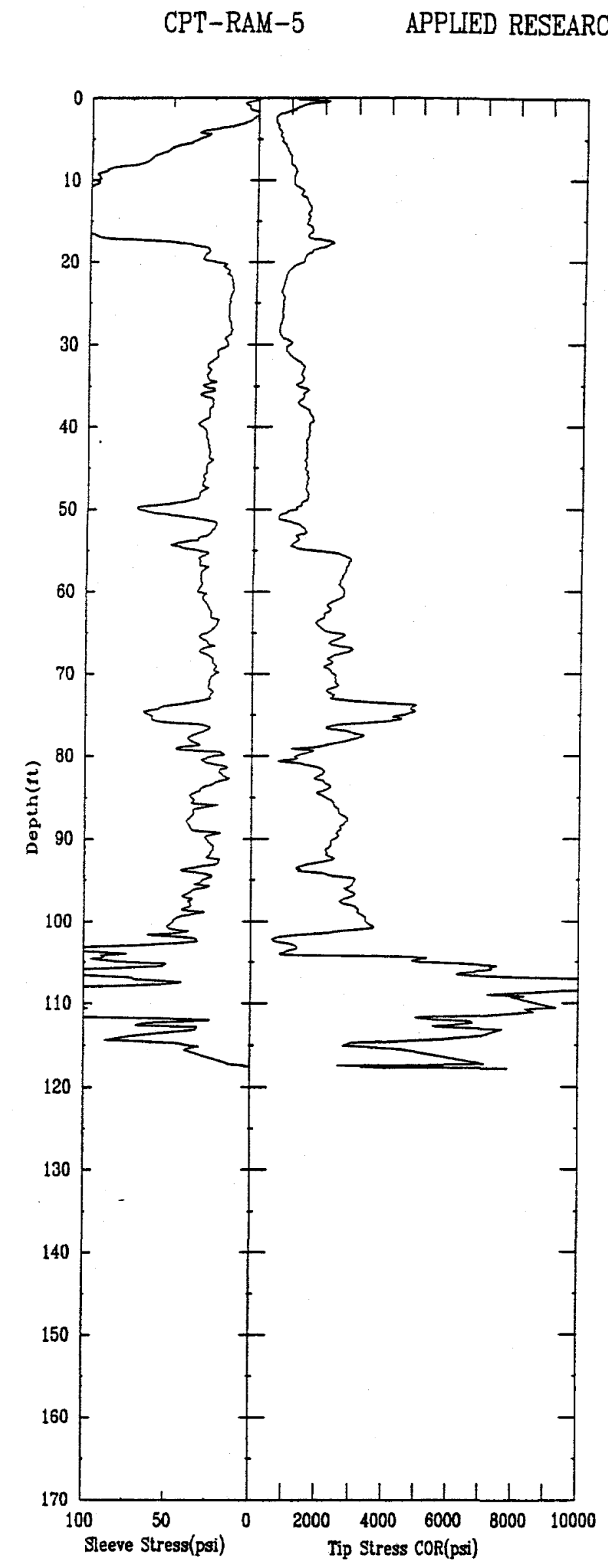

ASSOCIATES, INC.

$08 / 23 / 93$

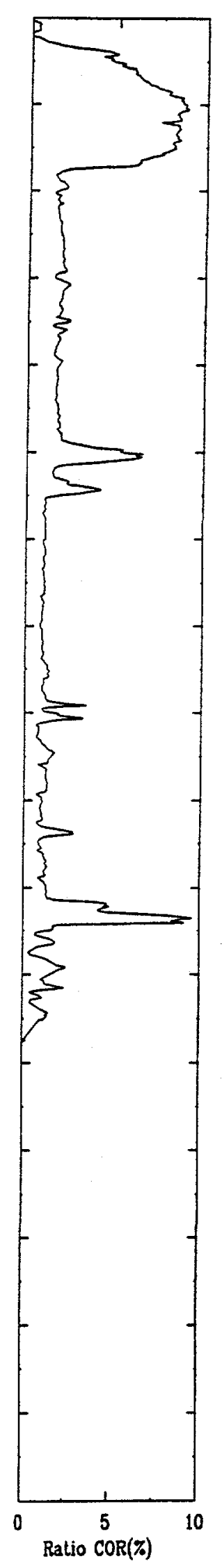


CPT-RAM-5

APPLIED RESEARCH ASSOCIATES, INC.

$08 / 23 / 93$
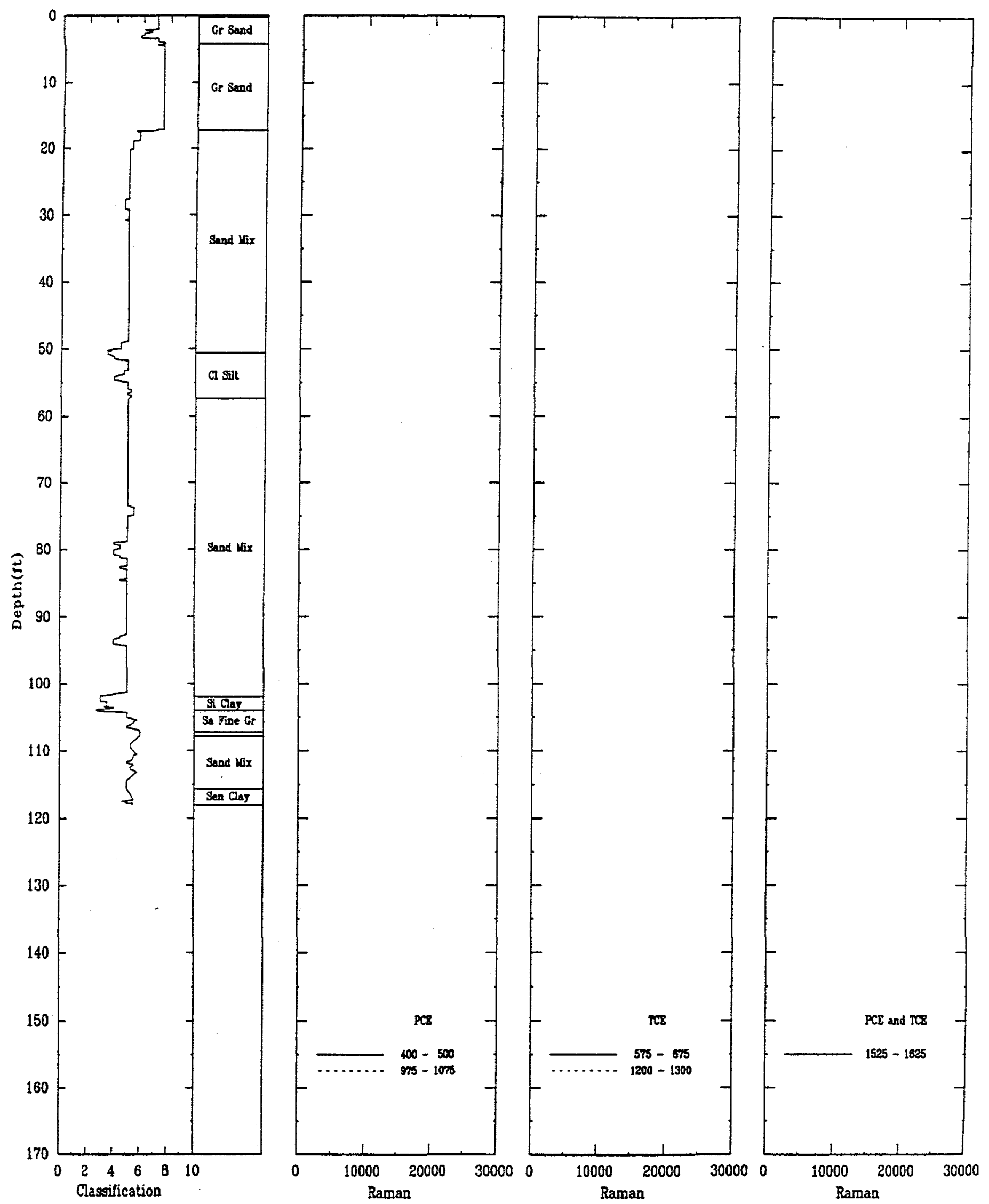

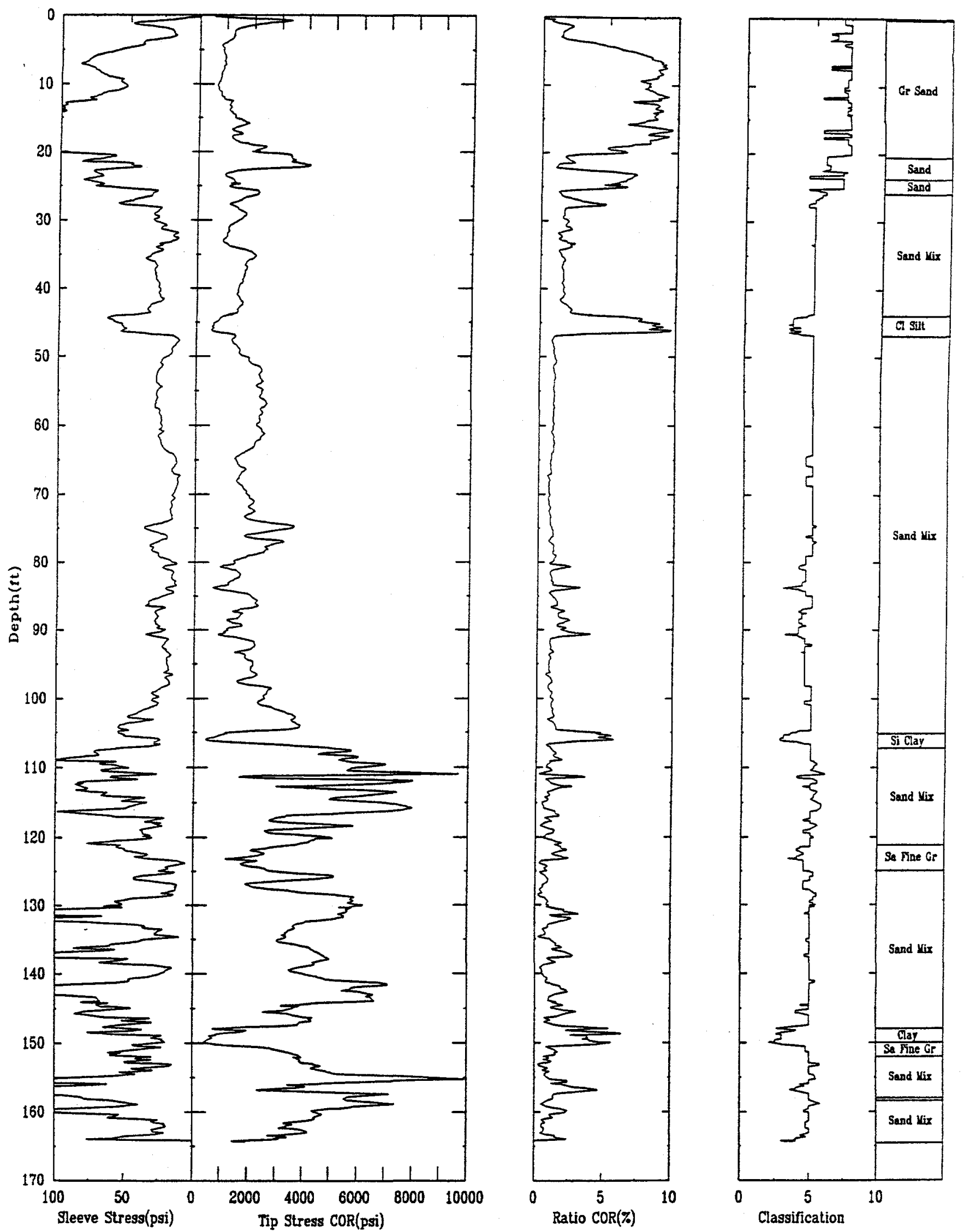

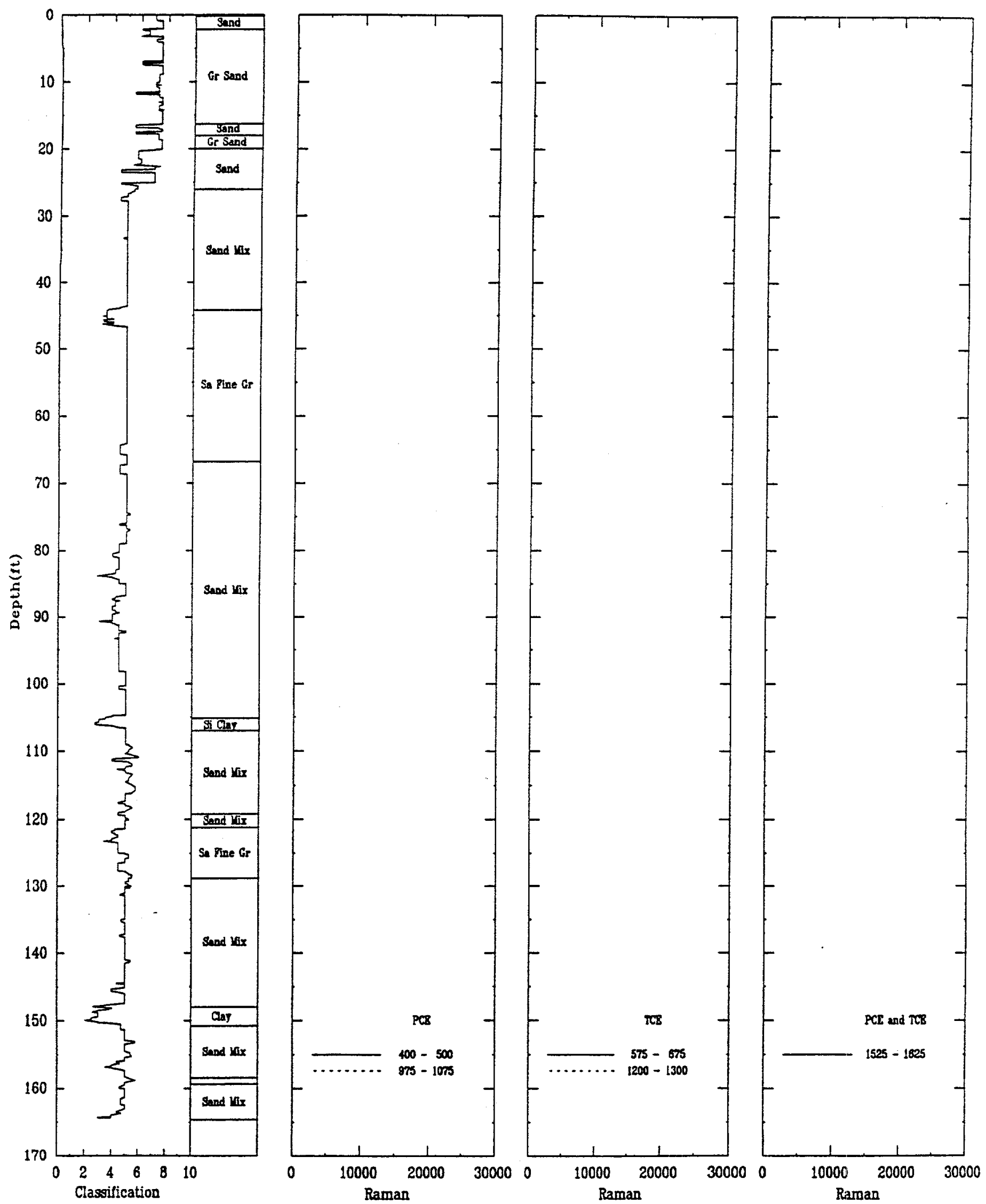

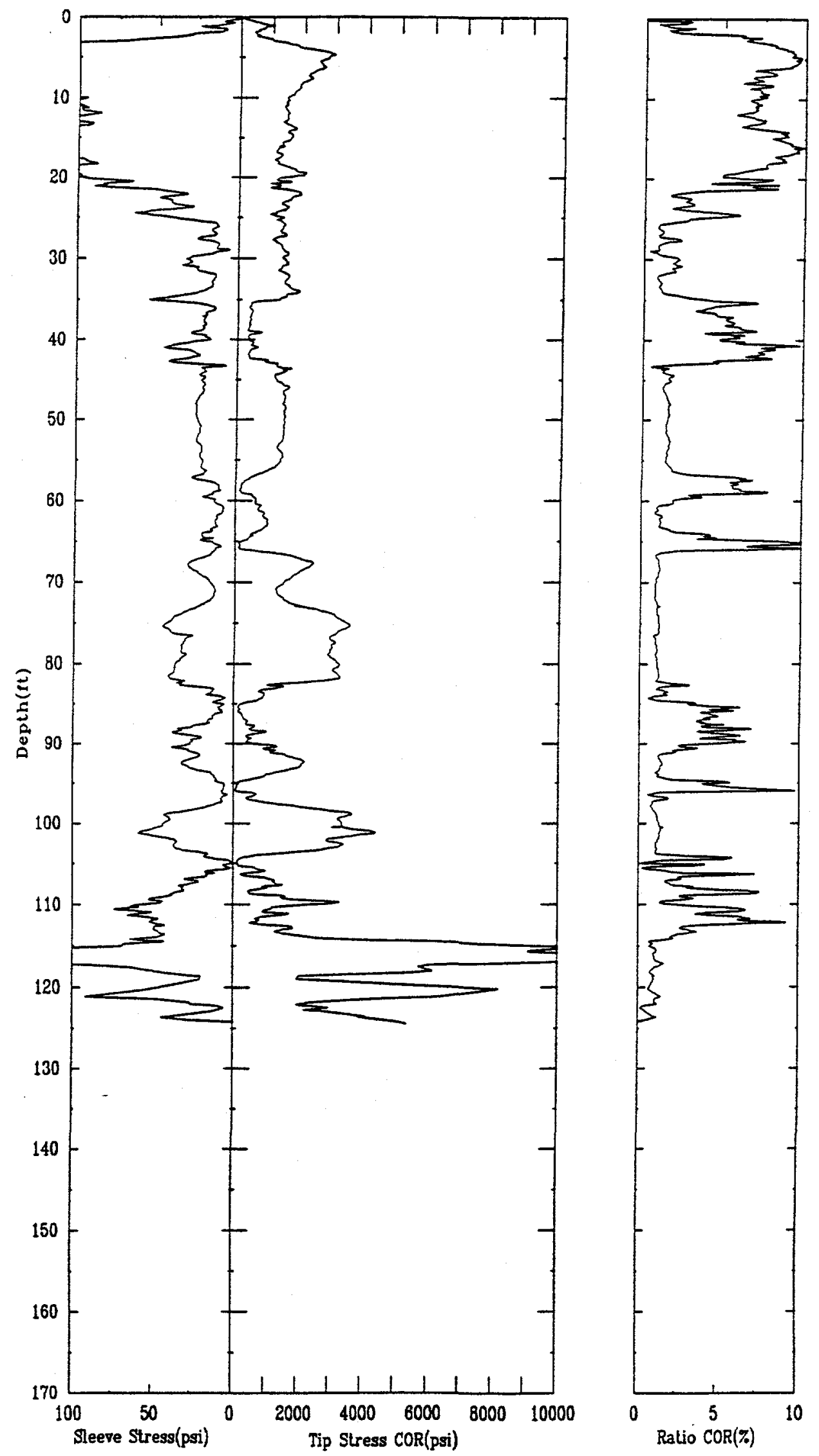

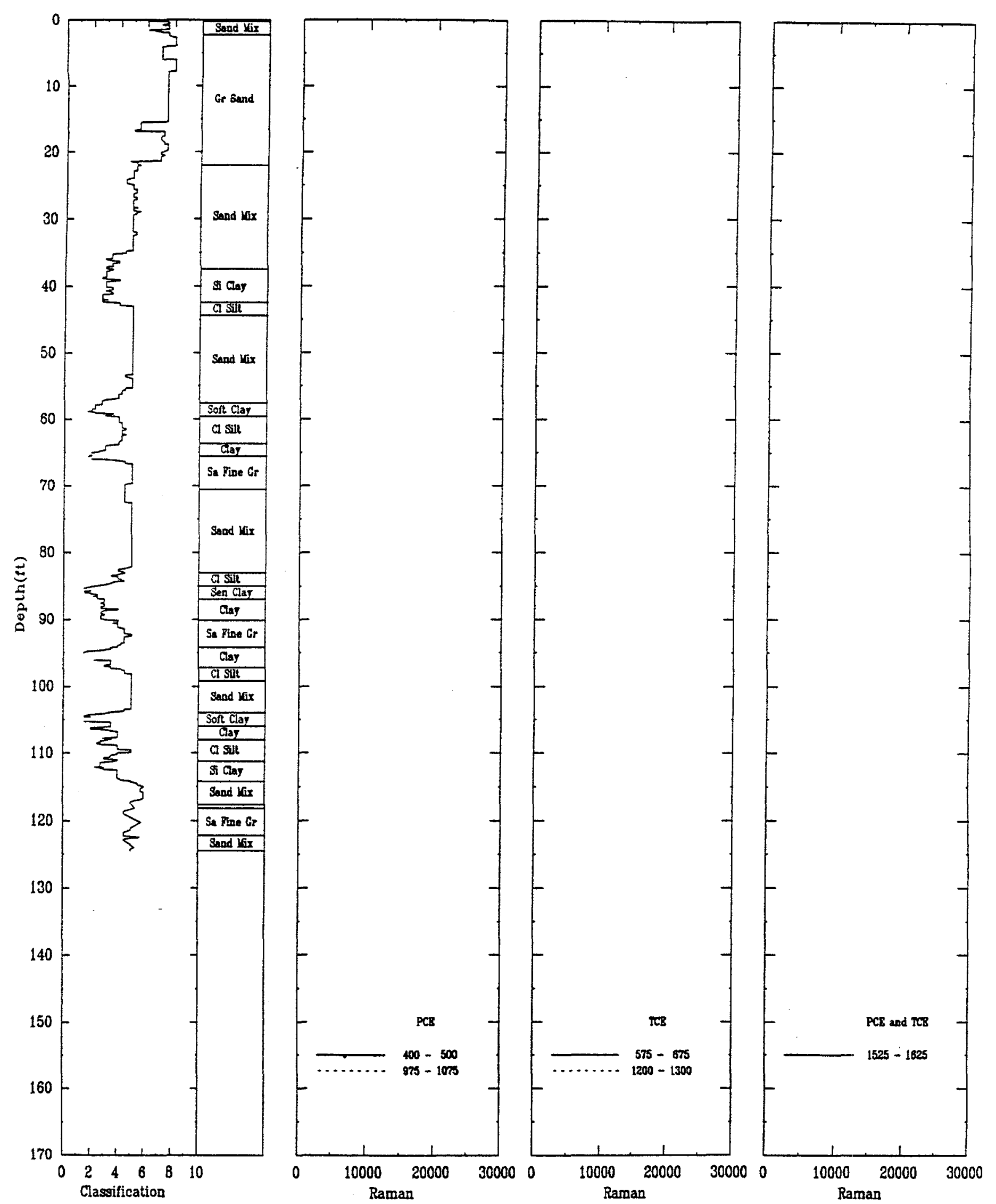
CPT-RAM-8
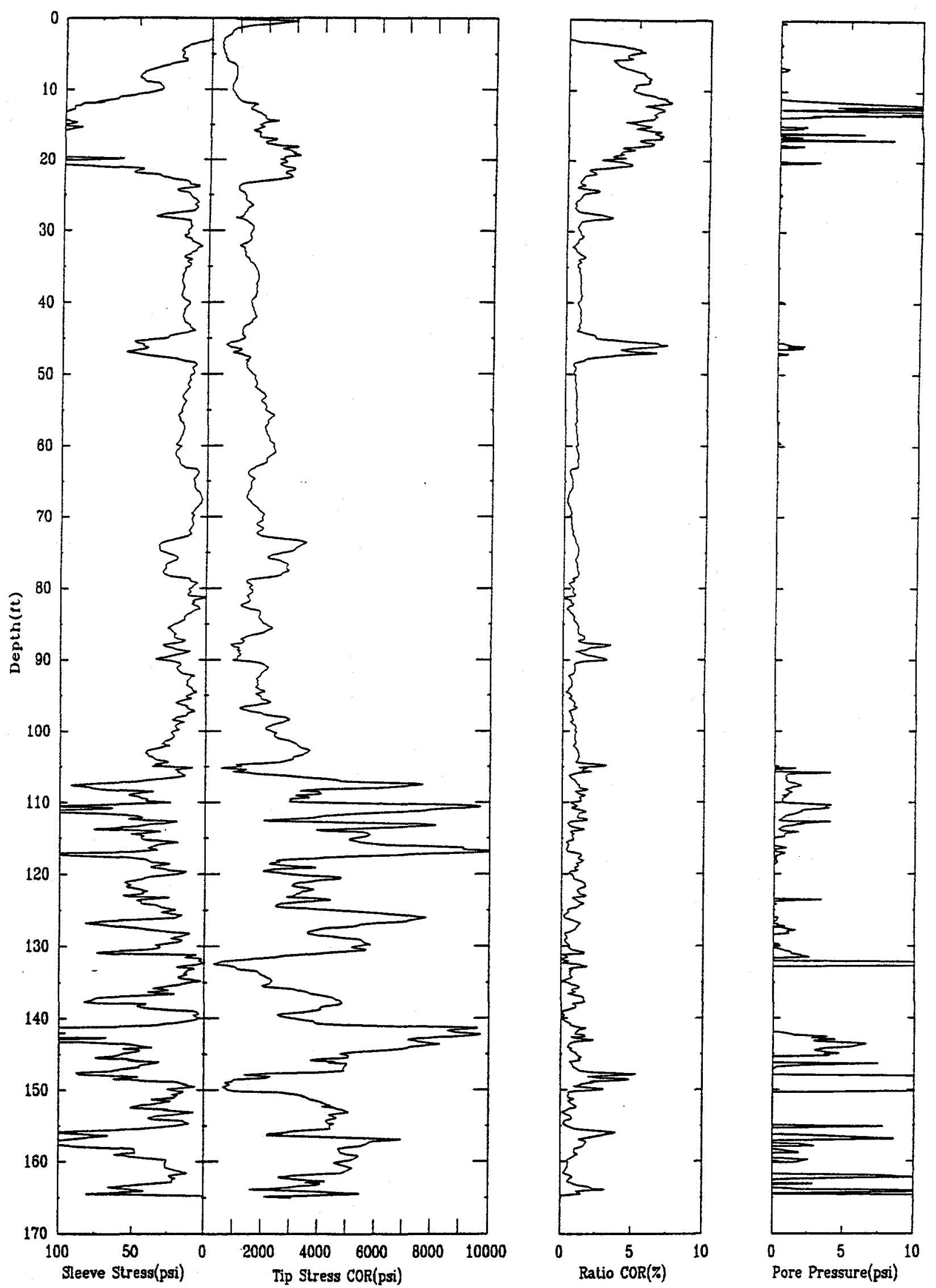

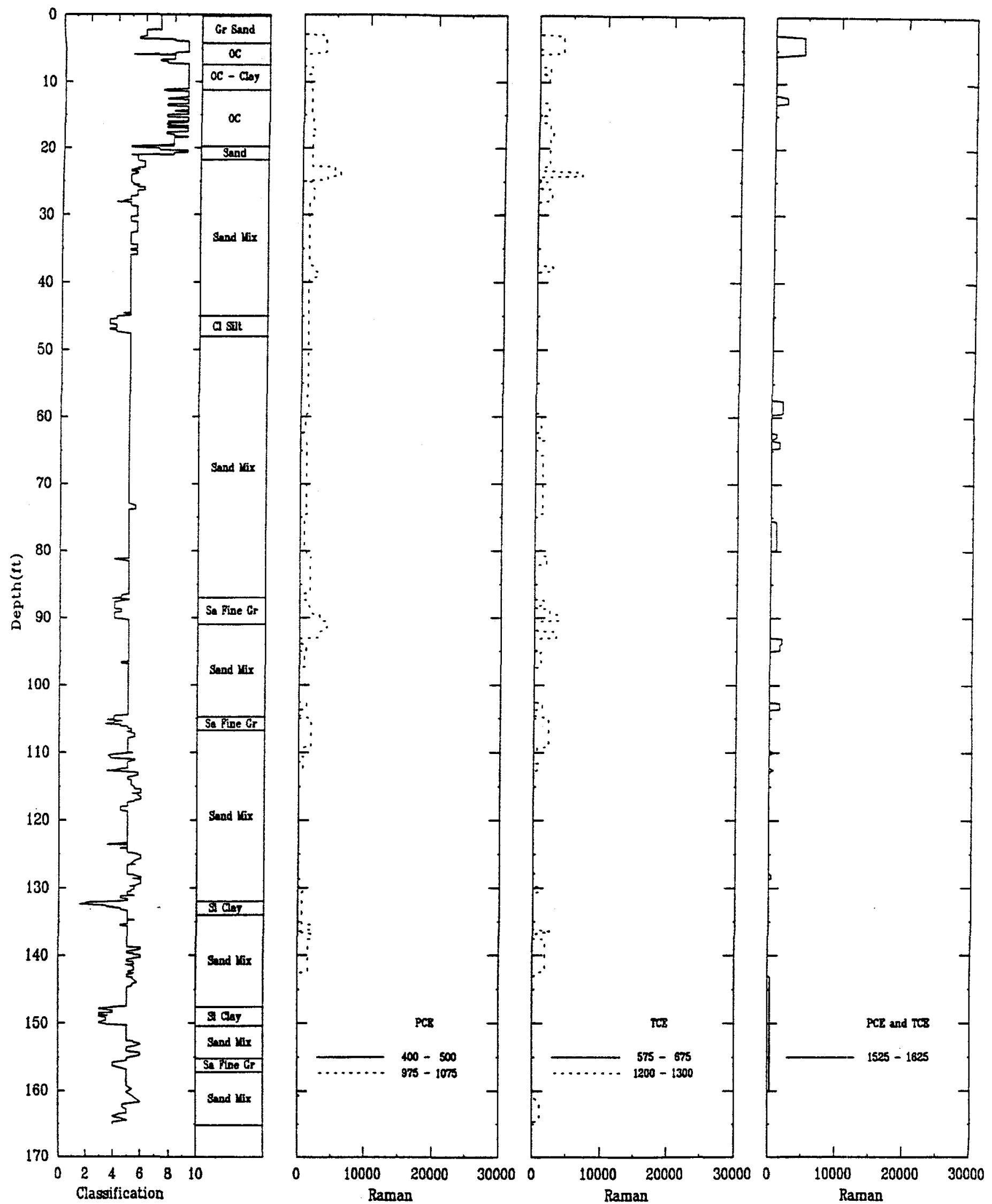

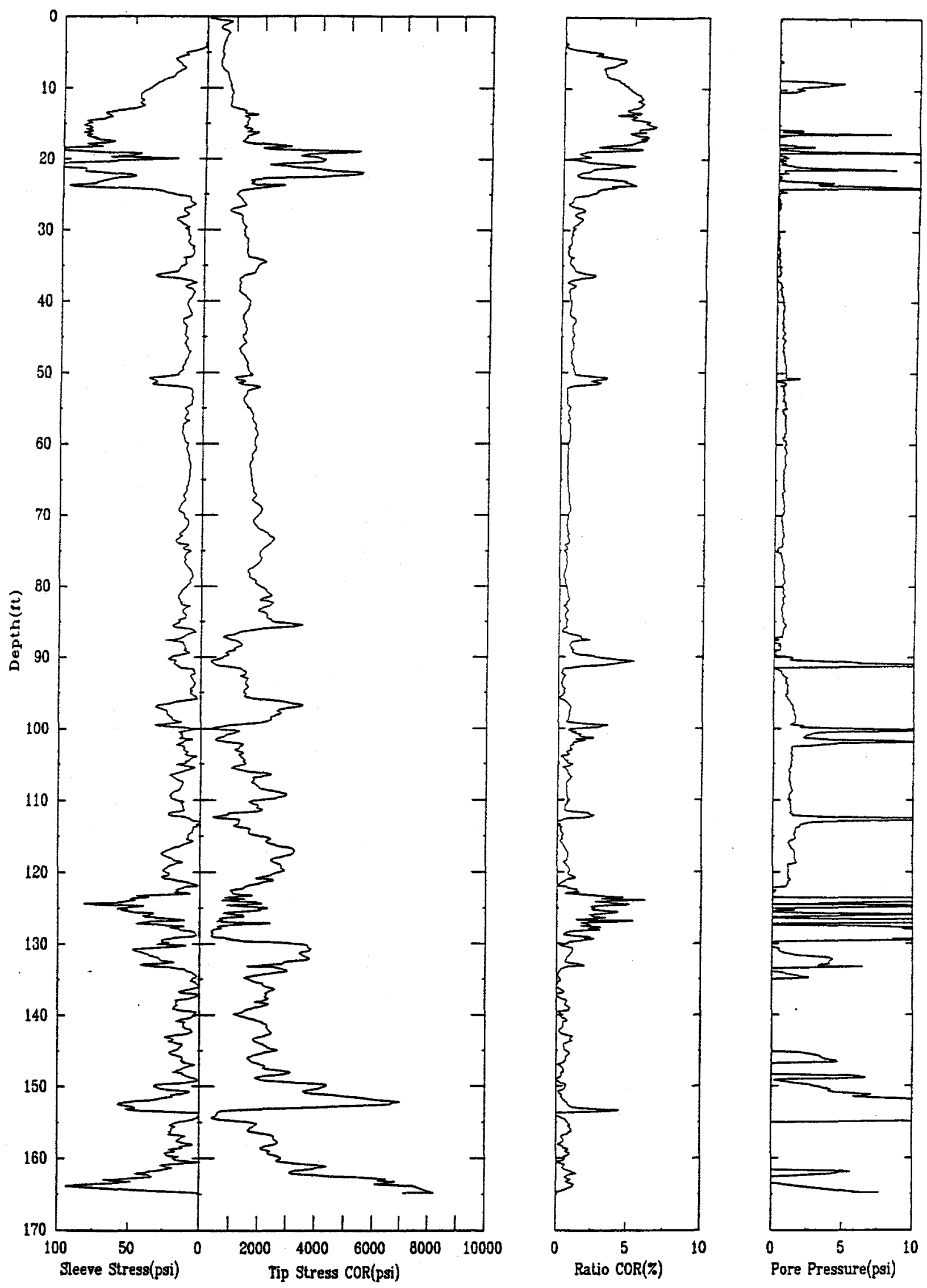


\section{CPT-RAM-9}

APPLIED RESEARCH ASSOCIATES, INC.

$08 / 24 / 93$
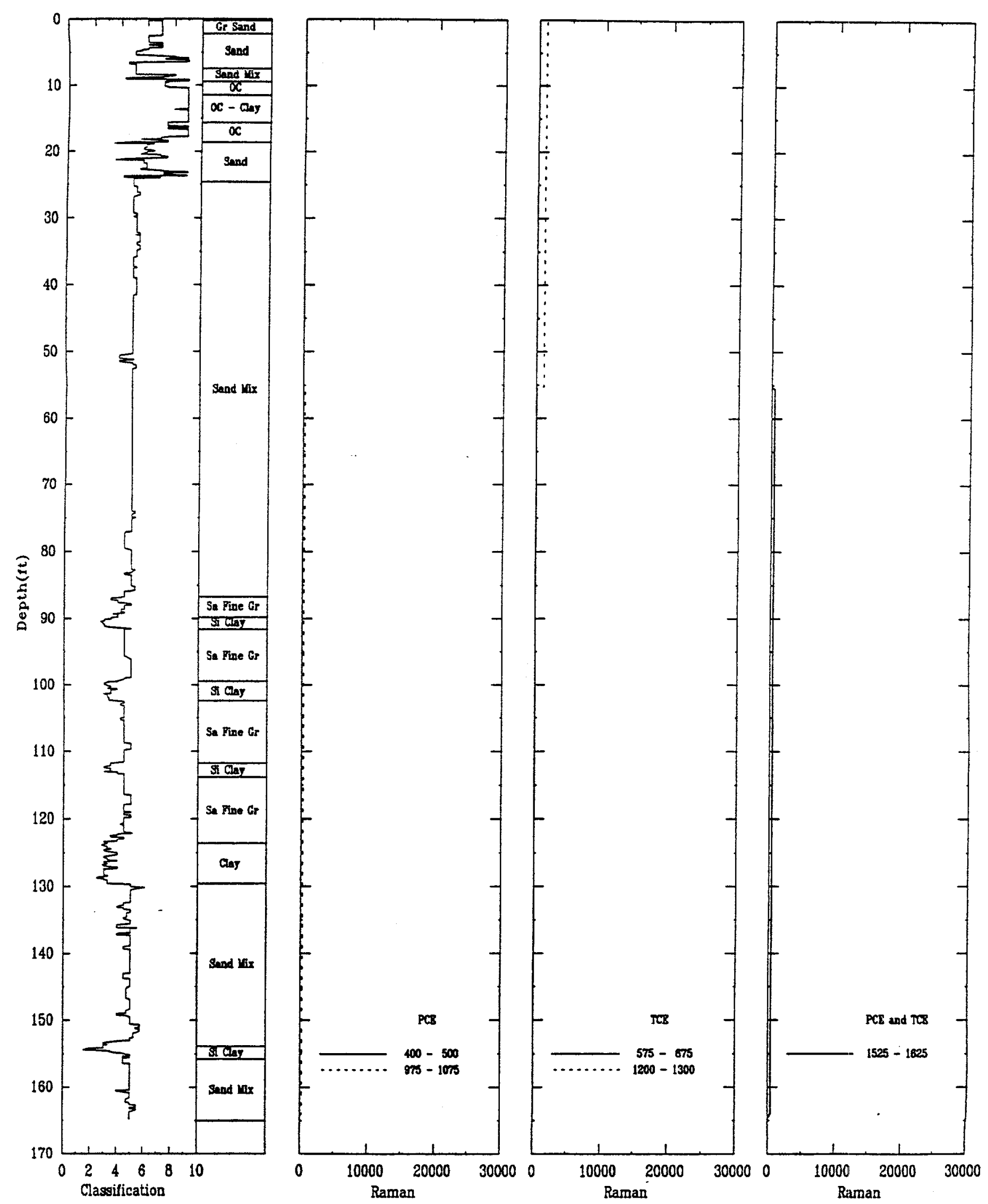

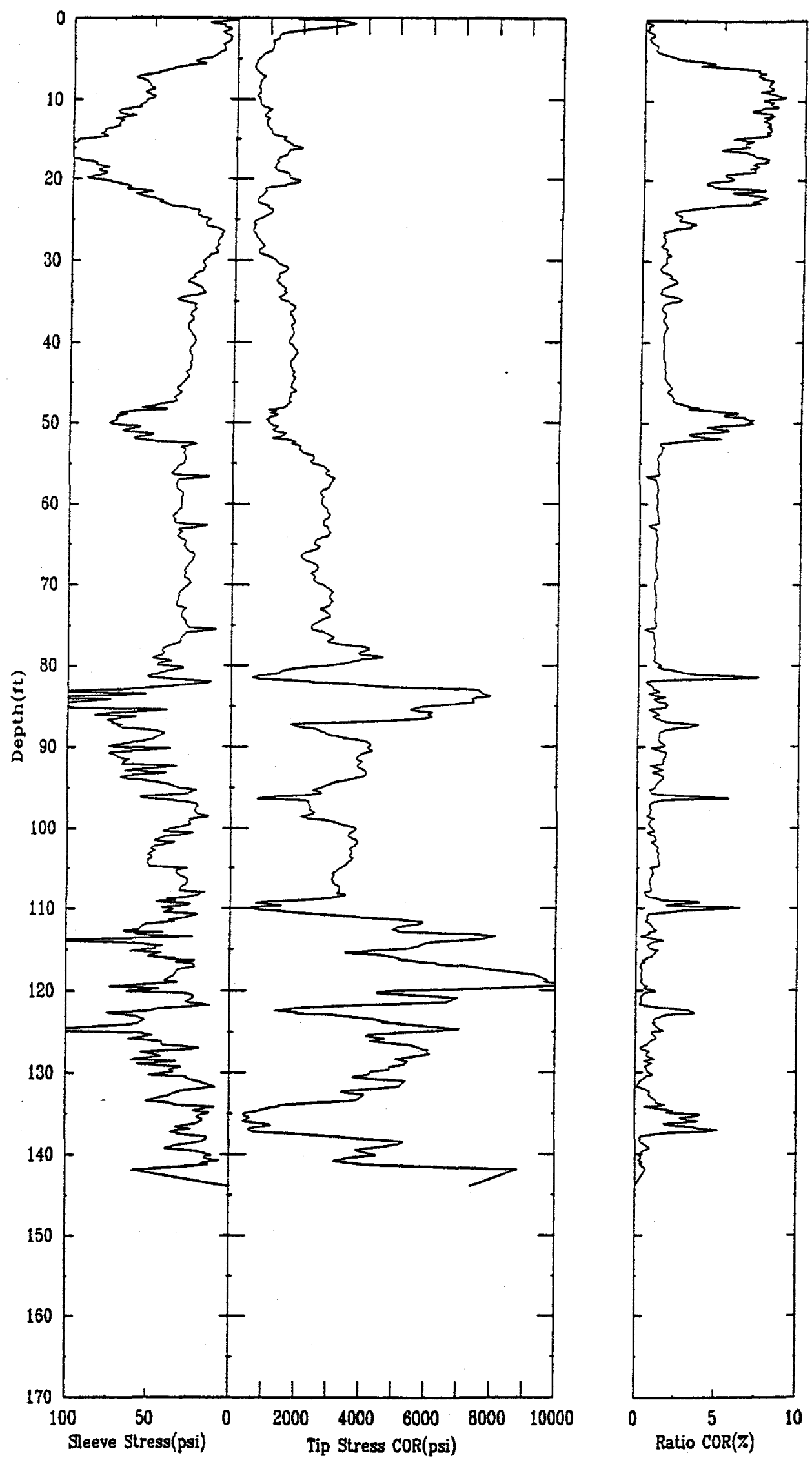

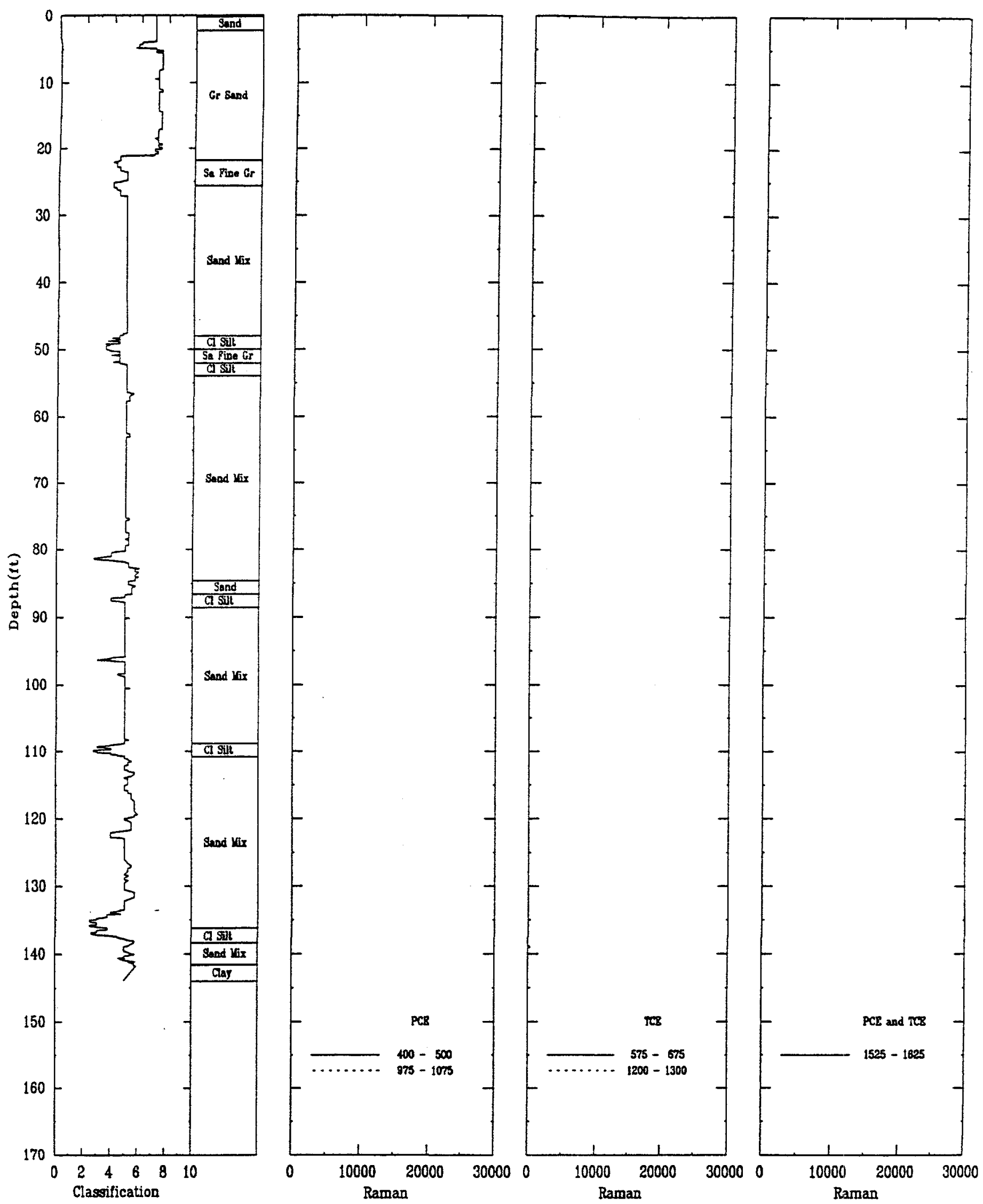

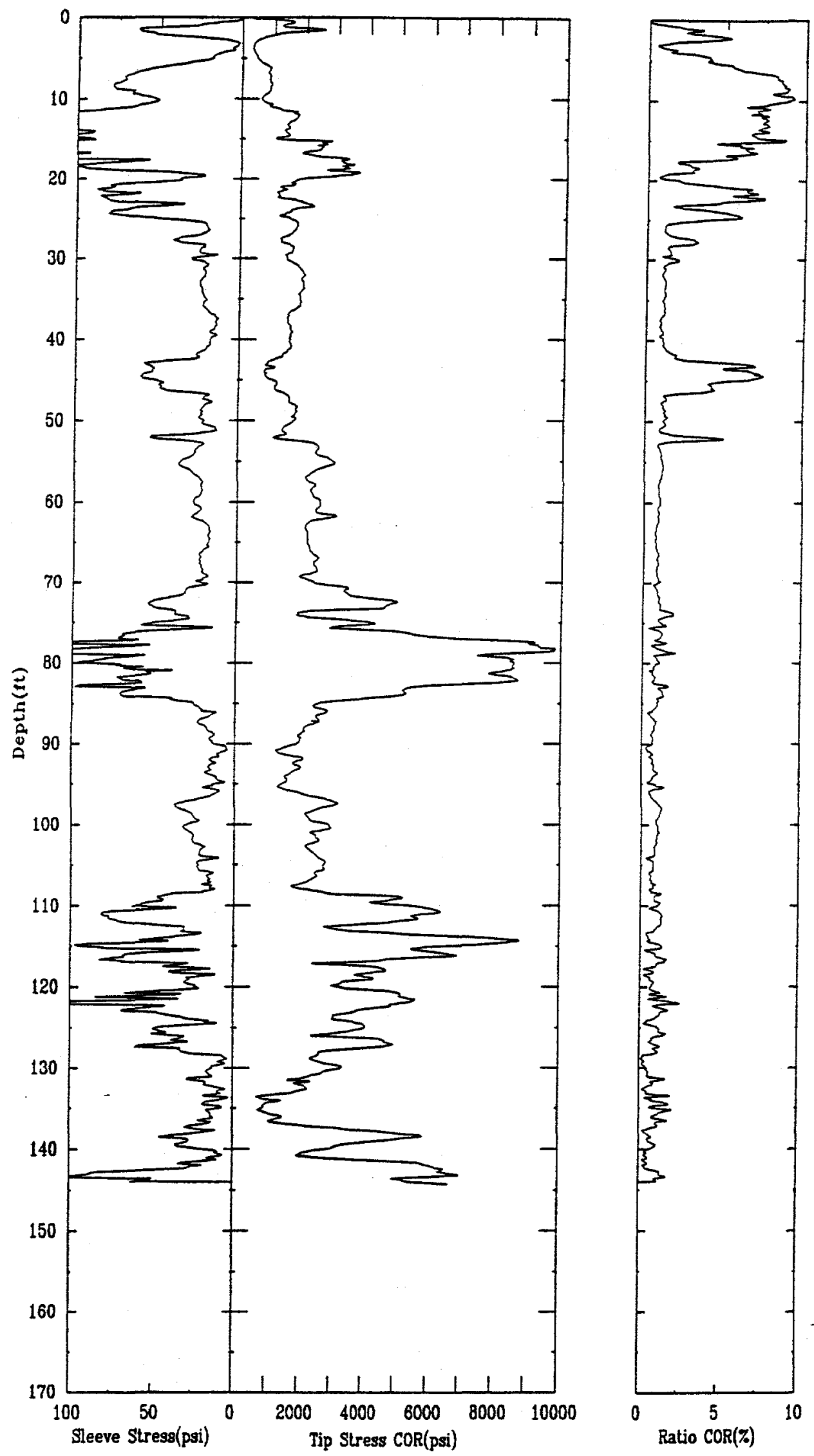

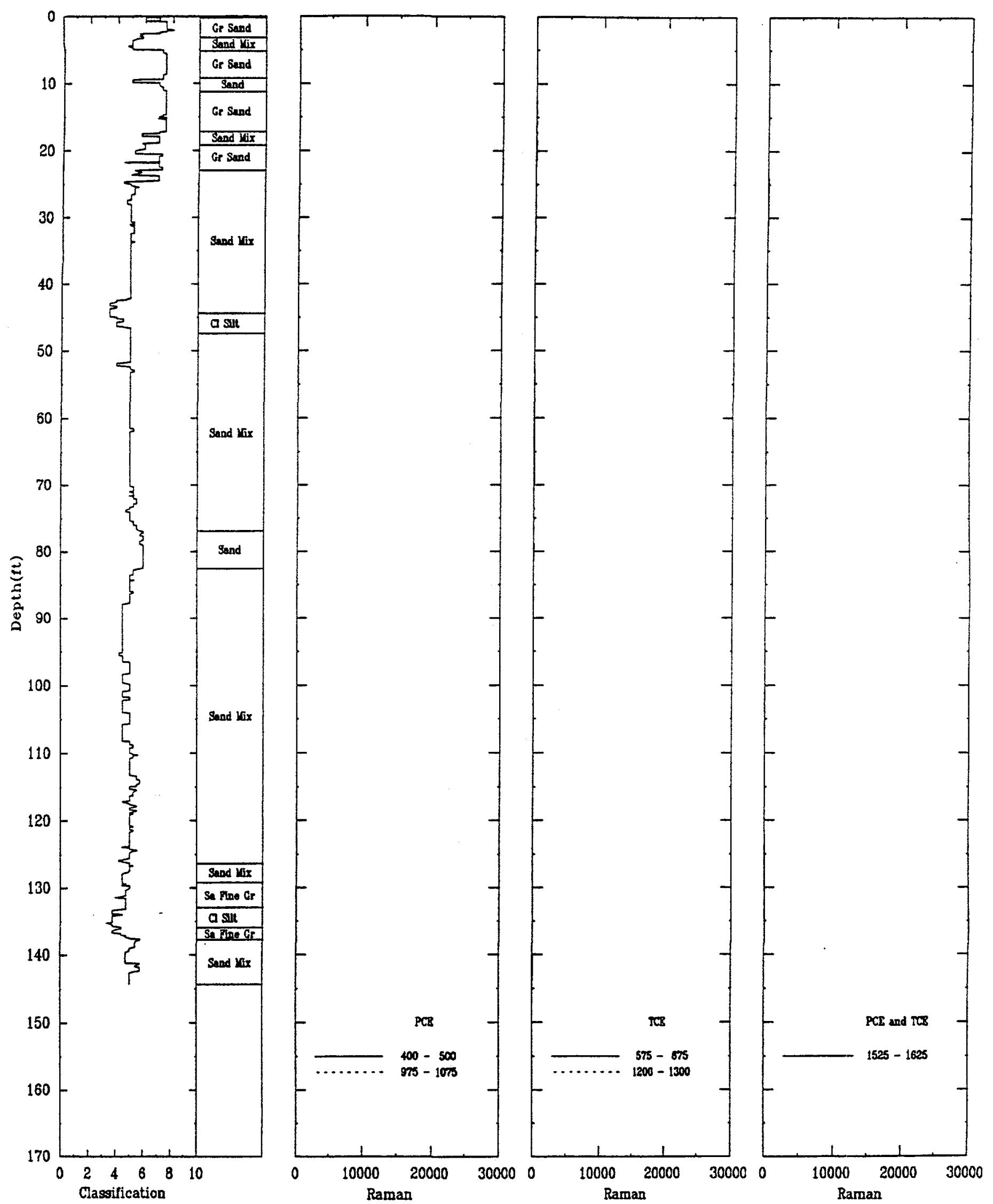

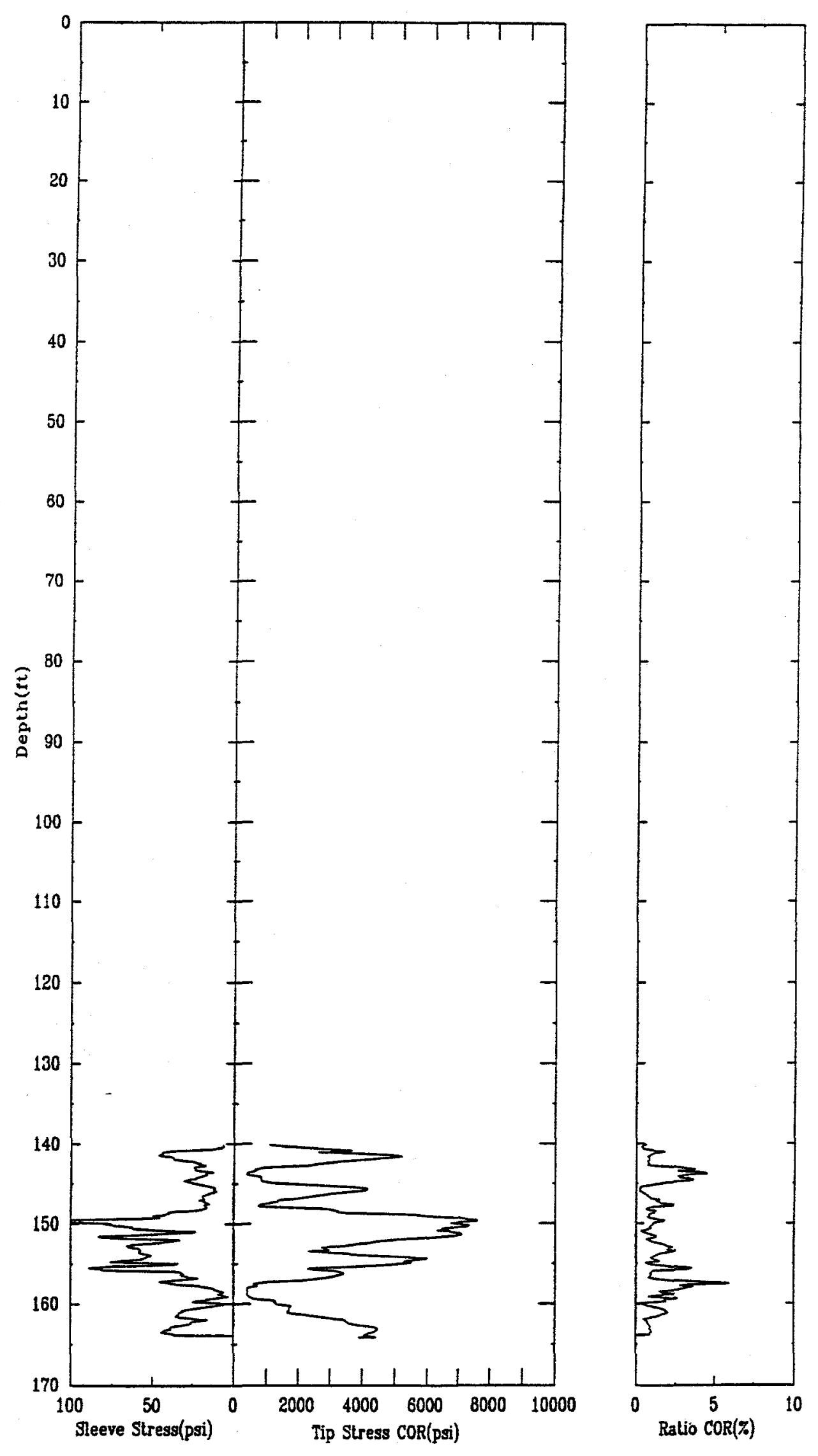

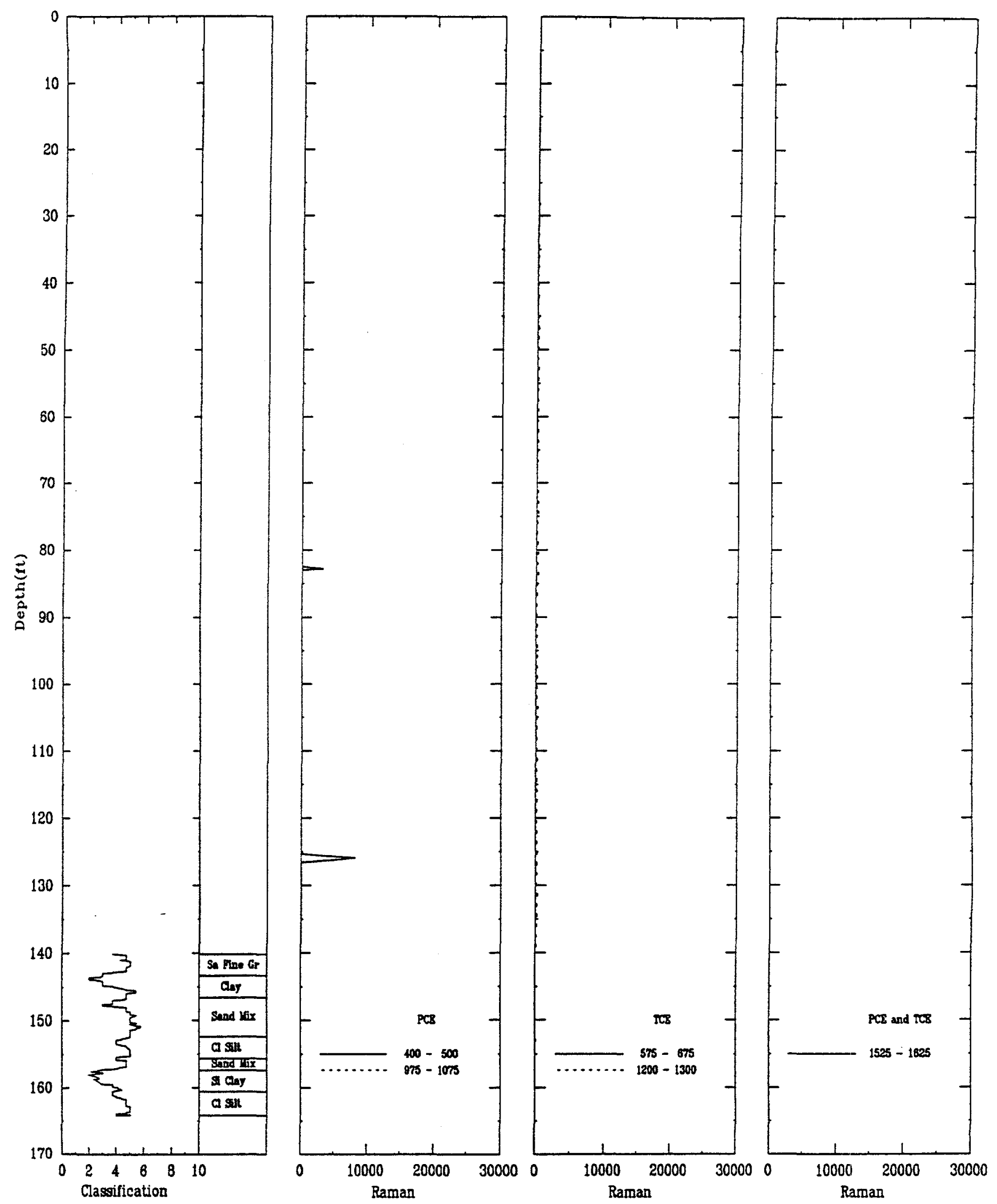

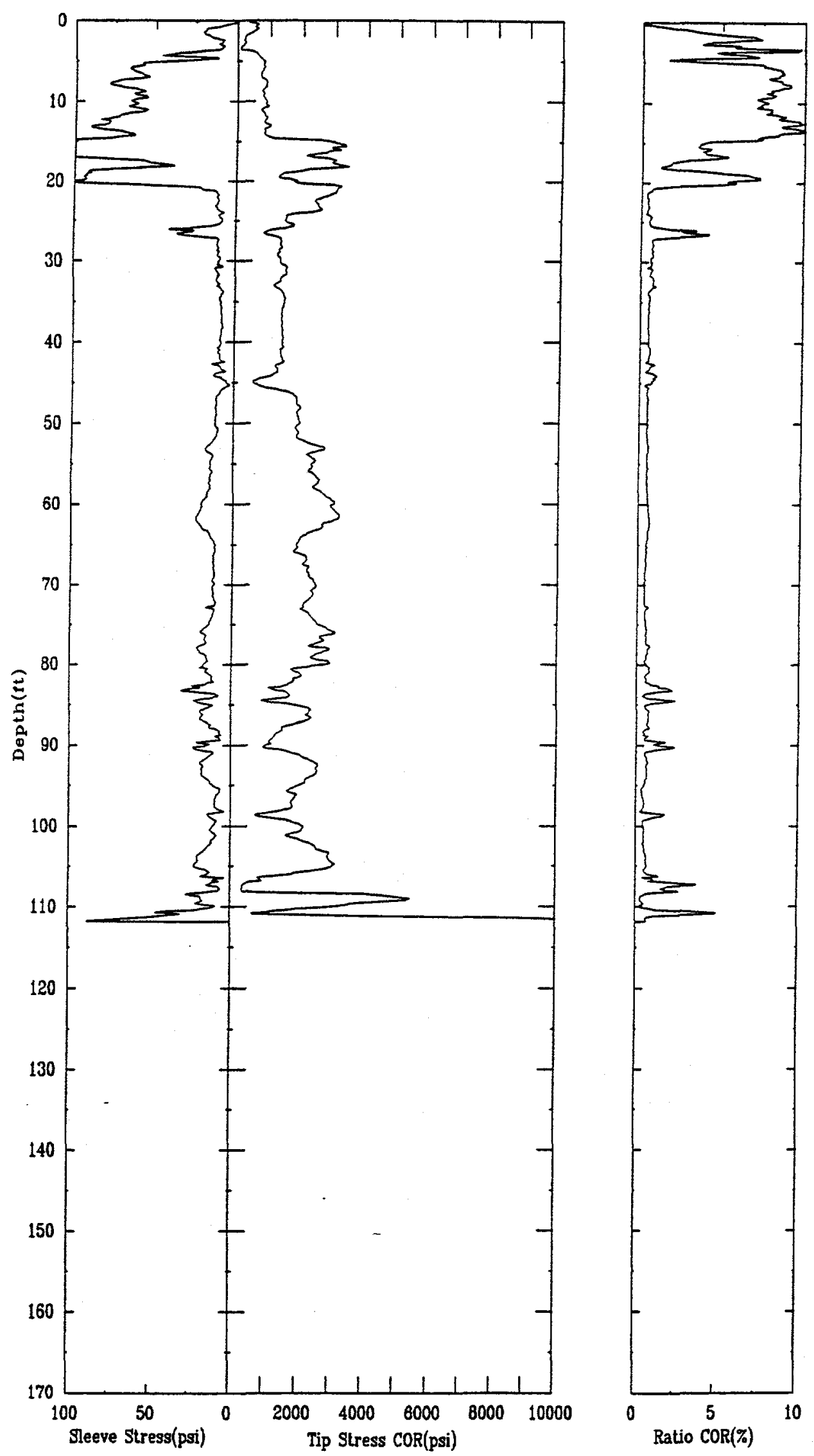

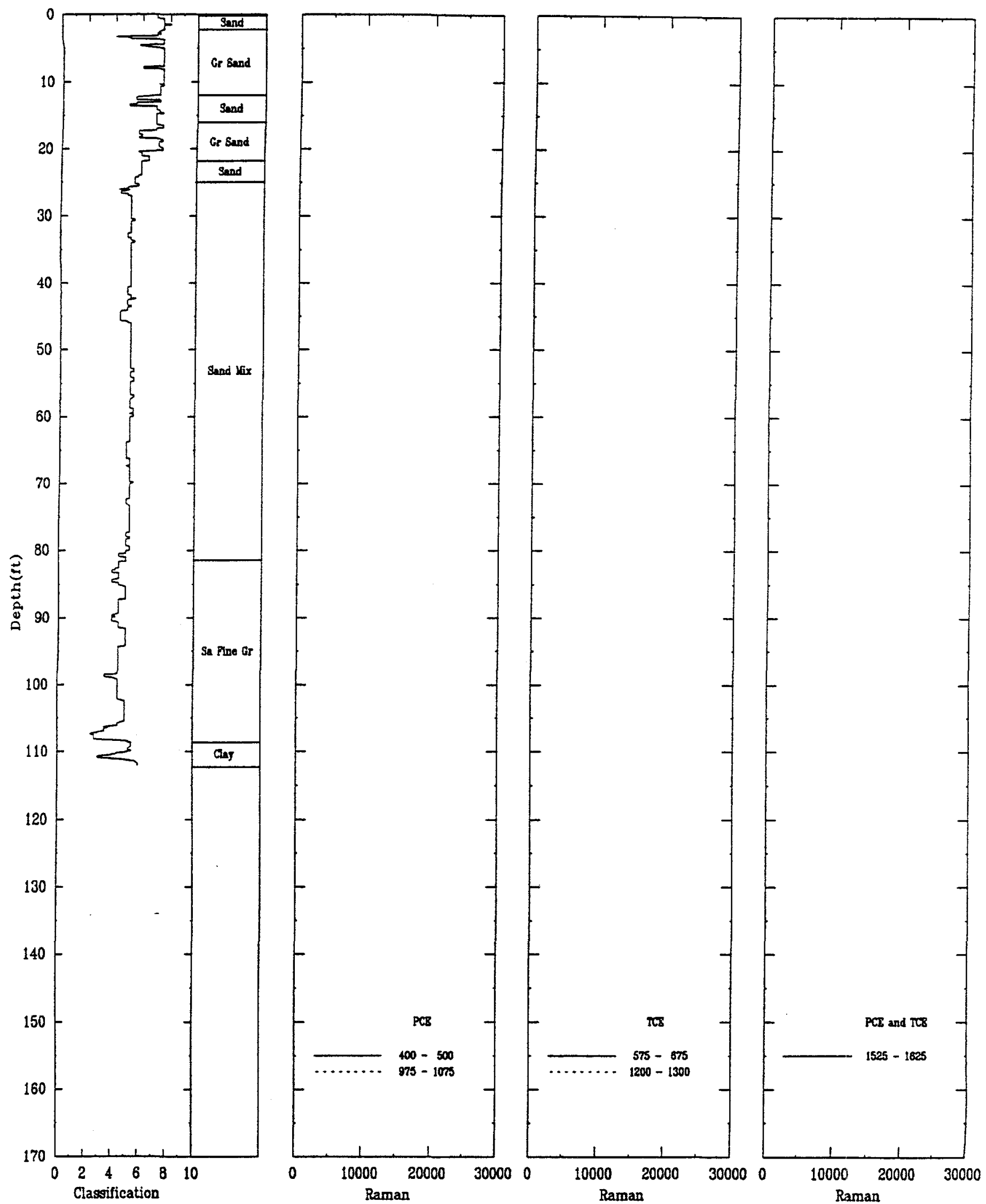

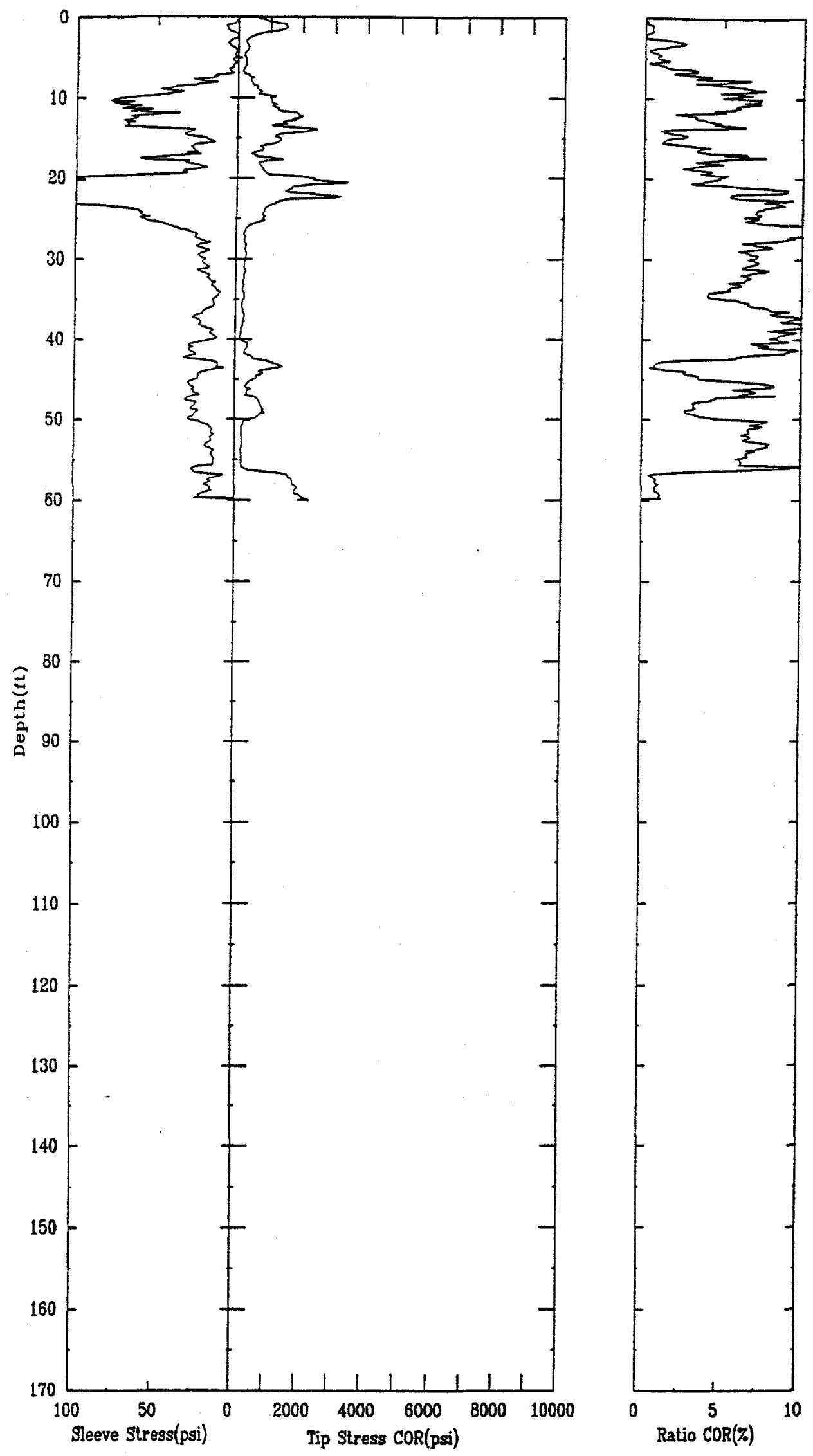

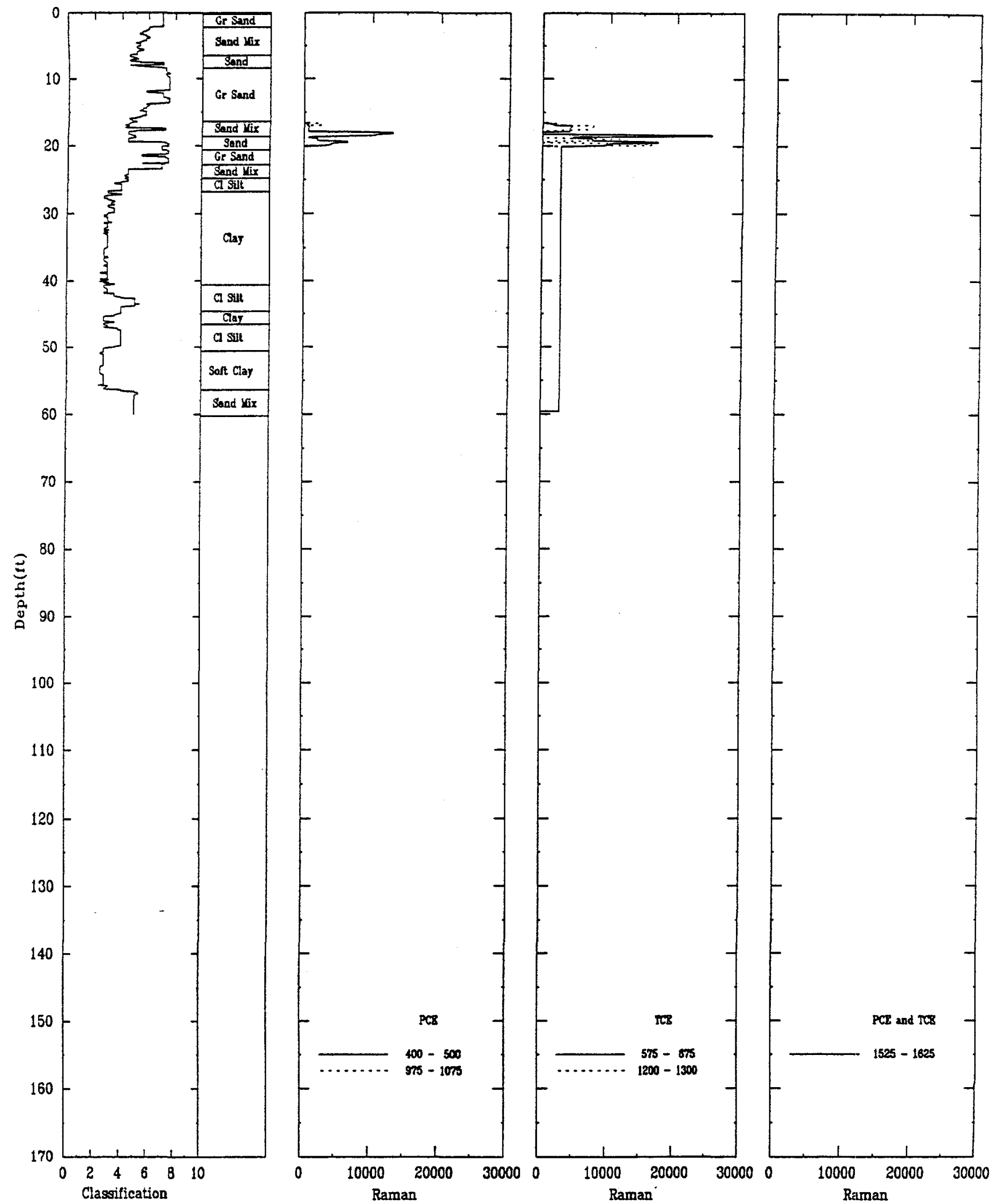

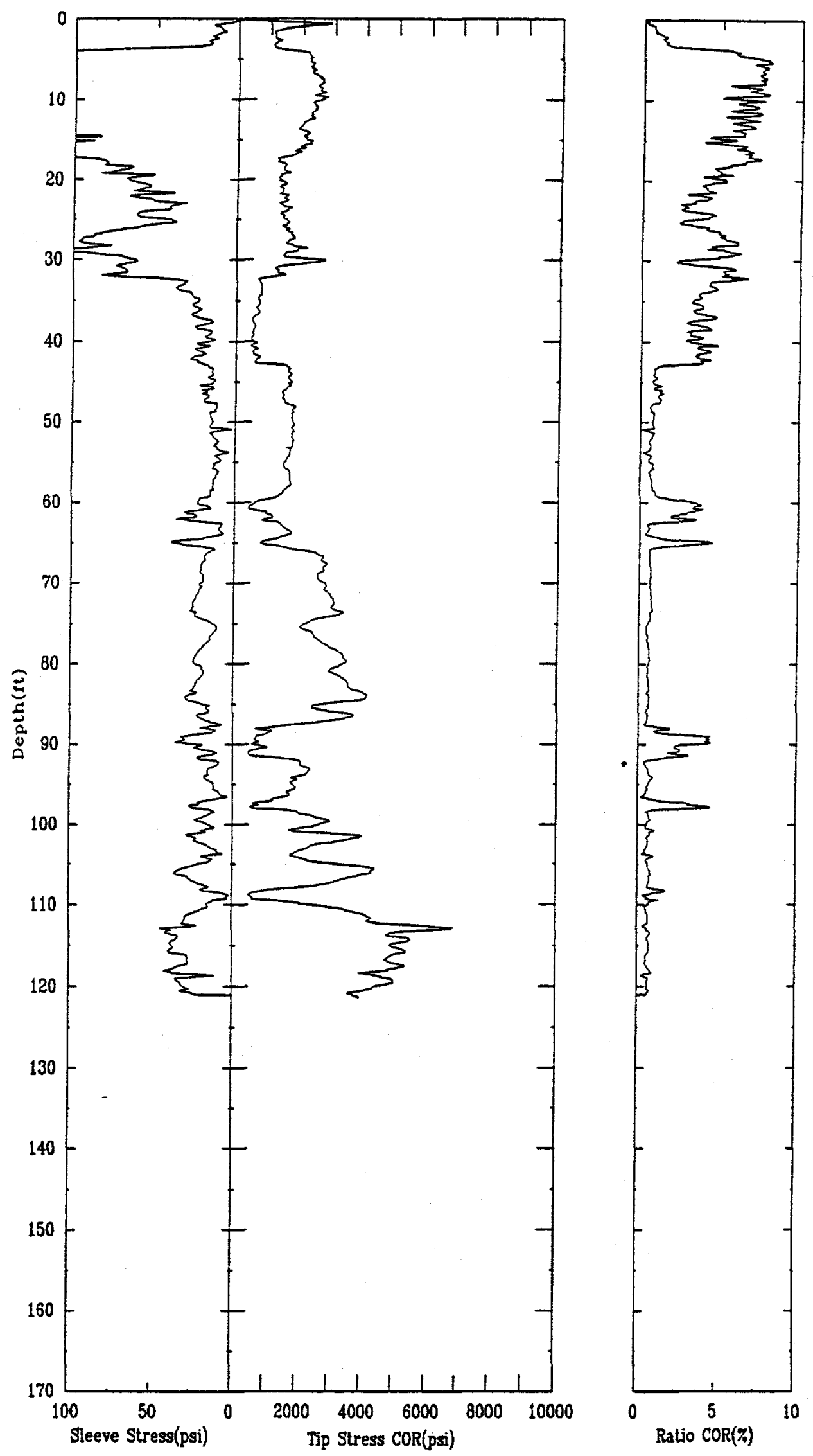

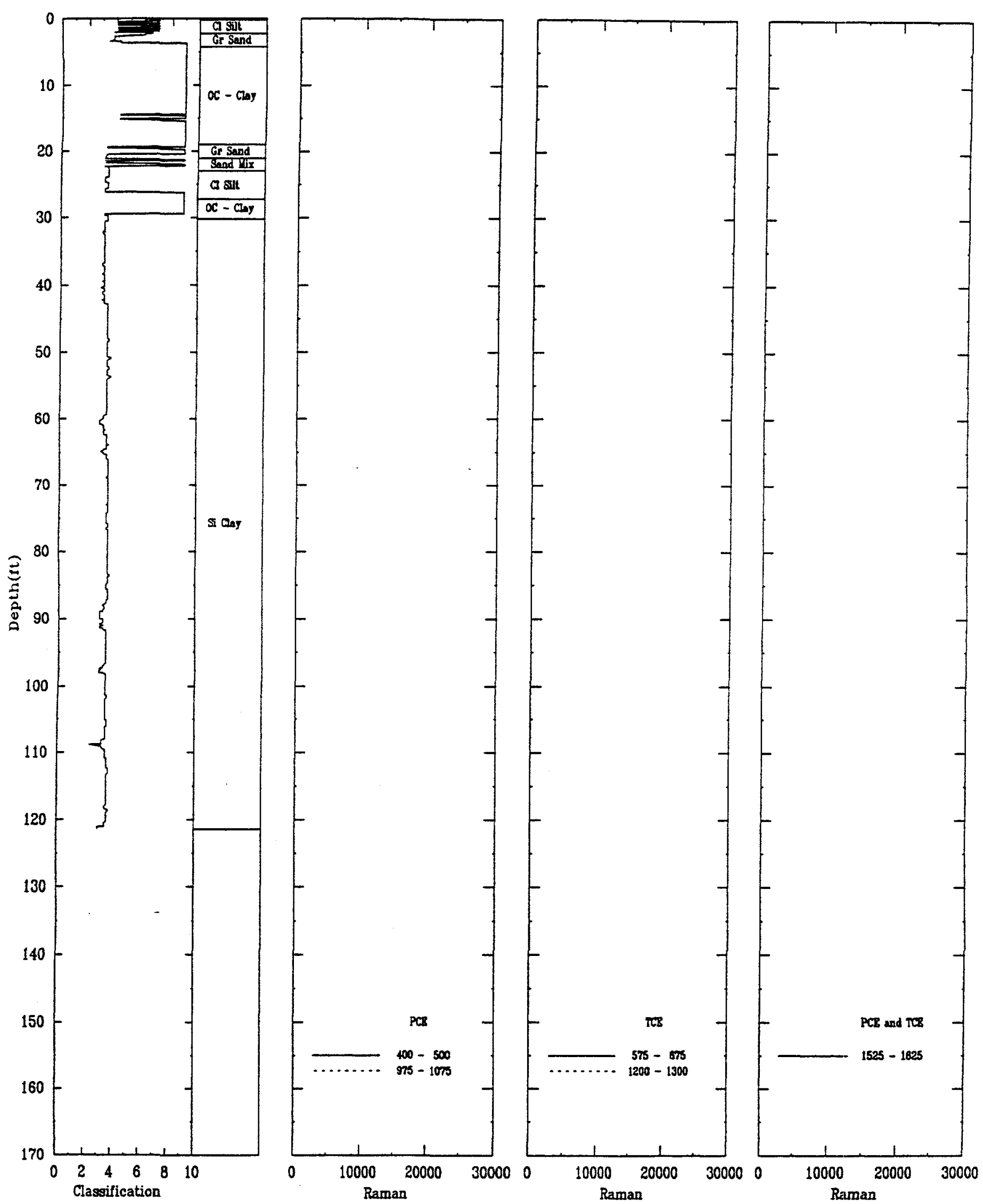

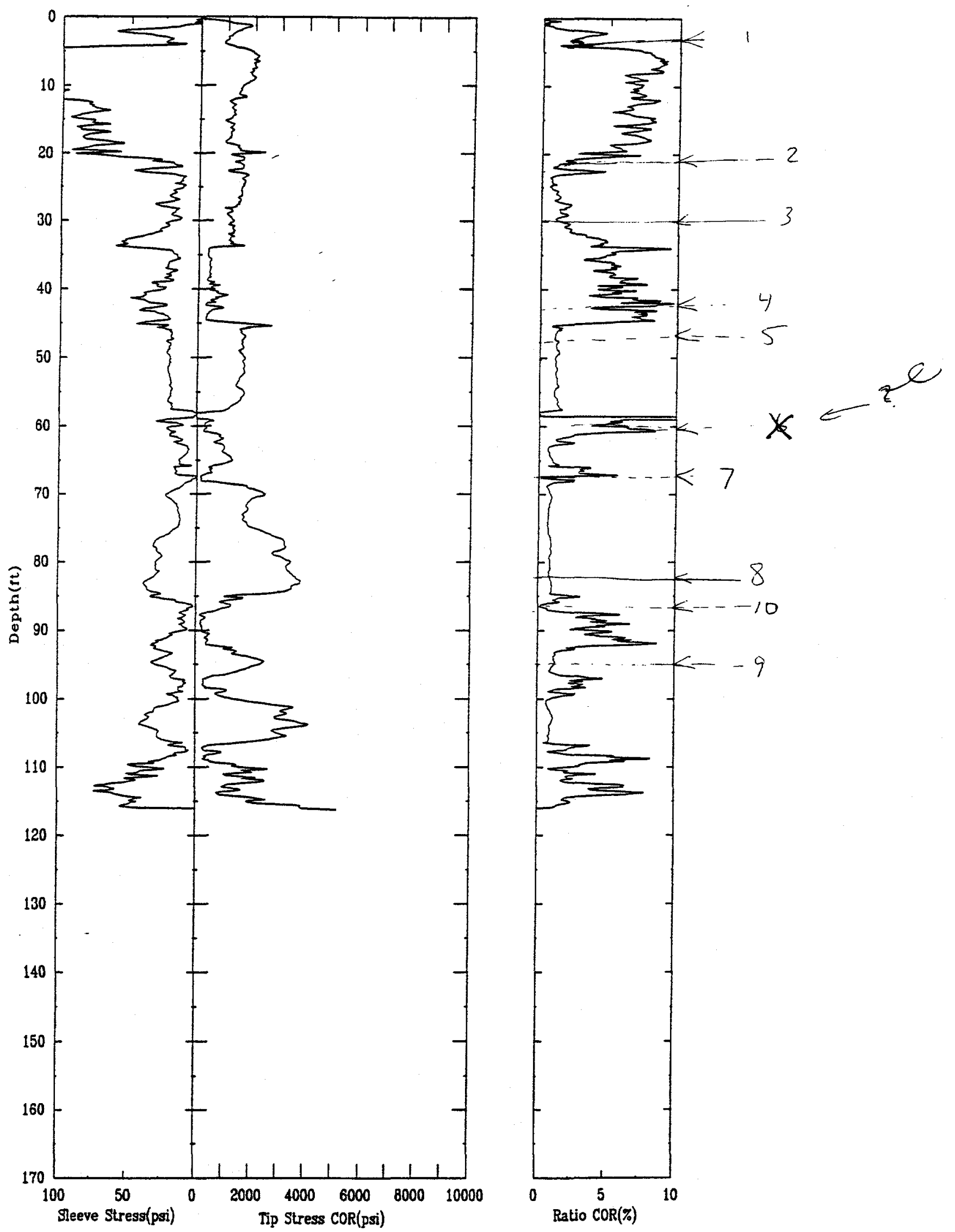

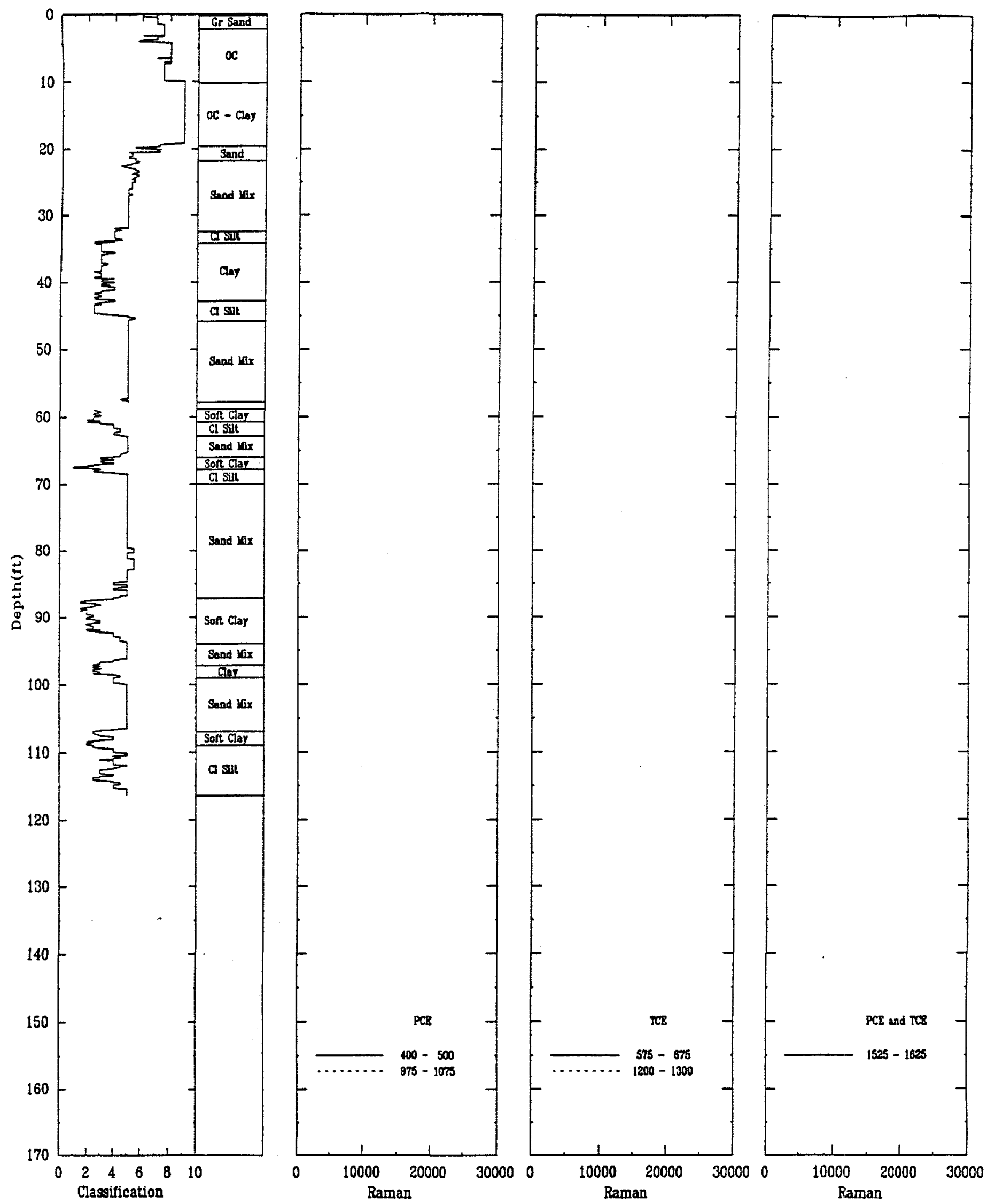

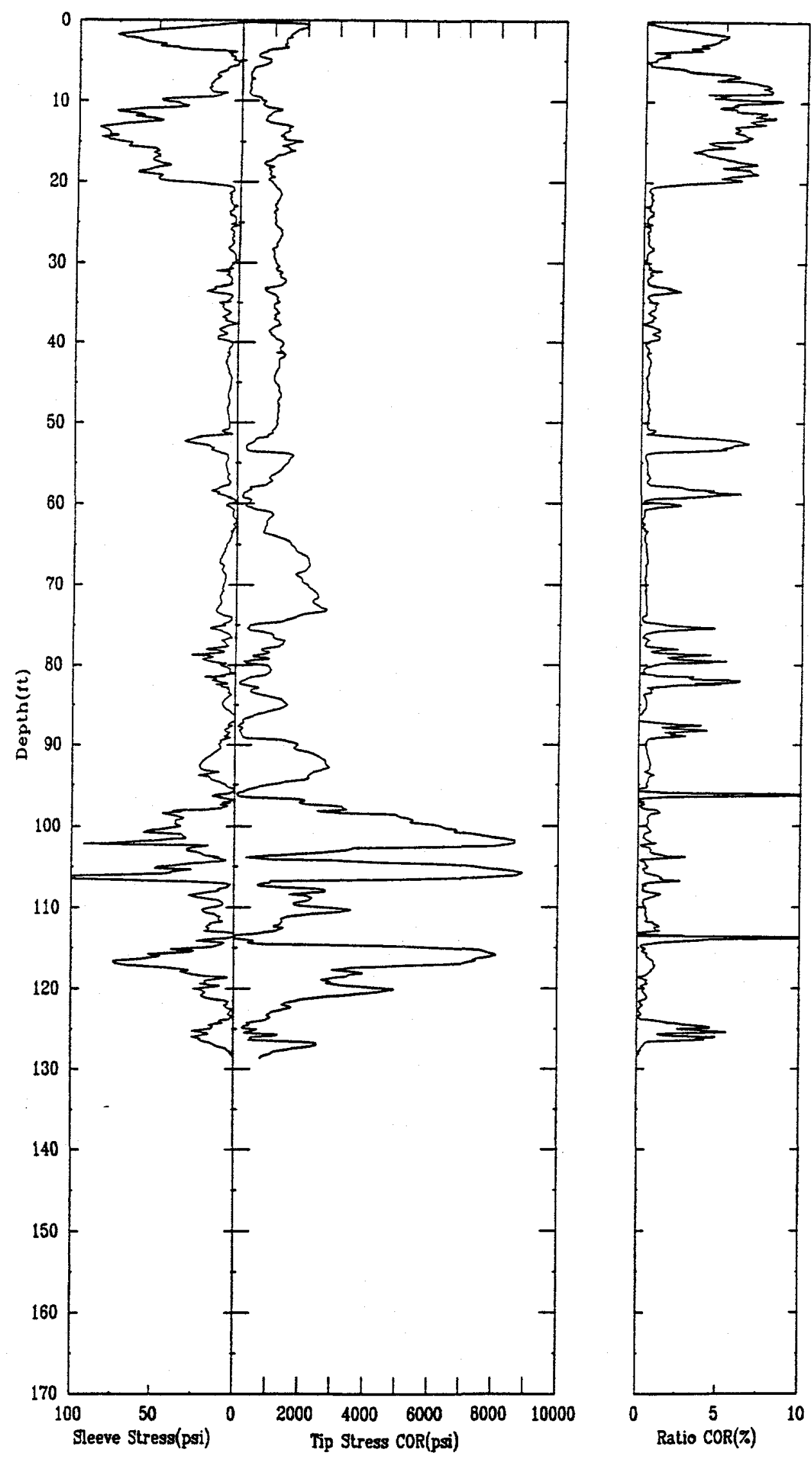

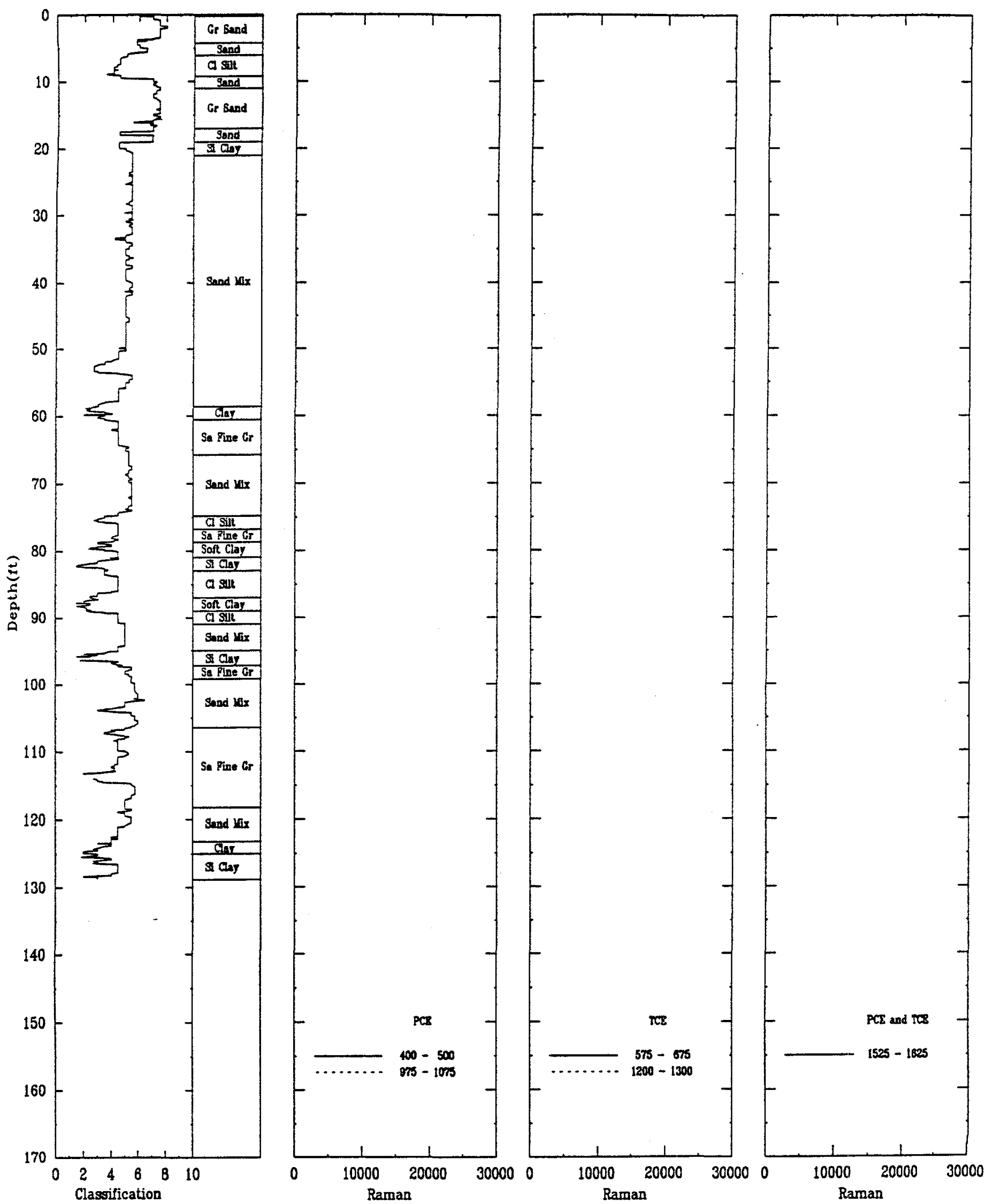